University of Louisville

ThinkIR: The University of Louisville's Institutional Repository

Electronic Theses and Dissertations

$12-2017$

\title{
Fused filament fabrication 3D printing using low-melting alloys.
}

Nirupama Warrier

University of Louisville

Follow this and additional works at: https://ir.library.louisville.edu/etd

Part of the Mechanical Engineering Commons

\section{Recommended Citation}

Warrier, Nirupama, "Fused filament fabrication 3D printing using low-melting alloys." (2017). Electronic Theses and Dissertations. Paper 2837.

https://doi.org/10.18297/etd/2837

This Master's Thesis is brought to you for free and open access by ThinkIR: The University of Louisville's Institutional Repository. It has been accepted for inclusion in Electronic Theses and Dissertations by an authorized administrator of ThinkIR: The University of Louisville's Institutional Repository. This title appears here courtesy of the author, who has retained all other copyrights. For more information, please contact thinkir@louisville.edu. 


\title{
FUSED FILAMENT FABRICATION 3D PRINTING USING LOW-MELTING ALLOYS
}

\author{
By \\ Nirupama Warrier \\ B. Tech, Aerospace Engineering, 2013

\begin{abstract}
A Thesis
Submitted to the faculty of the

for the Degree of

Master of Science

in Mechanical Engineering

Department of Mechanical Engineering

University of Louisville

Louisville, Kentucky
\end{abstract} \\ J. B. Speed School of Engineering of the University of Louisville \\ In Partial Fulfillment of the Requirements
}

December 2017 
Copyright 2017 by Nirupama Warrier

All rights reserved 



\title{
FUSED FILAMENT FABRICATION 3D PRINTING USING LOW-MELTING ALLOYS
}

\author{
By \\ Nirupama Warrier \\ B. Tech, Aerospace Engineering, 2013
}

A Thesis Approved on

November 29, 2017

by the following Thesis Committee:

Dr. Kunal Kate

Dr. Sundar Atre

Dr. Thomas Berfield

Dr. Jagannadh Satyavolu 


\section{DEDICATION}

This thesis is dedicated to my beloved family

To my late grandfather, Dr. C.B.C.Warrier

To my grandmother, Susheela

To my father, Dr. Nandakumar

To my mother, Dr. Sheela

$\&$

To my husband, Arun

whose unbounded love, support and encouragement kept me afloat at all times. 


\section{ACKNOWLEDGEMENTS}

First and foremost, I would like to thank my mentor, Dr. Kunal Kate for his continued guidance, support and encouragement throughout my term at the University of Louisville, without which this work would not have been possible. Thank you for being patient and motivating me through tough times.

I would also like to thank Dr. Sundar Atre for providing me with invaluable opportunities and imparting skills that will shape my personal life and professional career. Thank you for inspiring me and bringing out the best in me.

Thank you to my committee members, Dr. Thomas Berfield and Dr. Jagannadh Satyavlou for their valuable comments on my work. Thank you for being a part of my journey.

Thank you to my friends and colleagues at the Materials Innovation Guild encouragement for their invaluable comments and moral support. I would like to thank Harish, Subrata and Bhushan for supporting me throughout with their expertise in 3D printing, microscopy and design. I would also like to thank all my students at the UofL 3D printing incubator of Fall 2016 \& Spring 2017 for their valuable contributions to my work. 


\section{ABSTRACT \\ FUSED FILAMENT FABRICATION 3D PRINTING USING LOW-MELTING ALLOYS \\ Nirupama Warrier}

November 29, 2017

Fused Filament Fabrication (FFF) 3D printing technology has been a popular method of creating prototypes using plastics in the timeliest and most affordable manner for electronic, automotive, and biomedical applications. 3D printing of metals and alloys using FFF technology could provide low-cost alternatives and solutions to the Laser-Powder Bed Fusion Process (L-PBF) and Binder Jetting processes (BJ). In current work, low melting alloys have been used as a starting material and evaluated for FFF 3D printing using two methodologies. In the first methodology, Sn60Bi40 alloy in the form of wire was used as the feedstock for FFF extrusion and process parameters for the fabrication of $2 \mathrm{D}$ and $3 \mathrm{D}$ geometries were developed. In the second methodology, low melting alloys of Sn42Bi58, Sn60Bi40 and Sn89Sb7.5 were cast onto 3-D printed molds to fabricate metal structures. The influence of mold cooling temperature on the cast specimens of Sn60Bi40 alloy was evaluated. The fabricated specimens were evaluated for its part formability, mechanical properties, and microstructure. A prototype was fabricated using the FFF 3D printing methodology and a souvenir was cast using the FFF 3D casting methodology to show case the applicability of the FFF metal 3D printing process. 


\section{TABLE OF CONTENTS}



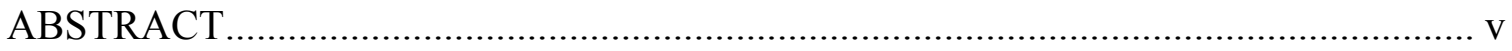

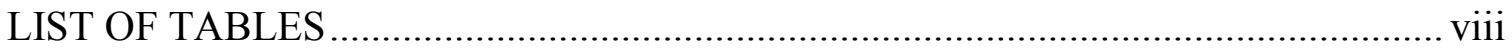

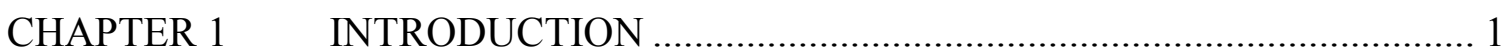

CHAPTER 2 MATERIALS PROPERTY DESIGN FOR 3D PRINTING WITH

LOW-MELTING ALLOYS ................................................................................ 4

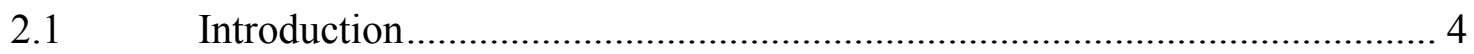

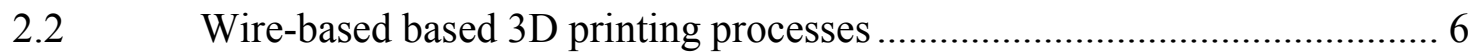

2.2.1 Fused Filament Fabrication (FFF) metal 3D printing ......................... 6

2.2.2 Wire-based arc welding 3D printing ................................................ 7

2.2.3 Wire-based Laser Metal Deposition(LMD) 3D printing.................... 10

2.2.4 Wire-based Electron Beam Melting (EBM) 3D printing .................... 12

2.3 Traditional casting methodology ........................................................ 13

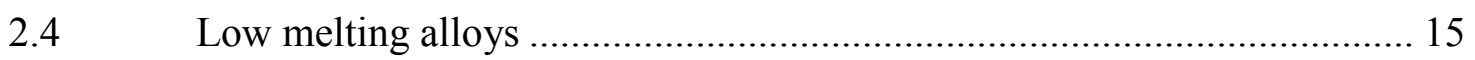

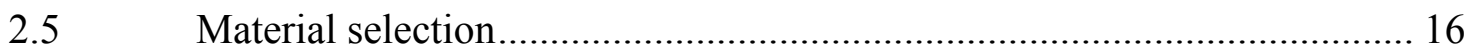

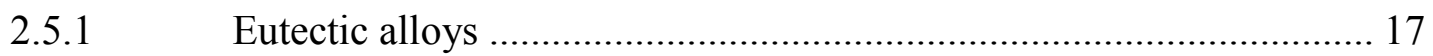

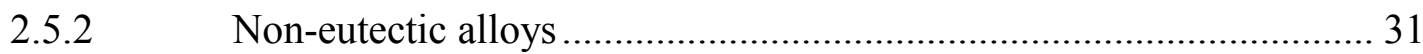

2.6 Thermoplastic materials used in $3 \mathrm{D}$ printing......................................... 49

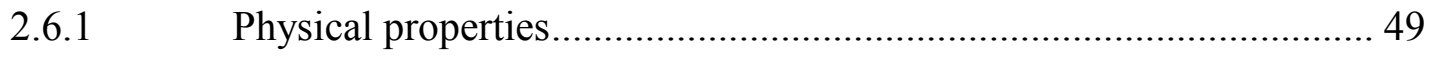

2.6.2 Mechanical properties ............................................................ 50

2.6.3 Thermal properties Figure 2.25 shows the thermal properties of popular 3D

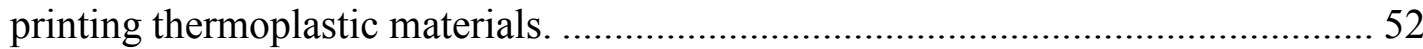

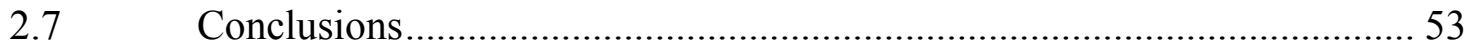

CHAPTER 3 FUSED FILAMENT FABRICATION 3D PRINTING AND

CASTING WITH LOW-MELTING ALLOYS .......................................................... 54

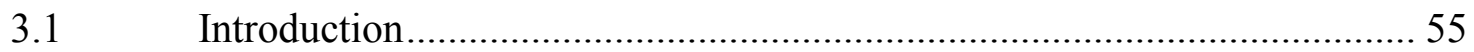

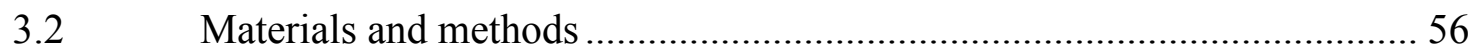

3.2.1 Materials for FFF casting and printing ......................................... 57

3.2.2 Method I - FFF 3D printing ............................................................ 58

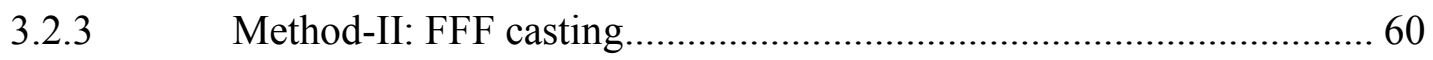

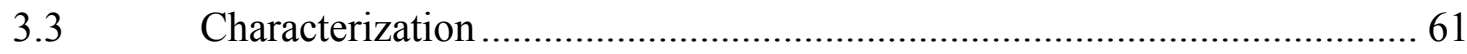

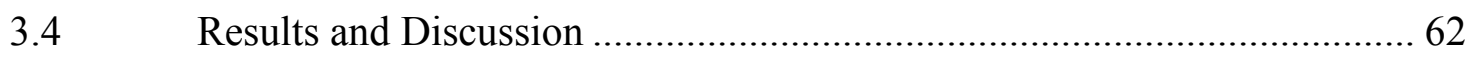




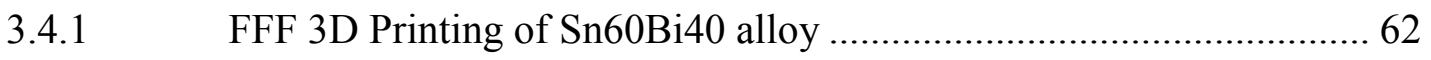

3.4.2 FFF 3D Casting of Sn60Bi40, Sn42Bi58 and Sn89Sb7.5 alloys ........ 69

3.4.3 Effect of cooling rate on the FFF 3D casting of Sn60Bi40 alloy ........ 77

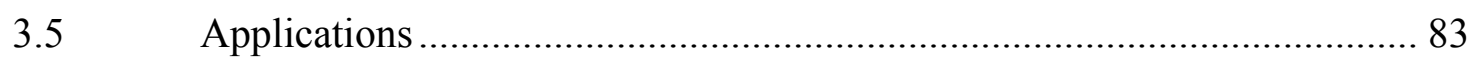

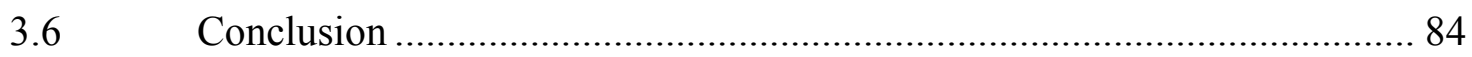

CHAPTER 4 CONCLUSIONS AND FUTURE WORK …………....................... 85

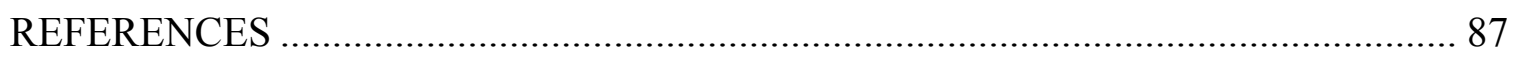

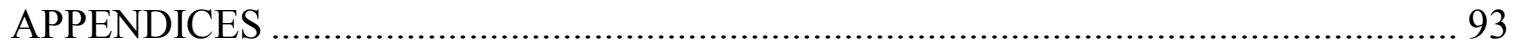






\section{LIST OF TABLES}

TABLE

PAGE

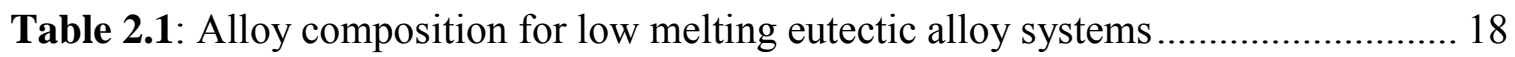

Table 2.2. Physical properties of the low melting eutectic alloy systems ...................... 20

Table 2.3: Mechanical properties of the low melting eutectic alloy systems ................. 24

Table 2.4: Thermal properties of low melting eutectic alloys.................................... 28

Table 2.5: Alloy composition for low melting non-eutectic alloy systems - ................. 32

Table 2.6: Physical properties of the low melting non- eutectic alloy systems .............. 35

Table 2.7: Mechanical properties of the low melting non-eutectic alloy systems .......... 40

Table 2.8: Thermal properties of the low melting non-eutectic alloys ......................... 45

Table 3.1: Physical and mechanical properties of the low melting alloys selected for the evaluation of metal fabrication using FFF 3D printing technology[40, 58-60].............. 58

Table 3.2: Printing process parameters developed for fabricating low-melting Sn60Bi40 alloy using FFF 3D printing technology.

Table 3.3: Dimensions and physical properties of the post-processed FFF 3D printed part of the Sn60Bi40 alloy 66

Table 3.4: Dimensions of the post-processed FFF 3D cast parts of Sn60Bi40, Sn42Bi58 and $\mathrm{Sn} 89 \mathrm{Sb} 7.5$ alloys 70 


\section{LIST OF TABLES (CONTINUED)}

Table 3.5: Physical properties of the post-processed FFF 3D cast parts of Sn60Bi40,

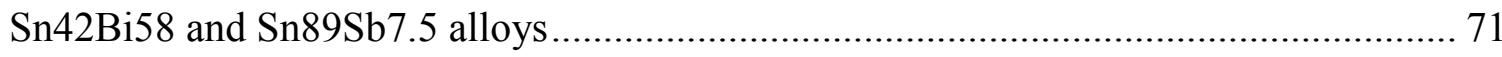

Table 3.6: Dimensions and tolerances of the post-processed FFF 3D cast parts of

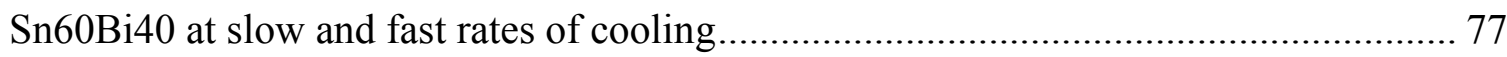

Table 3.7: Physical properties of the post-processed FFF 3D cast parts of Sn60Bi40 at

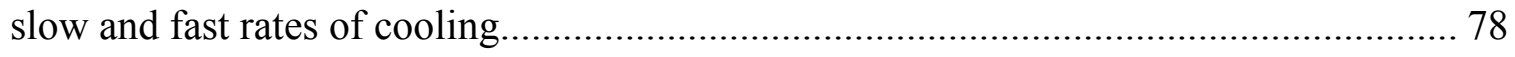

Table A.1: Experimental data showing the stages of melting for 8 samples ................. 97

Table A.2:Dimensional comparison of the SolidWorks design of the tensile mold and the tensile specimens fabricated using FFF 3D printing and FFF casting methodologies. .. 102

Table A.3: Dimensional comparison of the SolidWorks design of the mechanical wrench and the wrench fabricated using FFF 3D printing and FFF casting methodologies ....... 103

Table A.4: Density of the auxiliary liquid(water) with respect to temperature. ........... 106

Table A.5: Dimensions of the as-cast FFF 3D cast parts for Sn60Bi40, Sn42Bi58 and

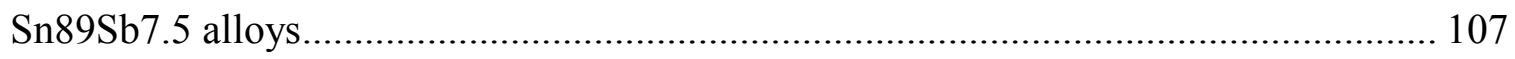

Table A.6: Physical properties of the as-cast FFF 3D cast parts for Sn60Bi40, Sn42Bi58

and $\mathrm{Sn} 89 \mathrm{Sb} 7.5$ alloys 108

Table A.7: Dimensions of the as-cast FFF 3D cast parts of Sn60Bi40 at slow and fast rates of cooling 110

Table A.8: Physical properties s of the as-cast FFF 3D cast parts of Sn60Bi40 at slow and fast rates of cooling

Table A.9: Dimensions and tolerances of the as-cast Sn60Bi40_M2 fabricated using the FFF casting methodology. 113 


\section{LIST OF TABLES (CONTINUED)}

Table A.10: Physical properties of the as-cast Sn60Bi40_M2 fabricated using the FFF casting methodology

Table A.11: Dimensions and tolerances of the post-processed Sn60Bi40_M2 fabricated

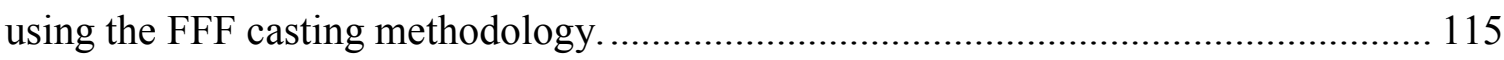

Table A.12: Physical properties of the post-processed Sn60Bi40_M2 fabricated using the FFF casting methodology. 116

Table A.13: Ultimate tensile strength and Young's modulus values of the post-processed

Sn60Bi40_M2 fabricated using the FFF casting methodology. 116

Table A.14: Physical and mechanical properties of tensile specimens fabricated using a heated mold 118 


\section{LIST OF FIGURES}

Figure 2.1: Schematic of metal-based FFF 3D printing technology......

Figure 2.2: Geometries fabricated using FFF metal 3D printing technology (a) 10 layer stacking of metal [2] (b) Attempt to fabricate in the x-y direction (c) Geometry of a 3D

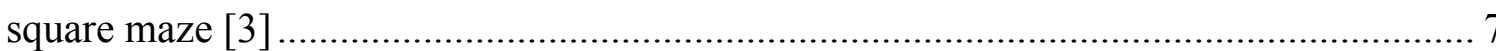

Figure 2.3: (a) A wire-based arch welding 3D printer in action [4] (b) Ducts with curved cross-section 3D printed using arch welding 3D printer [5] (c) A customized sprocket 3D

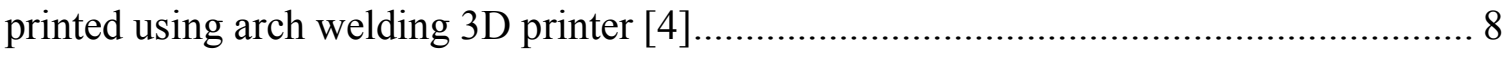

Figure 2.4: Schematic of a wire-based micro casting technology [7] ........................... 10

Figure 2.5: Illustration of a wire-based laser metal deposition technology[9] ................ 11

Figure 2.6: (a) Hollow cylinder [8] (b) Filled cylinder [9] .......................................... 11

Figure 2.7: Schematic of a wire-based EBM 3D printing process[1] ........................... 12

Figure 2.8: Parts fabricated using wire-based EBM 3D printing technology (a) 3D Star

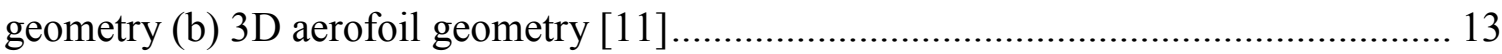

Figure 2.9: Schematic of an open mold process[13] ................................................... 14

Figure 2.10: (a) Low melting alloy used in remount cast for posterior crowns[19] (b)

Die-cast metal car models [20] (c),(f) Jewelry cast from low melting lead-free alloy[21] (d) Alloys as conductive ink in electronic circuitry (e ) Prototype of a mechanical wrench

Figure 2.11. Melting point of the low melting eutectic alloy systems 21 


\section{LIST OF FIGURES (CONTINUED)}

Figure 2.12. Density of the low melting eutectic alloy systems 22

Figure 2.13: Melting temperature vs. density of the low melting eutectic alloy systems 23

Figure 2.14: Ultimate tensile strength (UTS) of the low melting eutectic alloy systems 25

Figure 2.15: Percentage elongation of the low melting eutectic alloy systems

Figure 2.16: Coefficient of thermal expansion of the low melting eutectic alloy systems

Figure 2.17: Thermal conductivity of the low melting eutectic alloy systems............... 30

Figure 2.18: Density of the low melting non- eutectic alloy systems ........................... 39

Figure 2.19: Ultimate tensile strength (UTS) of the low melting non-eutectic alloy

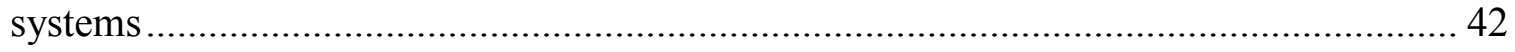

Figure 2.20: Percentage elongation of the non-eutectic alloy systems ........................ 43

Figure 2.21: Coefficient of thermal expansion (CTE) of the low melting non-eutectic

alloy systems

Figure 2.22: Specific heat vs. CTE of the non-eutectic bismuth and silver alloy systems

Figure 2.23 Physical properties of popular 3D printing thermoplastic materials

Figure 2.24: Mechanical properties of popular 3D printing thermoplastic materials ...... 50

Figure 2.25: Thermal properties of popular 3D printing thermoplastic materials 52

Figure 3.1: SolidWorks designs for the development of printing process parameters of low melting alloy, Sn60Bi40, using FFF 3D printing technology (a) 2D - Square toolpath (b) $3 \mathrm{D}-$ dog bone specimen 59 


\section{LIST OF FIGURES (CONTINUED)}

Figure 3.2: SolidWorks design of the ASTM E8 standard tensile specimen for FFF 3D printing with Sn60Bi40 alloy.

Figure 3.3: SolidWorks design of the tensile specimen mold. (a) Top view (b) Isometric

view

Figure 3.4: (a) Trial 1- 2D Square maze toolpath with discontinuity between depositions

(b) Trial 2- Successful fabrication of 2D square maze toolpath 64

Figure 3.5: FFF 3D printing of 3D geometry using Sn60Bi40 alloy (a) Trial 1 (b) Trial 2

(c) Trial 3 65

Figure 3.6: FFF 3D printed ASTM E8 standard tensile specimen of Sn60Bi40 alloy ... 65

Figure 3.7: Ultimate tensile strength, yield strength and percent elongation of the FFF 3D printed ASTM E8 tensile specimen of Sn60Bi40

Figure 3.8: (a) Bright Field (BF) Image of FFF 3D printed Sn60Bi40 alloy showing the primary tin-rich phase surrounded by eutectic structure. (50X) (b) Dark Field (DF) Image of FFF 3D printed Sn60Bi40 alloy which shows the layering of fine and coarse microstructure 68

Figure 3.9: (a) Process summary of the FFF cast methodology (b) Tensile molds 3D printed using PLA (c) Molten material cast onto the 3D printed mold (d) As-cast tensile specimens (e) Post-processed tensile specimens

Figure 3.10: Relative densities of the post-processed FFF 3D cast parts of Sn60Bi40, Sn42Bi58 and Sn89Sb7.5 alloys 72

Figure 3.11: Ultimate tensile strength of the post-processed FFF 3D cast parts of Sn60Bi40, Sn42Bi58 and Sn89Sb7.5 alloys 72 


\section{LIST OF FIGURES (CONTINUED)}

Figure 3.12: Percent elongation of the post-processed FFF 3D cast parts of Sn60Bi40,

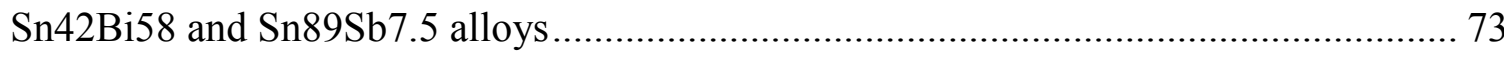

Figure 3.13: Strengths of the post-processed FFF 3D cast parts of Sn60Bi40, Sn42Bi58 and $\mathrm{Sn} 89 \mathrm{Sb} 7.5$ alloys

Figure 3.14: Optical microscopy images of the post-processed FFF 3D cast Sn42Bi58 (eutectic) and Sn60Bi40(non-eutectic) alloys (a) Bright field image of Sn42Bi58 showing bismuth and tin phases in the microstructure (b) Dark field image of Sn42Bi58 showing the eutectic structure (c) Bright field image of Sn60Bi40 showing bismuth and tin phases in the microstructure (d) Dark field image of Sn60Bi40 which shows the primary Sn-rich phase surrounded by eutectic structure 75

Figure 3.15: Optical microscopy image of the post-processed FFF 3D cast part of the

Sn89Sb7.5 alloy 76

Figure 3.16: Relative densities of the post-processed FFF 3D cast parts of Sn60Bi40 at slow and fast rates of cooling.

Figure 3.17: Ultimate Tensile Strengths of the post-processed FFF 3D cast parts of Sn60Bi40 at slow and fast rates of cooling......

Figure 3.18: Percentage elongation of the post-processed FFF 3D cast parts of Sn60Bi40 at slow and fast rates of cooling. 80

Figure 3.19: Strengths of the post-processed FFF 3D cast parts of Sn60Bi40 at slow and fast rates of cooling 81 


\section{LIST OF FIGURES (CONTINUED)}

Figure 3.20: (a) Optical microscopy image of the slow cooled non-eutectic Sn60Bi40 material (b) Optical microscopy image of the fast cooled non-eutectic Sn60Bi40 material

Figure 3.21: Metal prototypes fabricated using an FFF 3D printer. (a), (c) Mechanical wrench fabricated using FFF 3D printing methodology (b), (d)Customized UofL (University of Louisville) souvenir logo fabricated using FFF 3D casting methodology 83

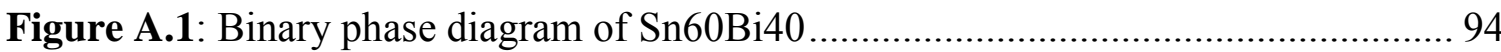

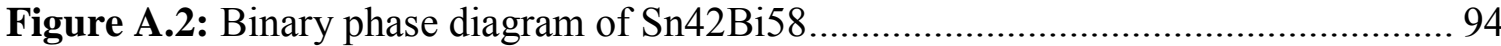

Figure A.3: Ternary phase diagram and Liquids projection of $\mathrm{Cu}-\mathrm{Sb}-\mathrm{Sn}$.................... 95

Figure A.4: Samples of the melted alloys over the temperature range of $135^{\circ} \mathrm{C}$ (left-

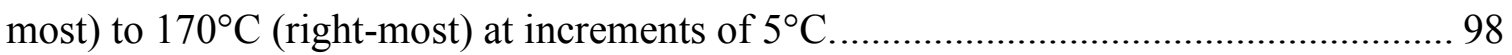

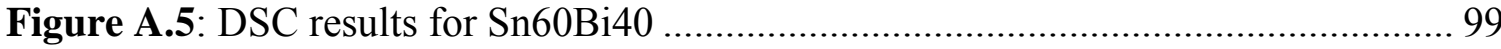

Figure A.6: Screenshot of the procedure followed for DSC analysis ......................... 100

Figure A.7: (a) Bottom surface (b) Top surface (c) Side profile (d) Rear end .......... 101 Figure A.8: (a) SolidWorks design of the tensile mold (b) FFF 3D Printed tensile

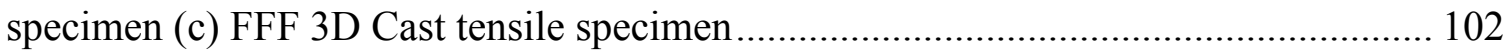
Figure A.9: (a) SolidWorks design of the mechanical wrench(b) FFF 3D Printed wrench prototype (c) FFF 3D Cast wrench prototype 103

Figure A.10: Stress-strain curve of 4 specimens of Sn60Bi40 using FFF cast methodology 104

Figure A.11: Stress-strain curve of both the Sn60Bi40, Sn42Bi58 and Babbitt. 104 


\section{LIST OF FIGURES (CONTINUED)}

Figure A.12: Comparison of ultimate tensile strength(UTS) of specimens fabricated using FFF 3D printing and FFF 3D casting methodologies, with respect to the literature

value. 105

Figure A.13: Relative densities of the as-cast FFF 3D cast parts for Sn60Bi40, Sn42Bi58 and Sn89Sb7.5 alloys 109

Figure A.14: Relative densities of the as-cast FFF 3D cast parts of Sn60Bi40 at slow and fast rates of cooling 112

Figure A.15: Samples of Sn60Bi40_M2 as cast fabricated using the FFF casting methodology .

Figure A.16: Samples of post-processed Sn60Bi40_M2 fabricated using the FFF casting methodology 115

Figure A.17: Stress-strain curves for Sn60Bi40_M2 samples fabricated using the FFF casting methodology.

Figure A.18: Optical microscopy imaging of etched FFF 3D cast Sn60Bi40 sample fabricated using a heated mold 119

Figure A.19: Optical microscopy imaging of etched FFF 3D cast Sn60Bi40 sample fabricated using a heated mold (50X, Bright field) 119

Figure A.20: Optical microscopy imaging of etched FFF 3D cast Sn60Bi40 sample ... 120 Figure A.21: Optical microscopy imaging of etched FFF 3D cast Sn60Bi40 sample... 120 Figure A.22: Optical microscopy imaging of etched FFF 3D cast Sn60Bi40 sample... 121 Figure A.23: Optical microscopy imaging of etched FFF 3D cast Sn42Bi58 sample (20X, Dark field ) 


\section{LIST OF FIGURES (CONTINUED)}

Figure A.24: Optical microscopy imaging of etched FFF 3D cast $\mathrm{Sn} 42 \mathrm{Bi} 58$ sample (50X,

Dark field )

Figure A.25: Optical microscopy imaging of etched FFF 3D cast Sn89Sb7.5 sample (20X, Dark field )

Figure A.26: Optical microscopy imaging of etched FFF 3D cast Sn89Sb7.5 sample (50X, Bright field ) 123

Figure A.27: Optical microscopy imaging of fast cooled FFF 3D cast Sn60Bi40 sample showing the fine colonies (10X, Bright field ) 123

Figure A.28: Optical microscopy imaging of slow cooled FFF 3D cast Sn60Bi40 sample showing the coarser colonies (10X, Bright field ) 124

Figure A.29: Optical microscopy imaging of slow cooled FFF 3D printed Sn60Bi40

sample showing the coarser colonies (20X, Bright field 124 


\section{CHAPTER 1}

\section{INTRODUCTION}

Fused Filament Fabrication (FFF) 3D printing has been a popular method of creating affordable prototypes and functional parts using thermoplastic materials. Metal 3D printing technologies such as the Laser-Powder Bed Fusion Process (L-PBF) and Binder Jetting (BJ) can often take up a lot of space, are expensive and require regular maintenance. Successful fabrication of metal products using FFF 3D printing could reduce the price point of metal printers paving the way for an affordable desktop metal 3D printer.

In FFF 3D printing technology, polymer filaments are fed through an extruder into a heated nozzle where it is melted and extruded layer-by-layer onto a heated bed platform to fabricate a 3D geometry. Once a layer is fabricated, the nozzle moves up in the z-direction (or, the base is lowered) to accommodate the subsequent layers. This process continues until the desired 3D structure is fabricated.

To fabricate metals using this technology, metal filament can be fed into the extruder and heated in the nozzle to deposit material layer by layer to fabricate a $3 \mathrm{D}$ geometry. Owing to the temperature limitations of an FFF 3D printer, low-melting alloys with melting temperatures below $300^{\circ} \mathrm{C}$ can be considered for extrusion. Low melting alloys, also 
known as fusible alloys, melt at relatively low temperatures and find applications in various fields including automotive, aerospace, electronics, healthcare and consumer sectors.

Due to the freedom of design provided by the layer-by-layer process of fabrication using FFF 3D printing technology, it is also desirable to design molds and cast molten metal in order to generate complex castings. In this way, the molder has the ability to overcome the manufacturing constraints of traditional mold making in order to generate rapid prototypes or fully functional parts. 3D printing of molds can also allow quick turnaround from the prototype design to production of individual custom parts, thereby decreasing the lead time and the associated costs.

However, there is limited knowledge and understanding of materials suited for 3D printing metals using FFF 3D printing technology. Chapter II reviews some of the existing wire based 3D printing technologies followed by an extensive survey on eutectic and noneutectic low melting alloy systems. Physical properties, mechanical properties and thermal properties of eutectic and non-eutectic alloy systems were extracted and reviewed to select the best candidate for 3D printing metals using FFF 3D printing technology. A low melting eutectic alloy of bismuth (Sn42Bi58), non-eutectic alloy of bismuth (Sn60Bi40), and a noneutectic alloy of antimony (Sn89Sb7.5) were selected for the study on the basis of their properties. A publication on the work titled 'Materials Property Design for 3D Printing with Low Melt Alloys' will be submitted to the 3D Printing and Additive Manufacturing jounral.

In Chapter III, the selected materials were evaluated for FFF 3D printing using two approaches. In the first approach, a low melting Sn60Bi40 alloy in the form of wire was used as the feedstock for FFF extrusion. The influence of FFF process parameters such as 
infill ratio, extrusion velocity, feed rate, nozzle temperature and bed temperature on the part fabrication were evaluated. In the second approach, low melting alloys of Sn42Bi58, Sn60Bi40 and Sn89Sb7.5 were cast onto 3-D printed molds to create metal structures. The influence of mold cooling temperature on Sn60Bi40 alloy was evaluated. The fabricated specimens were evaluated for its part formability, density, precision, mechanical properties, and microstructure. The work on FFF 3D printing was presented at the AMPM 2017 conference and was published in the AMPM2017 conference proceedings. A paper combining the works of FFF 3D printing and FFF casting has been submitted to the progress in additive manufacturing (PIAM) 2017 special edition and is under review.

Additionally, both approaches were used to fabricate customized prototypes of university logo souvenir and a mechanical wrench. It is expected that the FFF metal 3D printing technology will pave the way for the affordable fabrication of customized metal prototypes and alternatively on-demand custom metal spare parts for applications in fields such as tooling, consumer, automobile, aerospace and healthcare. 


\section{CHAPTER 2}

\section{MATERIALS PROPERTY DESIGN FOR 3D PRINTING WITH LOW-MELTING}

\section{ALLOYS}

Fused Filament Fabrication (FFF) 3D printing technology has been a popular method of creating prototypes using thermoplastics in the timeliest and most affordable manner for electronic, automotive, and biomedical applications. 3D printing of metals and alloys using FFF technology could provide low-cost alternatives and solutions to the Laser-Powder Bed

Fusion Process (L-PBF) and Binder Jetting processes (BJ). However, there is limited knowledge and understanding of materials suited for 3D printing metals using FFF technology. This work reviews the various wire-based 3D printing technologies followed by an extensive survey on low melting alloy systems; physical properties, mechanical properties and thermal properties of eutectic and non-eutectic alloy systems were extracted and reviewed to select the best candidate for 3D printing metals using FFF technology.

\subsection{Introduction}

Wire-based $3 \mathrm{D}$ printing process is a promising alternative to the powder-based $3 \mathrm{D}$ printing methods and allows for the fabrication of large components with complex geometries, higher deposition rates and material efficiencies of up to $100 \%$. 
The parts fabricated using this methodology exhibit good dimensional accuracies, surface finish, and mechanical properties for applications in aerospace, automotive, dentistry and rapid tooling industry[1]. This work begins with the review of the various wire-based 3D printing technologies, their working and the recent advances in the field.

Fused Filament Fabrication (FFF) 3D printing is a popular wire-based 3D printing process for creating affordable prototypes and functional parts using thermoplastic materials. In FFF 3D printing technology, polymer filaments are fed through an extruder into a heated nozzle where it is melted and extruded layer-by-layer onto a heated platform to fabricate a 3D geometry. To fabricate metals using this technology, metal filament is fed into the extruder and heated in the nozzle to deposit material layer by layer to form a 3D geometry. Due to the freedom of design provided by the layer-by-layer process of fabrication using FFF 3D printing technology, it is also desirable to design complex molds and cast molten metal in order to generate complex castings.

Owing to the temperature limitations of an FFF 3D printer, low melting alloys with melting temperatures below $300^{\circ} \mathrm{C}$ can be considered for fabrication using FFF technology. Low melting alloys are divided into eutectic and non-eutectic alloys based on their melting behavior. The composition, physical properties, mechanical properties and thermal properties of these eutectic and non-eutectic low melting alloys systems are investigated in order to select the best candidate for extrusion using FFF 3D printing technology. 


\subsection{Wire-based based 3D printing processes}

Wire-based 3D printing processes can be divided into heater-based (FFF), arc weldingbased, laser-based and electron-beam based 3D printing technologies on the basis of the energy or heat source required to melt the metal.

\subsubsection{Fused Filament Fabrication (FFF) metal 3D printing}

FFF metal 3D printing is a wire-based 3D printing process in which metals or alloys in the form of wire are fed through an extruder into a heated nozzle where it is melted and extruded layer by layer onto a heated bed platform to fabricate a 3D geometry. Once a layer is fabricated, the nozzle moves up in the z-direction (or, the base is lowered) to fabricate the subsequent layers. This process continues until the desired 3D structure is fabricated [1]. Figure 2.1 shows the schematic of FFF metal 3D printing technology.



Figure 2.1: Schematic of metal-based FFF 3D printing technology

P.C. Hsiesh et al modified the extruder and firmware of a commercial FFF 3D printer to fabricate low melting alloys using FFF metal 3D printing technology. G codes were developed, and effects of printing process parameters such as extrusion velocity and print 
speed were evaluated to ensure smooth extrusion of the material. Successful deposition of metal in five and ten-layer stacks were achieved. Attempts to fabricate in $\mathrm{x}$-direction was not successful due to the high cohesive properties of the material[2](see Figure 2.2 (b))

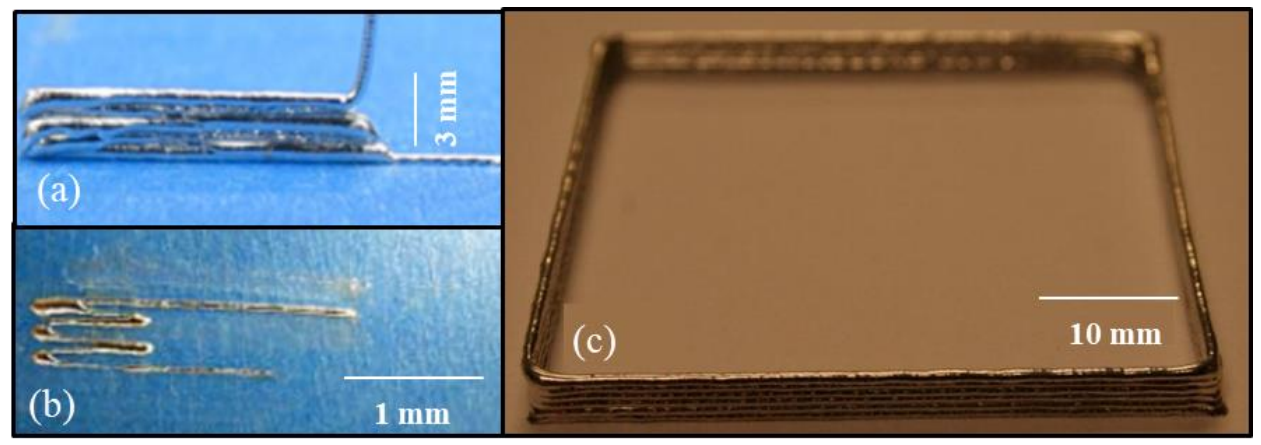

Figure 2.2: Geometries fabricated using FFF metal 3D printing technology (a) 10 layer stacking of metal [2] (b) Attempt to fabricate in the x-y direction (c) Geometry of a 3D square maze [3]

Jorge Mireles et al modified the nozzle diameter of an FDM 3000 system to achieve controlled deposition of eutectic and non-eutectic Sn-Bi alloys. Toolpath commands were modified, and process parameters such as head velocity were decreased, and nozzle temperature was increased for continuous deposition of 2D and 3D structures. Figure 2.2 (c) shows the geometry of a stacked 3D square maze fabricated using this technology.

The fabrication of more complex 3D geometries needs to be demonstrated, and the microstructure between layers for such structures need to be analyzed[3].

\subsubsection{Wire-based arc welding 3D printing}

Welding based 3D printing technology uses gas metal arc welding to deposit material(metal) layer by layer to create a 3D geometry. It is based on droplet manufacturing process and helps in attaining dense metal parts for a variety of applications. 
Anzalone et al developed an open source wire-based arch welding 3D printer consisting of a low cost commercial gas-metal arc welder controlled by an automatic three-axis stage controller and Argon shielding gas (see Figure 2.3 (a)). A fixture was designed to anchor the welding gun at an angle, $90^{\circ}$ to the build surface. Upon receiving the print job, the print bed moves to its home position, the welder initiates and automatically deposits metal layer by layer in the form of a bead pattern[4].Figure $\mathbf{2 . 3}$ (c) shows a customized sprocket 3D printed using this printer.

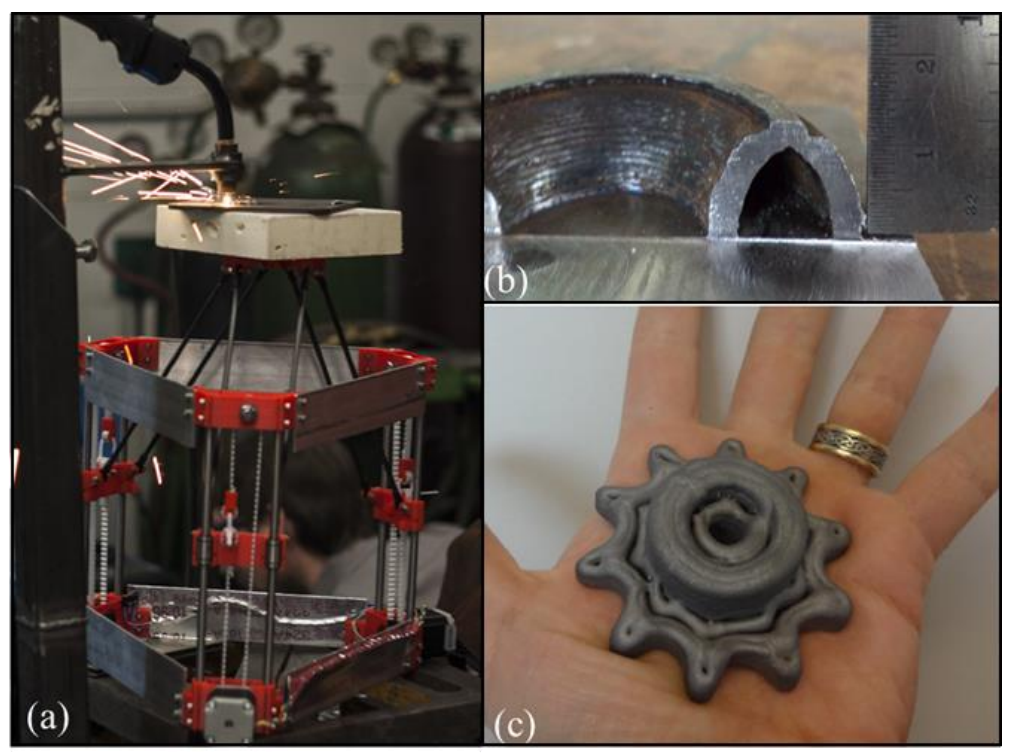

Figure 2.3: (a) A wire-based arch welding 3D printer in action [4] (b) Ducts with curved cross-section 3D printed using arch welding 3D printer [5] (c) A customized sprocket 3D printed using arch welding 3D printer [4]

The machine used by Zhang et al consists of welding torch rotating equipment fixed to a 3D positioner, the path and angle of the torch is controlled by a microcontroller. As in an FFF system, the geometry of each layer is defined by the 2D mechanical motion on the $\mathrm{x}-$ $y$ axis, and the layer height is defined by the upward motion of the piston on the z-axis[6]. 
Figure 2.3 (b) shows the curved cross-section of a hollow torus fabricated using this technology.

Panchangnula et al developed a feature based slicing approach for realizing complex overhanging structures using processes involving both additive and subtractive manufacturing technologies. Weld deposition process was used to deposit material, and CNC milling was used to complete the machining process by minor material removal at desired locations . Each layer was deposited by overlapping single beads and then milled using the CNC machine to ensure a flat top surface for dimensional accuracy[5].

Micro casting is a technology similar to arc welding process wherein the metal wire is charged from a contact tip and melted in the arc placed between a tungsten electrode and the feedstock. This creates superheated molten droplets to build a $3 \mathrm{D}$ geometry layer by layer[7].The molten droplet deposits onto the print bed, where it remains for a considerable amount of time during which it undergoes reheating and local re-melting. Figure 2.4 shows the schematic of a wire-based microcasting technology. 


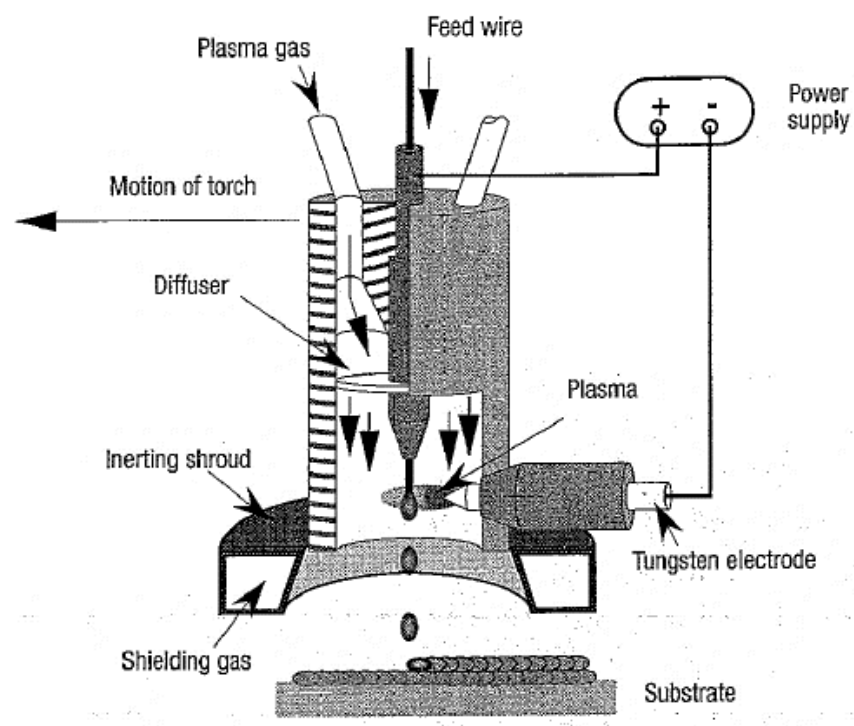

Figure 2.4: Schematic of a wire-based micro casting technology [7]

A drawback with arc welding based 3D printing is that the setup is more suited to be used in a garage or machine shop with adequate ventilation and protection. It also requires the use of protective equipment to prevent burns from UV exposure and sparks such as appropriate clothing, footwear, safety helmet and gloves and raises safety concerns for operation in a research lab, hospital or outer-space.

\subsubsection{Wire-based Laser Metal Deposition(LMD) 3D printing}

In the wire-feed LMD, the metal wire is fed into the path of a laser and simultaneously melt to create deposits resulting in a 3D geometry. LMD 3D printing technology utilizes all of the material supplied making it highly material efficient and cost-efficient[8]. 


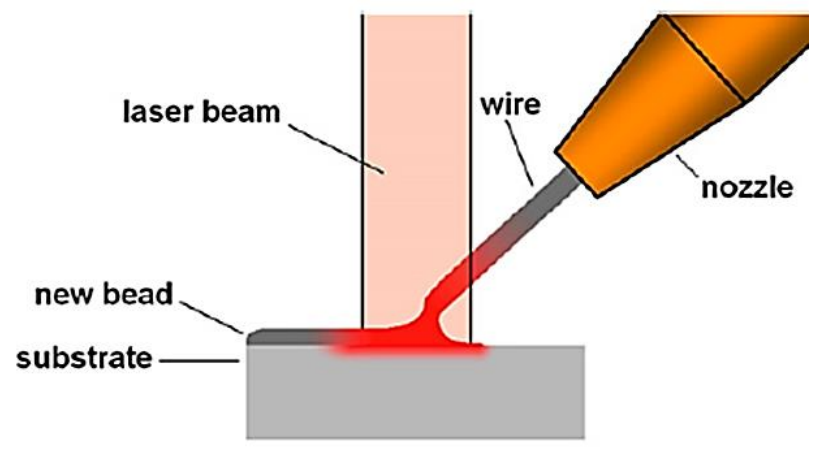

Figure 2.5: Illustration of a wire-based laser metal deposition technology[9]

Figure 2.5 shows a robotized metal-wire laser deposition system developed by Heralić et al The setup consists of a high power laser with a maximum power of $6 \mathrm{~kW}$, camera-based monitoring system, laser scanner, wire feeder optical system, collimator and focusing lens [9].

The wire feeder has a regulated feeding mechanism with fast response rate, ensuring good compliance with the system nozzle feed rate. The deposition tool follows the specified pattern through which the laser-robotic arm moves and creates a melt pool on the substrate, onto which the wire feeds continuously and melts, creating a beaded pattern. This process continues layer over layer to form the desired contour. Figure 2.6 (a) and (b) shows 3D geometries manufactured using this technique.

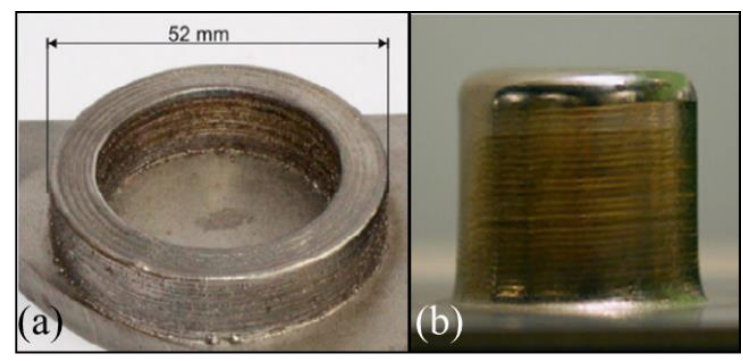

Figure 2.6: (a) Hollow cylinder [8] (b) Filled cylinder [9] 


\subsubsection{Wire-based Electron Beam Melting (EBM) 3D printing}

EBM freeform fabrication is a NASA patented process wherein the metal wire is fed into a molten pool created on the substrate using an electron beam. The process is conducted in a highly vacuum environment and is capable of bulk metal deposition [1]. Figure 2.7 shows the schematic of a wire-based EBM 3D printing process.

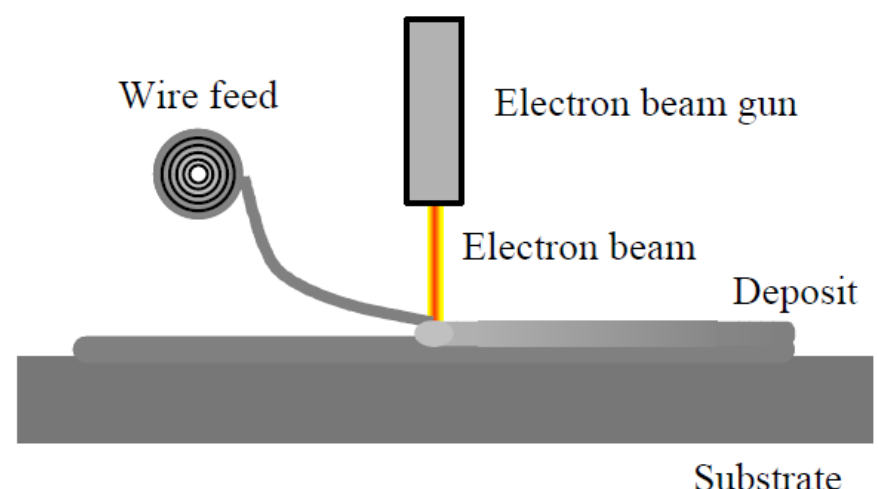

Figure 2.7: Schematic of a wire-based EBM 3D printing process[1]

The material deposition rate is highly efficient as in the laser-melting technology with an efficiency rate of $100 \%$. The process is also compatible with a wide range of materials and has a power efficiency of $95 \%$ due to which it is highly desirable for bulk production environments[10]. Figure 2.8 shows geometries fabricated using the wire-based EBM 3D printing technology. 


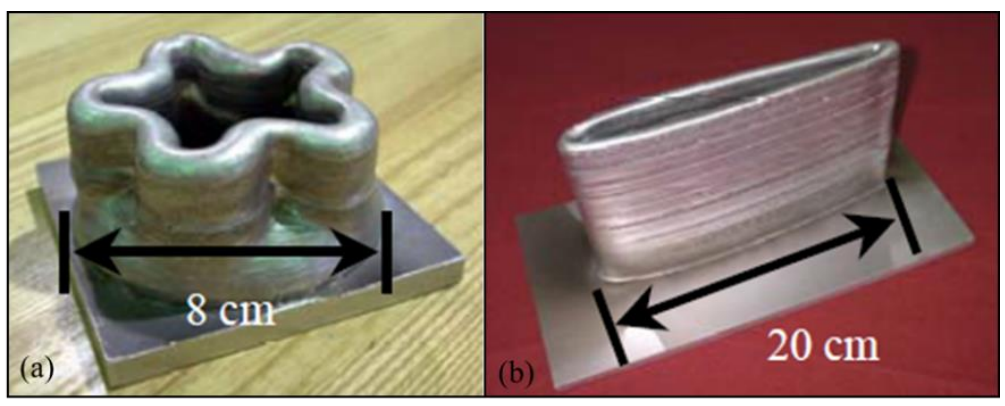

Figure 2.8: Parts fabricated using wire-based EBM 3D printing technology (a) 3D Star geometry (b) 3D aerofoil geometry [11]

The fabricated components exhibit comparable mechanical properties; the tensile properties were relatively consistent over a wide range of process conditions. However, there seems to be a trade-off between the rate of deposition and the grain size of materials deposited. [11]

\subsection{Traditional casting methodology}

Casting is one of the oldest fabrication process, dating back to $4000 \mathrm{BC}$. In this process, the material to be fabricated is melted and poured into a mold, which determines the shape of the cast part. The material cools and solidifies to take the shape of the mold cavity. Factors affecting the pouring operation include pouring temperature, pouring rate, and turbulence. [12]

Molds can be broadly divided into two types: closed mold and open mold. A closed mold consists of a delivery system for the molten metal to reach the mold cavity, where the part hardens and solidifies. An open mold casting simply consists of a container that has the shape of the desired part, with one surface open to the environment. The process allows easy modification of mold sizes thus enabling the customized fabrication of large parts 
with ease[13]. Other advantages of open mold method incudes low startup costs and rapid production cycle [14]. Figure 2.9 shows the schematic of an open mold process.

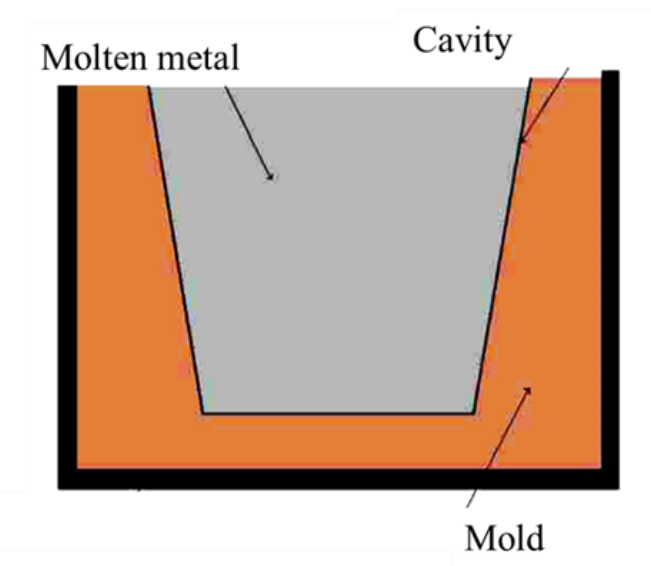

Figure 2.9: Schematic of an open mold process[13]

The casting process can be performed on any metal that can be heated to the liquid state. This process can be used to fabricate parts for automobile sector such as door handles, locks, outer casing or housing for motors, pumps, wheels and in the consumer sector to make toy cars, planes, and similar prototypes.

However, mass production of customized parts using casting methodology often requires long set-up times leading to the increase in the assembly line, thereby increasing the lead time. Casting also requires the use of furnaces and possess environmental problems and poses safety hazards to humans when processing hot molten metals. Moreover, intricate casting geometries are generally possible only with the expendable mold, which needs to be destroyed. Part shapes in the permanent-mold processes are limited by the need to open the mold [12]. 
Due to the freedom of design provided by the layer-by-layer process of fabrication using FFF 3D printing technology, the molder has the ability to overcome the manufacturing constraints of traditional mold making in order to generate complex castings[15, 16]for prototype evaluation or fully functional parts. In addition, fabricating molds using an FFF 3D printer can enable the designer to integrate complex internal geometries into the mold design. 3D printing of molds can also allow quick turnaround from the prototype design to production of individual custom parts, thereby decreasing the lead time and associated costs. [16] Thus FFF 3D printer can be used to create casting in a few days instead of weeks, saving a sizable amount of time as compared to traditional manufacturing methods. This also saves costs associated with potential rework and prototyping without investing in expensive tooling. [17, 18]

\subsection{Low melting alloys}

Low melt alloys can be divided into groups of eutectic and non-eutectic alloy depending on their melting behavior. Eutectic alloys are those alloys which melt at a specific temperature like metals. Non-eutectic alloys melt over a range of temperatures; the material is usually slushy between their liquidus and solidus temperatures.

Low melting alloys find applications in various fields including automotive, aerospace, electronics, healthcare and consumer sectors. It is suitable as anchoring, jigs, and fixtures, encapsulation molds, bearing coatings, jewelry, cosmetics and is used as a replacement of mercury in thermometers, fabrication of dyes and castings, prototyping of prosthetics, dental models and so on. Figure 2.10 shows some of the applications in which low melting alloys are commonly used. 


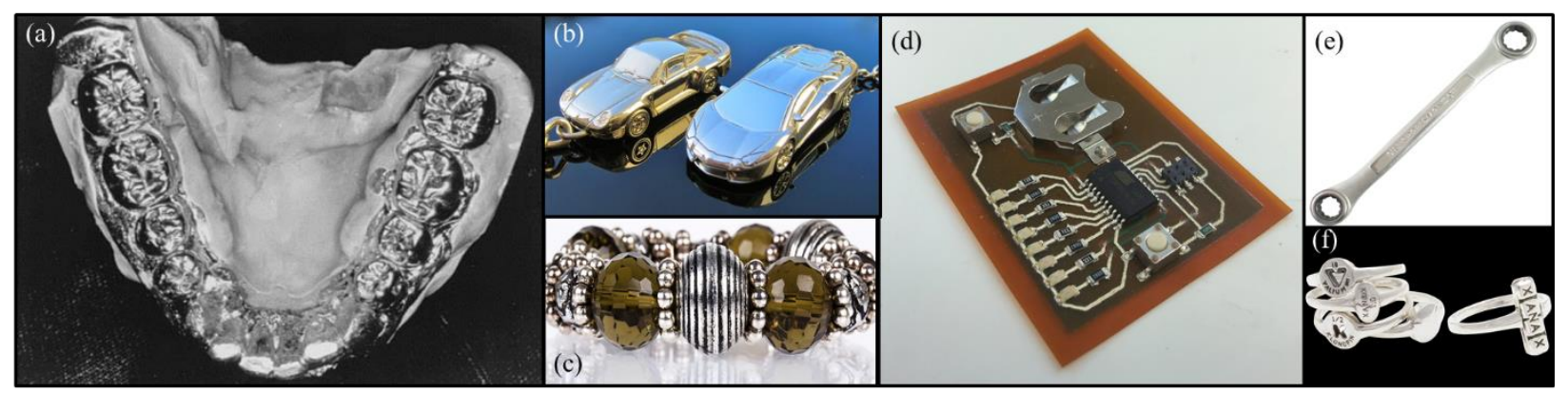

Figure 2.10: (a) Low melting alloy used in remount cast for posterior crowns[19] (b) Diecast metal car models [20] (c),(f) Jewelry cast from low melting lead-free alloy[21] (d) Alloys as conductive ink in electronic circuitry (e ) Prototype of a mechanical wrench

It is interesting to note that all or some of these applications require customization and oneat-a time production, which is a major reason why $3 \mathrm{D}$ printing of low melting alloys is desirable.

\subsection{Material selection}

As a part of studying the feasibility of 3D printing metals using an FFF 3D printer, extensive material investigation was conducted on eutectic and non-eutectic low melting alloys. Due to the temperature limitations of an FFF 3D printer, only low melting alloy systems with onset melting temperatures ranging from of $100-300^{\circ} \mathrm{C}$ were considered. Additionally, the lead content was limited to a maximum composition of $10 \%$ to reduce the toxicity and possibility of leaching. Twenty-one eutectic alloys systems of bismuth, indium, and tin, and fifty-five non-eutectic alloy systems of bismuth, indium, tin, antimony, cadmium, silver and lead were evaluated [22-41].

Bismuth alloy systems exhibit significantly low melting point and improved wettability. Indium alloys exhibit low melting points and high ductility, but is rare and not readily 
available. Gold has excellent thermal fatigue properties, but has comparatively high ranges of liquids temperature and is also very costly. Antimony alloys exhibit superior tensile strength and wettability properties. Silver alloys show sufficient mechanical strength, but has low ductility and also is highly toxic. [42]

Some of these alloy systems also contain traces of cadmium, copper, and zinc. The presence of copper in the alloy lowers its melting point and improves wettability. It also leads to increasing resistance to thermal fatigue. The presence of zinc reduces the melting point of the alloy but is highly susceptible to corrosion and oxidation. Cadmium is considered highly toxic. [33]

It is necessary to review the physical properties, mechanical properties and thermal properties of the low melt alloy material to select the best candidates for 3D printing using an FFF metal 3D printing technology.

\subsubsection{Eutectic alloys}

Eutectic alloys are those alloys which melt at a specific temperature like metals. Low melting non-eutectic alloys of bismuth, indium, tin, and gold were reviewed. The composition, physical, mechanical and thermal properties of these low melting eutectic alloys systems are analyzed and described in this section.

\subsubsection{Composition and physical properties}

Alloy composition for low melting eutectic alloys of bismuth, indium, tin, and gold alloys are shown in Table 2.1 [22-41] 
Table 2.1: Alloy composition for low melting eutectic alloy systems

\begin{tabular}{|c|c|c|c|c|c|c|c|c|}
\hline \multirow[t]{2}{*}{ Alloy } & \multirow[t]{2}{*}{ Name } & \multicolumn{7}{|c|}{ Composition } \\
\hline & & $\mathbf{B i}$ & In & Sn & $\mathbf{A g}$ & $\mathbf{Z n}$ & $\mathbf{C u}$ & $\mathbf{A u}$ \\
\hline \multirow[t]{5}{*}{ Bismuth } & 58Bi42Sn & 58 & & 42 & & & & \\
\hline & 100Bi & 100 & & & & & & \\
\hline & 50Bi50Sn & 50 & & 50 & & & & \\
\hline & 52Bi48Sn & 52 & & 48 & & & & \\
\hline & 42Sn56Bi2In & 56 & 2 & 42 & & & & \\
\hline \multirow[t]{3}{*}{ Indium } & 100In & & 100 & & & & & \\
\hline & $52 \operatorname{In} 48 \mathrm{Sn}$ & & 52 & 48 & & & & \\
\hline & 97In3 Ag & & 97 & & 3 & & & \\
\hline \multirow[t]{9}{*}{ Tin } & 92Sn8Zn & & & 92 & & 8 & & \\
\hline & $96.5 \mathrm{Sn} 3.5 \mathrm{Ag}$ & & & 96.5 & 3.5 & & & \\
\hline & 91Sn9Zn & & & 91 & & 9 & & \\
\hline & $99.3 \mathrm{Sn} 0.7 \mathrm{Cu}$ & & & 99.3 & & & 0.7 & \\
\hline & $95.5 \mathrm{Sn} 3.8 \mathrm{Ag} 0.7 \mathrm{Cu}$ & & & 95.5 & 3.8 & & 0.7 & \\
\hline & $99.85 \mathrm{Sn} 0.04 \mathrm{Cu} 0.03 \mathrm{Bi}$ & 0.03 & & 99.85 & & & 0.04 & \\
\hline & $93 \mathrm{Sn} 3 \mathrm{Ag} 4 \mathrm{Cu}$ & & & 93 & 3 & & 4 & \\
\hline & $48 \mathrm{Sn} 46 \mathrm{Bi} 2 \mathrm{Ag} 4 \mathrm{Cu}$ & 46 & & 48 & 2 & & 4 & \\
\hline & $100 \mathrm{Sn}$ & & & 100 & & & & \\
\hline Gold & $80 \mathrm{Au} 20 \mathrm{Sn}$ & & & 20 & & & & 80 \\
\hline
\end{tabular}


In the eutectic bismuth alloy system, phase composition of bismuth ranges from $50 \%$ to $100 \%$. Bismuth typically forms eutectic alloys with tin and indium. Compositions of tin in bismuth-tin alloy range from $42 \%$ to $50 \%$. The composition of indium in the bismuthindium alloy is $2 \%$, the remainder being bismuth and tin. Major phase compositions of indium in the eutectic indium alloys typically range from $52 \%$ to $100 \%$. Indium forms indium-tin alloys with $48 \%$ of tin and indium-silver alloys with $3 \%$ silver. Tin material forms alloys with a broader set of elements such as bismuth, silver, copper, and zinc. However, the majority of alloy composition is occupied by tin alone, compositions ranging from $48 \%$ to $100 \%$, with an average tin composition of $89.39 \%$. The percentage of bismuth in a tin-bismuth alloy ranges from as low as $0.03 \%$ to $46 \%$. The proportions of silver and copper in tin falls in close ranges of $2-3.5 \%$ for silver and 0.7 to $4 \%$ for copper. Zinc compositions in the tin are typically higher, ranging from percentages of $8-9 \%$. The only low melting eutectic alloy with gold as the primary component is an alloy composition of $80 \%$ gold and $20 \%$ tin.

Physical properties for low melting eutectic alloys of bismuth, indium, tin, and gold along are shown in Table 2.2 
Table 2.2. Physical properties of the low melting eutectic alloy systems

\begin{tabular}{|c|c|c|c|c|}
\hline \multirow[t]{2}{*}{ Alloy } & \multirow[t]{2}{*}{ Name } & $\begin{array}{c}\text { Melting } \\
\text { Temperature }\end{array}$ & Density & \multirow[t]{2}{*}{ References } \\
\hline & & ${ }^{\circ} \mathbf{C}$ & $\mathrm{g} / \mathrm{cm}^{3}$ & \\
\hline \multirow[t]{5}{*}{ Bismuth } & 58Bi42Sn & 138 & 8.72 & {$[26,31]$} \\
\hline & $100 \mathrm{Bi}$ & 271.4 & 9.80 & [31] \\
\hline & 50Bi50Sn & 152 & 8.37 & [31] \\
\hline & 52Bi48Sn & 151 & 8.42 & [31] \\
\hline & 42Sn56Bi2In & 140 & 8.55 & [31] \\
\hline \multirow[t]{3}{*}{ Indium } & 100In & 157 & 7.02 & [31] \\
\hline & 52In48Sn & 118 & 7.30 & {$[31]$} \\
\hline & $97 \operatorname{In} 3 \mathrm{Ag}$ & 143 & 7.38 & {$[31]$} \\
\hline \multirow[t]{9}{*}{ Tin } & $92 \mathrm{Sn} 8 \mathrm{Zn}$ & 199 & 7.38 & [31] \\
\hline & $96.5 \mathrm{Sn} 3.5 \mathrm{Ag}$ & 221 & 7.80 & [31] \\
\hline & 91Sn9Zn & 199 & 7.27 & [31] \\
\hline & $99.3 \mathrm{Sn} 0.7 \mathrm{Cu}$ & 227 & 7.31 & [26] \\
\hline & $95.5 \mathrm{Sn} 3.8 \mathrm{Ag} 0.7 \mathrm{Cu}$ & 221 & 7.37 & [31] \\
\hline & $99.85 \mathrm{Sn} 0.04 \mathrm{Cu} 0.03 \mathrm{Bi}$ & 239 & 7.29 & {$[39,43]$} \\
\hline & $93 \mathrm{Sn} 3 \mathrm{Ag} 4 \mathrm{Cu}$ & 221 & 7.42 & [39] \\
\hline & 48Sn46Bi2Ag4Cu & 146 & 8.44 & {$[31]$} \\
\hline & $100 \mathrm{Sn}$ & 231.9 & 7.30 & {$[31]$} \\
\hline Gold & 80Au20Sn & 280 & 14.51 & [31] \\
\hline
\end{tabular}


Melting temperatures of the bismuth material system range from $138^{\circ} \mathrm{C}$ to $271.4^{\circ} \mathrm{C}$. In fact, all the bismuth alloys have comparatively low melting temperatures ranging from $138^{\circ} \mathrm{C}$ to $152^{\circ} \mathrm{C}$. Pure bismuth, however, exhibits the highest melting temperature at the temperature of $271^{\circ} \mathrm{C}$. Indium materials have melting temperatures ranging from $118^{\circ} \mathrm{C}$ to $157^{\circ} \mathrm{C}$, wherein the indium-tin alloy has the lowest melting temperature of $118^{\circ} \mathrm{C}$, and pure indium has the highest melting temperature of $157^{\circ} \mathrm{C}$. Tin materials exhibited higher melting temperatures ranging from $146{ }^{\circ} \mathrm{C}$ to $239{ }^{\circ} \mathrm{C}$, averaging to a temperature of $211.65^{\circ} \mathrm{C}$. Except for the tin-bismuth alloy which showed lower melting temperatures of $146^{\circ} \mathrm{C}$, all the remaining alloys as well as pure tin material showed higher melting temperatures ranging from $199^{\circ} \mathrm{C}$ to $239^{\circ} \mathrm{C}$. Gold alloys exhibited the high melting temperatures of $281^{\circ} \mathrm{C}$.

A pictorial representation of the melting point of the low melting eutectic alloy systems is shown in Figure 2.11.

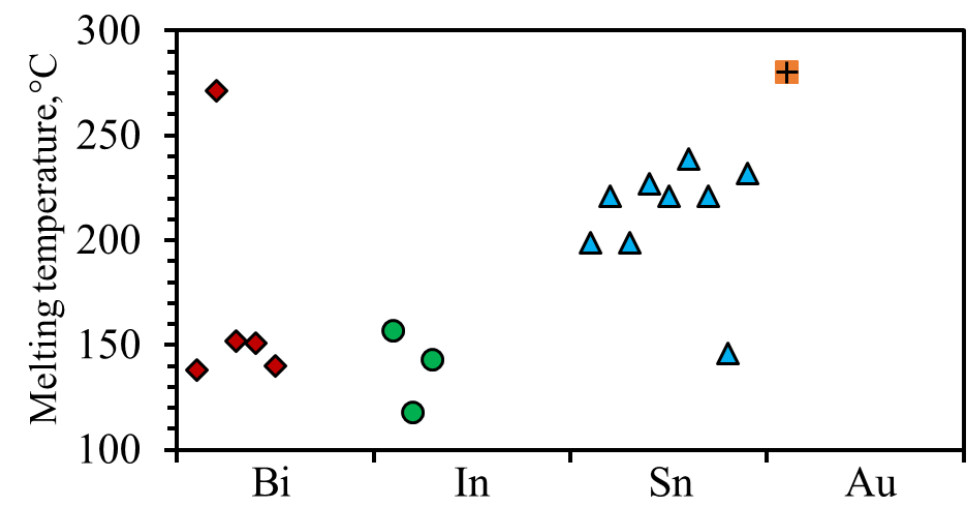

Figure 2.11. Melting point of the low melting eutectic alloy systems

Figure 2.11 shows that bismuth and indium show lowest ranges of melting temperatures typically within $150{ }^{\circ} \mathrm{C}$, disregarding the pure bismuth material which melts at higher 
temperatures as can be seen. Majority of the tin material system shows higher values of melting temperatures ranging between $200^{\circ} \mathrm{C}$ and $250^{\circ} \mathrm{C}$. The lower melting tin alloy in the figure is a composition of tin-bismuth with only $48 \%$ tin. Gold alloy exhibits higher melting temperatures above $250^{\circ} \mathrm{C}$.

Densities of bismuth eutectic system range from $8.37 \mathrm{~g} / \mathrm{cm}^{3}$ to $9.8 \mathrm{~g} / \mathrm{cm}^{3}$. The highest density of $9.8 \mathrm{~g} / \mathrm{cm}^{3}$ is exhibited by the pure bismuth material. Indium alloys have lower density ranges of $7.02 \mathrm{~g} / \mathrm{cm}^{3}$ to $7.38 \mathrm{~g} / \mathrm{cm}^{3}$. Pure tin has a density of $7.3 \mathrm{~g} / \mathrm{cm}^{3}$. Densities of the tin system increase to $8.44 \mathrm{~g} / \mathrm{cm}^{3}$ when tin forms alloys with heavier elements such as zinc, silver, and copper. The gold-tin alloy shows the highest density of all the material systems with a density of $14.51 \mathrm{~g} / \mathrm{cm}^{3}$.

A pictorial representation of the densities of the low melting eutectic alloy systems is shown in Figure 2.12.

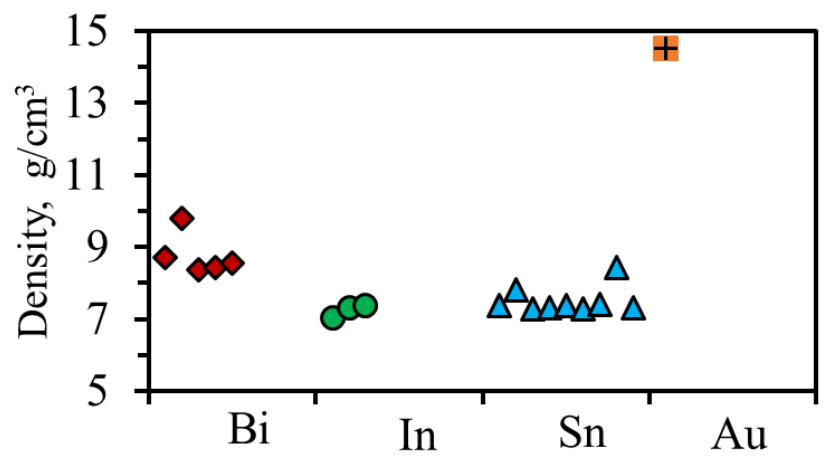

Figure 2.12. Density of the low melting eutectic alloy systems

Figure 2.12 shows that out of all the material systems, bismuth and gold alloy systems exhibit the highest density. Gold eutectic system, with the gold-tin alloy, displays the highest density closer to a scale of 15 , with a value of $14.51 \mathrm{~g} / \mathrm{cm}^{3}$. Bismuth alloys exhibit 
densities in the scale of $8-11 \mathrm{~g} / \mathrm{cm}^{3}$ as plotted, averaging to a range of $8.77 \pm 0.59 \mathrm{~g} / \mathrm{cm}^{3}$. Indium and tin show lower ranges of densities in scales of $7-7.5 \mathrm{~g} / \mathrm{cm}^{3}$ as can be observed from the graph. Indium shows the lowest density of $7.23 \pm-0.189 \mathrm{~g} / \mathrm{cm}^{3}$. Indium is followed closely by the tin alloys with a density of $7.50 \pm 0.384 \mathrm{~g} / \mathrm{cm}^{3}$.

A representative graph of melting temperature vs. density of the low melting eutectic alloy systems is plotted in Figure 2.13.



Figure 2.13: Melting temperature vs. density of the low melting eutectic alloy systems

It can be observed in Figure 2.13 Indium is the least dense of all the materials systems and has the least ranges of melting temperatures. Tin is as less dense as indium but melts at higher temperatures. Bismuth alloy system exhibits high densities along with convenient melting temperatures, even lower than its lighter counterpart, tin. Gold is the densest of all and melts at the higher temperatures.

\subsubsection{Mechanical properties}

Mechanical properties for low melting eutectic alloys of bismuth, indium, tin, and gold along are shown in Table $\mathbf{2 . 3}$ 
Table 2.3: Mechanical properties of the low melting eutectic alloy systems

\begin{tabular}{|c|c|c|c|c|c|}
\hline \multirow{2}{*}{ Alloy } & \multirow{2}{*}{ Name } & UTS & Elongation & Hardness & \multirow{2}{*}{ References } \\
\hline & & MPa & $\%$ & HV5(RT) & \\
\hline \multirow{5}{*}{ Bismuth } & 58Bi42Sn & 55.4 & 46 & 23 & [37] \\
\hline & $100 \mathrm{Bi}$ & 1.96 & & 7 & [37] \\
\hline & 50Bi50Sn & 61.8 & 53 & & [26] \\
\hline & 52Bi48Sn & 60.9 & 57 & & [26] \\
\hline & 42Sn56Bi2In & 66.1 & 47 & 116 & [26] \\
\hline \multirow{3}{*}{ Indium } & 100In & 1.88 & 41 & 116 & [26] \\
\hline & $52 \operatorname{In} 48 \operatorname{Sn}$ & 11.8 & 83 & 5 & [26] \\
\hline & 97In $3 \mathrm{Ag}$ & 5.51 & & 2 & [37] \\
\hline \multirow{9}{*}{ Tin } & 92Sn8Zn & & & & [33] \\
\hline & $96.5 \mathrm{Sn} 3.5 \mathrm{Ag}$ & 55 & 35 & & [26] \\
\hline & $91 \mathrm{Sn} 9 \mathrm{Zn}$ & 53.1 & 33 & 22 & [37], [33] \\
\hline & $99.3 \mathrm{Sn} 0.7 \mathrm{Cu}$ & 29.4 & 21 & 9 & [37] \\
\hline & $95.5 \mathrm{Sn} 3.8 \mathrm{Ag} 0.7 \mathrm{Cu}$ & & 64 & & [26] \\
\hline & $99.85 \mathrm{Sn} 0.04 \mathrm{Cu} 0.03 \mathrm{Bi}$ & 18.6 & 57 & 3.9 & [33] \\
\hline & $93 \mathrm{Sn} 3 \mathrm{Ag} 4 \mathrm{Cu}$ & & & & [44] \\
\hline & $48 \mathrm{Sn} 46 \mathrm{Bi} 2 \mathrm{Ag} 4 \mathrm{Cu}$ & 69.4 & 3 & & [37], [44] \\
\hline & $100 \mathrm{Sn}$ & 13.2 & 268 & 4 & [26] \\
\hline Gold & 80Au20Sn & & 2 & 274.6 & [37], [26] \\
\hline
\end{tabular}


The ultimate tensile strength (UTS) of the bismuth alloys ranges from 55.4MPa to 66.1MPa. Pure bismuth, however, has a very low UTS of 1.96MPa. The tensile strength of indium alloys is nearly ten times lesser than the bismuth alloys, with values ranging from 5.51MPa to $11.8 \mathrm{MPa}$. The UTS of pure indium, on the other hand, does not vary considerably from the pure bismuth material and has a value of 1.88MPa. Pure tin has significantly higher values of tensile strength with a value of 268MPa. The values of UTS in tin alloys ranges broadly from 13.2MPa for pure tin to $69.4 \mathrm{MPa}$ for tin alloys. In general, tin alloys having greater percentage composition of tin ( $99 \%$ and higher) has lower values of tensile strength, tin alloys with compositions of bismuth, zinc and silver elements exhibit higher values of UTS.

A representative graph of the ultimate tensile strength of the low melting eutectic alloy systems is shown in Figure 2.14.

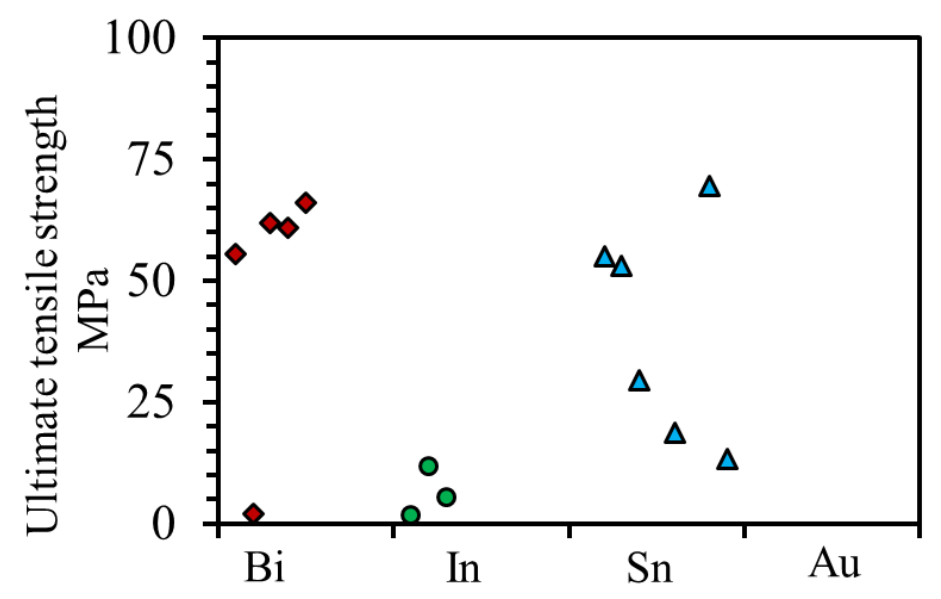

Figure 2.14: Ultimate tensile strength (UTS) of the low melting eutectic alloy systems 
Figure 2.14 shows that bismuth alloys have higher values of UTS typically in the range of $50 \mathrm{MPa}$ to $70 \mathrm{MPa}$, disregarding the pure bismuth material with lower tensile strengths of approximately $1.5 \mathrm{MPa}$. The tin material system is shown to exhibit high values of UTS like the bismuth system but over a wide range of values. Tin eutectic systems which exhibit UTS over the range of 50MPa are typically the alloys of tin with zinc, bismuth and silver elements. The tin alloys systems which have UTS values below 30MPa are found to have over 99 percentages of the tin composition. The UTS of the gold-tin alloy was not available in the literature.

The percentage elongation of the eutectic bismuth alloy systems falls in narrow ranges of $47 \%$ to $57 \%$. The percentage elongation of pure indium is comparatively lesser, with a value of $41 \%$, but increases to a value of $83 \%$ when indium forms an alloy with $48 \%$ composition of tin. The elongation values of tin fall in broad ranges of $3 \%$ to $268 \%$. The lowest value is exhibited by alloys with only about $50 \%$ composition of tin. As the composition of tin in the alloy increases, the percentage elongation of the alloy increases and eventually reaches its highest range the for the pure tin material. The gold alloy is found to have the least percentage elongation values of $3 \%$, equivalent to that of the tinbismuth alloy discussed earlier.

A representative graph of percentage elongations of the low melting eutectic alloy systems is plotted in Figure 2.15 


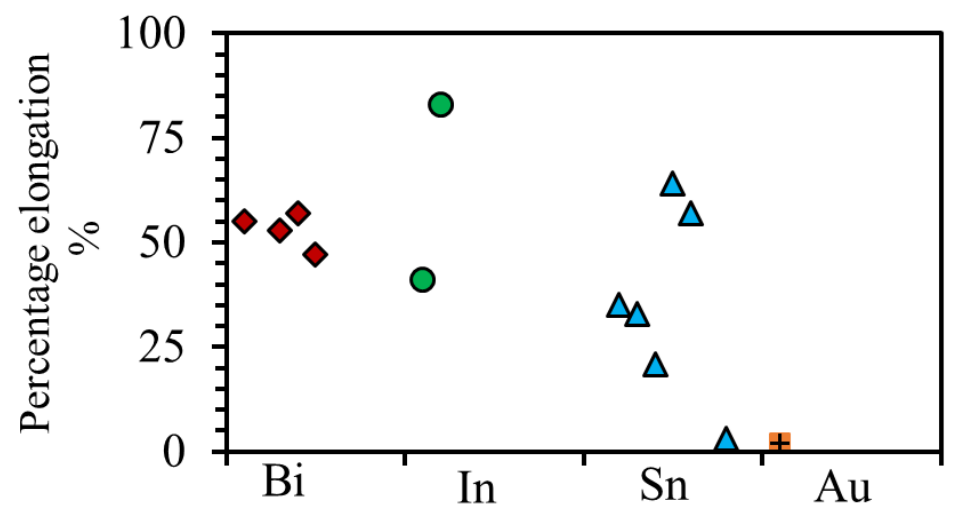

Figure 2.15: Percentage elongation of the low melting eutectic alloy systems

As shown in Figure 2.15, pure indium is found to exhibit the highest range of percentage elongations among all the low melting eutectic systems considered. Bismuth alloys are found to exhibit percentage elongation values in the ranges of $45 \%$ to $55 \%$. The percentage elongation values of tin alloys fall over a broad range of values, the lower elongation values corresponding to alloys with lower percentages of tin and the higher elongation values corresponding to elements with a higher percentage of tin. The gold-tin alloy is found to exhibit the lowest elongation value among all the low melting eutectic alloy systems considered.

\subsubsection{Thermal properties}

Thermal properties for low melting eutectic alloys of bismuth, indium, tin, and gold along are shown in Table 2.4 
Table 2.4: Thermal properties of low melting eutectic alloys

\begin{tabular}{|c|c|c|c|c|c|}
\hline \multirow[t]{2}{*}{ Alloy } & \multirow[t]{2}{*}{ Name } & CTE & $\mathbf{k}$ & Cp & \multirow[t]{2}{*}{ References } \\
\hline & & $10^{-6} \mathrm{~K}$ & W/m.K & $\mathrm{J} / \mathrm{Kg}, \mathrm{K}$ & \\
\hline \multirow[t]{5}{*}{ Bismuth } & 58Bi42Sn & 15 & 18.41 & 46 & [44] \\
\hline & 100Bi & 13.4 & 86 & 48 & [37] \\
\hline & 50Bi50Sn & & 22 & 43 & {$[37],[45]$} \\
\hline & 52Bi48Sn & 12.13 & & 40 & [26] \\
\hline & 42Sn56Bi2In & 16.01 & & 45 & [44] \\
\hline \multirow[t]{3}{*}{ Indium } & 100In & 29 & 83.7 & 44 & [33] \\
\hline & $52 \operatorname{In} 48 \mathrm{Sn}$ & 20 & 34 & & [37] \\
\hline & 97In $3 \mathrm{Ag}$ & 22 & 73 & & [33] \\
\hline \multirow[t]{9}{*}{ Tin } & 92Sn8Zn & 20.5 & & & [37] \\
\hline & $96.5 \mathrm{Sn} 3.5 \mathrm{Ag}$ & 20.04 & 78 & 64 & {$[45]$} \\
\hline & 91Sn9Zn & 31.77 & 61 & 69 & {$[37],[33]$} \\
\hline & $99.3 \mathrm{Sn} 0.7 \mathrm{Cu}$ & & 66 & & [37] \\
\hline & $95.5 \mathrm{Sn} 3.8 \mathrm{Ag} 0.7 \mathrm{Cu}$ & 20.04 & 60 & & [37], [26] \\
\hline & $99.85 \mathrm{Sn} 0.04 \mathrm{Cu} 0.03 \mathrm{Bi}$ & 23.8 & 62.6 & 22 & [40] \\
\hline & $93 \mathrm{Sn} 3 \mathrm{Ag} 4 \mathrm{Cu}$ & 14.83 & & 65 & {$[37]$} \\
\hline & $48 \mathrm{Sn} 46 \mathrm{Bi} 2 \mathrm{Ag} 4 \mathrm{Cu}$ & 14.38 & & 36 & [44], [26] \\
\hline & $100 \mathrm{Sn}$ & 17.9 & 73 & 22 & [33] \\
\hline Gold & $80 \mathrm{Au} 20 \mathrm{Sn}$ & 16 & 57 & & [26] \\
\hline
\end{tabular}


As shown in Table 2.4, the coefficient of thermal expansion (CTE) of both the pure bismuth and bismuth alloys ranges in between 12.13E-06 K and 16.01 E-06 K. The CTE of the pure indium material is $29 \mathrm{E}-06 \mathrm{~K}$ and that of the indium-tin alloy is a slightly lower value of $20 \mathrm{E}-06 \mathrm{~K}$. Pure tin has a CTE in similar ranges of $17.9 \mathrm{E}-06 \mathrm{~K}$ and so does the gold-tin alloy with a CTE of 16E-06 K. Tin-zinc alloys are found to exhibit the highest values of CTE among all the low melting eutectic systems with a value of $31.77 \mathrm{E}-06 \mathrm{~K}$, followed by the pure indium material.

A representative graph of coefficient of thermal expansion of the low melting eutectic alloy systems has been plotted in Figure 2.16.

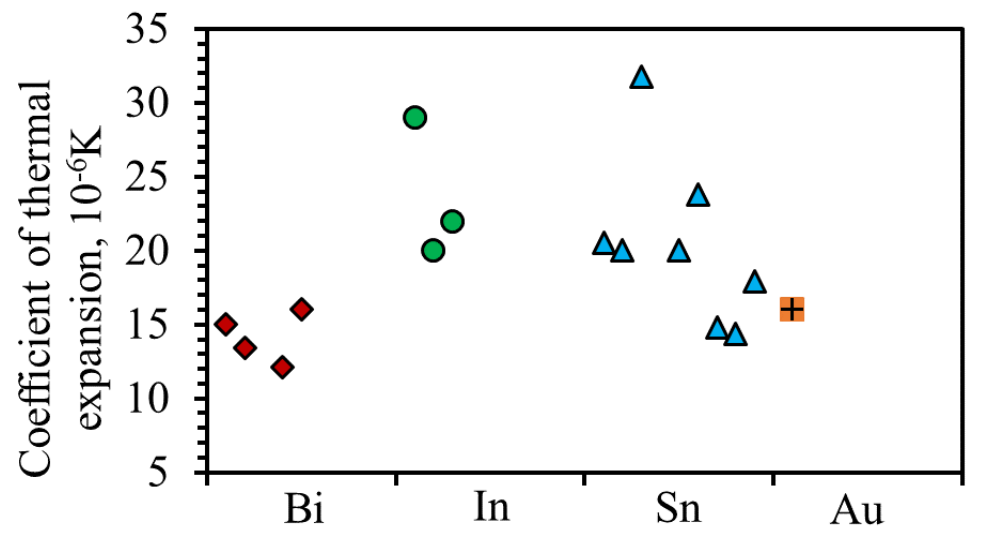

Figure 2.16: Coefficient of thermal expansion of the low melting eutectic alloy systems

From Figure 2.16, it can be stated that bismuth alloys tend to exhibit the least thermal expansion values among all the low melting eutectic alloys considered. Bismuth is closely followed by the tin-bismuth and tin-silver alloys. The tin alloys, however, fall into a broad range of values from scales of 15 to 30 , owing to the wide range of the tin-alloy compositions considered. The gold-tin alloy falls in the average thermal expansion ranges of all the eutectic systems considered. 
The thermal conductivity of bismuth-tin alloys averages to $20.20 \pm 1.79 \mathrm{~W} / \mathrm{m} . \mathrm{K}$ and the thermal conductivity of indium-tin alloys is equivalent to $34 \mathrm{~W} / \mathrm{m} . \mathrm{K}$. Pure bismuth and pure indium materials are shown to exhibit higher conductivity values of $86 \mathrm{~W} / \mathrm{m} . \mathrm{K}$ and 83.7 W/m.K respectively. Indium-silver alloy also falls into close ranges of the pure materials, with a value of $73 \mathrm{~W} / \mathrm{m} . \mathrm{K}$. The tin alloys and pure tin material has thermal conductivity values in the range of $61 \mathrm{~W} / \mathrm{m} . \mathrm{K}$ to $78 \mathrm{~W} / \mathrm{m} . \mathrm{K}$, averaging to a value of 66.76 $\pm 6.60 \mathrm{~W} / \mathrm{m} . \mathrm{K}$. The gold alloy has a thermal conductivity value of $57 \mathrm{~W} / \mathrm{m} . \mathrm{K}$.

A representative graph of the thermal conductivity of the low melting eutectic alloy systems is plotted in Figure 2.17.

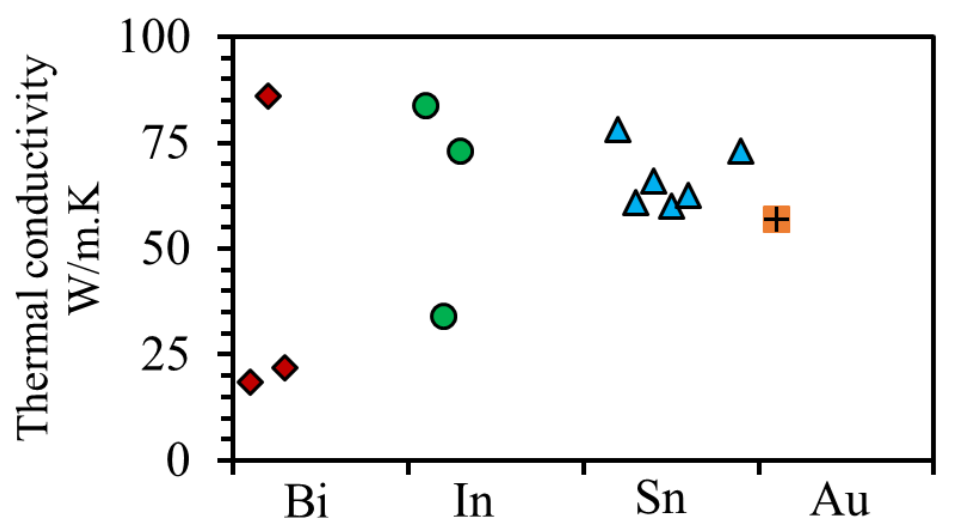

Figure 2.17: Thermal conductivity of the low melting eutectic alloy systems

Figure 2.17 shows that two of the bismuth alloys exhibit the lowest range of thermal conductivity values amongst the low melting eutectic system considered. From Table 2.1 it can be observed that they are the tin alloys of bismuth. The highest values of thermal conductivity for the bismuth alloys correspond to their pure metal counterparts. The conductivity values of tin alloys range above $58 \mathrm{~W} / \mathrm{m} . \mathrm{K}$ and corresponds to an average of $66.77 \pm 6.61 \mathrm{~W} / \mathrm{m} . \mathrm{K}$. Higher conductivity values of indium correspond to those alloys with 
higher compositions of Indium; pure indium exhibits the highest conductivity value of $84 \mathrm{~W} / \mathrm{m} . \mathrm{K}$.

\subsubsection{Non-eutectic alloys}

Non-eutectic alloys melt over a range of temperatures; the material is usually slushy between their liquidus and solidus temperatures. Low melting non-eutectic alloys of indium, antimony, cadmium, silver, bismuth, and lead were reviewed. The physical, mechanical and thermal properties of the low melting non-eutectic alloys systems are analyzed and described in this section.

\subsubsection{Composition and physical properties}

Alloy composition for low melting non-eutectic alloys of bismuth, indium, antimony, cadmium, silver, and lead are shown in Table 2.5 
Table 2.5: Alloy composition for low melting non-eutectic alloy systems -

\begin{tabular}{|c|c|c|c|c|c|c|c|c|c|c|}
\hline \multirow[t]{2}{*}{ Alloy } & \multirow[t]{2}{*}{ Name } & \multicolumn{9}{|c|}{ Composition } \\
\hline & & Sn & Ag & $\mathbf{B i}$ & In & $\mathbf{P b}$ & $\mathrm{Cu}$ & $\mathbf{S b}$ & Cd & $\mathbf{Z n}$ \\
\hline \multirow{2}{*}{ Bismuth } & 80Sn10Bi10In & 80 & & 10 & 10 & & & & & \\
\hline & 60Sn40Bi & 60 & & 40 & & & & & & \\
\hline \multirow[t]{2}{*}{ Indium } & 90In10Ag & & 10 & & 90 & & & & & \\
\hline & $50 \operatorname{In} 50 \mathrm{Sn}$ & 50 & & & 50 & & & & & \\
\hline \multirow[t]{4}{*}{ Antimony } & $89 \mathrm{Sn} 7.5 \mathrm{Sb} 3.5 \mathrm{Cu}$ & 89 & & & & & 3.5 & 7.5 & & \\
\hline & $95 \mathrm{Sn} 5 \mathrm{Sb}$ & 95 & & & & & & 5 & & \\
\hline & $91.75 \mathrm{Sn} 8 \mathrm{Sb} 0.25 \mathrm{Cu}$ & 91.75 & & & & & 0.25 & 8 & & \\
\hline & $92 \mathrm{Sn} 4 \mathrm{Sb} 4 \mathrm{~Pb}$ & 92 & & & & 4 & & 4 & & \\
\hline Cadmium & $78 \mathrm{Cd} 17 \mathrm{Zn} 5 \mathrm{Ag}$ & & 5 & & & & & & 78 & 17 \\
\hline \multirow[t]{8}{*}{ Silver } & $95.5 \mathrm{Sn} 4 \mathrm{Ag} 0.5 \mathrm{Cu}$ & 95.5 & 4 & & & & 0.5 & & & \\
\hline & $\mathrm{Sn} 2.5 \mathrm{Ag} 0.8 \mathrm{Cu} 0.5 \mathrm{Sb}$ & 96.2 & 2.5 & & & & 0.8 & 0.5 & & \\
\hline & Sn2.8Ag20In & 77.2 & 2.8 & & 20 & & & & & \\
\hline & $98 \mathrm{Sn} 2 \mathrm{Ag}$ & 98 & 2 & & & & & & & \\
\hline & $93 \mathrm{Sn} 3 \mathrm{Ag} 4 \mathrm{Cu}$ & 93 & 3 & & & & 4 & & & \\
\hline & 94Sn2.5Ag2Bi1.5Sb & 94 & 2.5 & 2 & & & 4 & 1.5 & & \\
\hline & 93.5Sn3Ag1Cu1Bi1.5Sb & 93.5 & 3 & 1 & & & 1 & 1.5 & & \\
\hline & 78.4Sn2Ag9.8Bi9.8In & 78.4 & 2 & 9.8 & 9.8 & & & & & \\
\hline
\end{tabular}


Table 2.5 (continued): Alloy composition of the low melting non- eutectic alloy systems

\begin{tabular}{|c|c|c|c|c|c|c|c|c|c|c|}
\hline \multirow[t]{2}{*}{ Alloy } & \multirow[t]{2}{*}{ Name } & \multicolumn{9}{|c|}{ Composition } \\
\hline & & Sn & $\mathbf{A g}$ & $\mathbf{B i}$ & In & $\mathbf{P b}$ & $\mathbf{C u}$ & $\mathbf{S b}$ & $\mathbf{C d}$ & $\mathbf{Z n}$ \\
\hline \multirow[t]{14}{*}{ Silver } & $40.5 \mathrm{Sn} 2 \mathrm{Ag} 56 \mathrm{Bi} 1.5 \mathrm{Sb}$ & 40.5 & 2 & 56 & & & & 1.5 & & \\
\hline & 95Sn3Ag2Sb & 95 & 3 & & & & & 2 & & \\
\hline & $93.5 \mathrm{Sn} 2 \mathrm{Ag} 8 \mathrm{Cu}$ & 93.5 & 2 & & & & 8 & & & \\
\hline & 86.4Sn5Ag8.6In2Sb & 86.4 & 5 & & 8.6 & & 8 & 2 & & \\
\hline & 96.1Sn2.6Ag0.8Cu0.5Sb & 96.1 & 2.6 & & & & 8 & 0.5 & & \\
\hline & 78.4Sn9.8Bi9.8In2Ag & 78.4 & 2 & 9.8 & 9.8 & & & & & \\
\hline & $\mathrm{Sn} 3 \mathrm{Ag} 0.5 \mathrm{Cu}$ & 96.5 & 3 & & & & 0.5 & & & \\
\hline & 39Sn3Ag54Bi2In2Sb & 39 & 3 & 54 & 2 & & & 2 & & \\
\hline & Sn3.5Ag5Bi0.7Cu & 90.8 & 3.5 & 5 & 3 & & 0.7 & & & \\
\hline & Sn3Ag3Bi & 94 & 3 & 3 & & & & & & \\
\hline & $\mathrm{Sn} 4 \mathrm{Ag} 0.5 \mathrm{Cu}$ & 95.5 & 4 & & & & 0.5 & & & \\
\hline & 94Sn6Ag & 94 & 6 & & & & & & & \\
\hline & $95 \mathrm{Sn} 5 \mathrm{Ag}$ & 95 & 5 & & & & & & & \\
\hline & $\mathrm{Sn} 0.2 \mathrm{Ag} 2 \mathrm{Cu} 0.8 \mathrm{Sb}$ & 97 & 0.2 & & & & 2 & 0.8 & & \\
\hline \multirow[t]{2}{*}{ Lead } & $95 \mathrm{Sn} 5 \mathrm{~Pb}$ & 95 & & & & 5 & & & & \\
\hline & $90 \mathrm{Sn} 6 \mathrm{~Pb} 2 \mathrm{Sb} 2 \mathrm{Cd}$ & 90 & & & & 6 & & 2 & 2 & \\
\hline
\end{tabular}


In the non-eutectic bismuth alloy system, phase composition of bismuth ranges from $2 \%$ to $57 \%$. Bismuth typically forms eutectic alloys with tin combined with indium, silver or antimony. The percentage of tin in the alloy is in the range of $41-90 \%$. Compositions of indium, silver, and antimony are in the lower ranges of $1-10 \%$, the remainder being bismuth and tin. Indium forms indium-tin alloys with $50 \%$ of tin and indium-silver alloys with $10 \%$ silver. Major phase compositions of tin in the non-eutectic antimony alloys are typically over $90 \%$, ranging from $89-95 \%$, the remainder being antimony (4-7.5\%) or compositions of antimony with copper $(0.25-3.5 \%)$ or lead (4\%).The composition of cadmium in the low melting non-eutectic cadmium alloy is $78 \%$, it forms alloys with $17 \%$ of Zinc and $5 \%$ of silver. Silver material forms alloys with a broader set of elements such as tin, bismuth, indium, copper, and antimony. However, the majority of alloy composition is occupied by tin, with compositions ranging from $39 \%$ to $97 \%$, with an average tin composition of $87.16 \%$. The percentage of silver in the alloy ranges from as low as $0.2 \%$ to $10 \%$. The percentages of bismuth in the non-eutectic silver alloy are in very broad ranges of $1 \%$ to $56 \%$. A similar trend is observed in case of indium with compositions ranging from as low as $1 \%$ to $90 \%$. The percentages of and copper and antimony in silver falls in close ranges of $0.5-4 \%$ for copper and 1 to $2 \%$ for antimony. The composition of lead in the low melting non-eutectic alloy under consideration is $5-6 \%$, the remainder being compositions of tin (over $90 \%$ ) with antimony and cadmium ( $2 \%$ each), the majority being tin. Tin constitutes over $90 \%$ of the alloy with the remainder being lead and $2 \%$ each of antimony or cadmium.

Physical properties for low melting non-eutectic alloys of bismuth, indium, antimony, cadmium, silver, and lead along are shown in Table 2.6 
Table 2.6: Physical properties of the low melting non- eutectic alloy systems

\begin{tabular}{|c|c|c|c|c|}
\hline \multirow[t]{2}{*}{ Alloy } & \multirow[t]{2}{*}{ Name } & $\begin{array}{c}\text { Melting } \\
\text { Temperature }\end{array}$ & Density & \multirow[t]{2}{*}{ References } \\
\hline & & $\circ \mathbf{C}$ & $\mathrm{g} / \mathrm{cm}^{3}$ & \\
\hline \multirow[t]{9}{*}{ Bismuth } & 48Sn46Bi2In & $126-140$ & 8.52 & {$[26]$} \\
\hline & $55 \mathrm{Sn} 45 \mathrm{Bi}$ & $138-164$ & 8.25 & {$[44]$} \\
\hline & $41 \mathrm{Sn} 57 \mathrm{Bi} 2 \mathrm{Ag}$ & $140-147$ & 8.6 & {$[44]$} \\
\hline & $41 \mathrm{Sn} 57 \mathrm{Bi} 2 \mathrm{Sb}$ & $141-150$ & 8.52 & {$[44]$} \\
\hline & 42Sn57Bi1Ag & $138-149$ & 8.53 & {$[44]$} \\
\hline & 41Sn57Bi2In & $127-140$ & 8.6 & {$[44]$} \\
\hline & 90Sn2Bi8In & $206-215$ & 7.34 & {$[44]$} \\
\hline & 80Sn10Bi10In & $170-200$ & 7.49 & {$[44]$} \\
\hline & 60Sn40Bi & $131.11-170$ & 8.21 & {$[46]$} \\
\hline \multirow[t]{2}{*}{ Indium } & 90In10Ag & $141-238$ & 7.54 & {$[26]$} \\
\hline & $50 \operatorname{In} 50 \mathrm{Sn}$ & $117-127$ & 7.3 & {$[47]$} \\
\hline \multirow[t]{4}{*}{ Antimony } & 89Sn7.5Sb3.5Cu & $241-354$ & 7.38 & {$[40,48]$} \\
\hline & $95 \mathrm{Sn} 5 \mathrm{Sb}$ & $232-240$ & 7.25 & {$[26]$} \\
\hline & $91.75 \mathrm{Sn} 8 \mathrm{Sb} 0.25 \mathrm{Cu}$ & $273.88-329.44$ & 7.29 & {$[40]$} \\
\hline & $92 \mathrm{Sn} 4 \mathrm{Sb} 4 \mathrm{~Pb}$ & $273.88-329.45$ & 7.28 & {$[44]$} \\
\hline Cadmium & 78Cd17Zn5Ag & $249-316$ & & {$[26]$} \\
\hline
\end{tabular}


Table 2.6 (continued): Physical properties of the low melting non- eutectic alloy systems

\begin{tabular}{|c|c|c|c|c|}
\hline \multirow[t]{2}{*}{ Alloy } & \multirow[t]{2}{*}{ Name } & $\begin{array}{c}\text { Melting } \\
\text { Temperature }\end{array}$ & Density & \multirow[t]{2}{*}{ References } \\
\hline & & ${ }^{\circ} \mathbf{C}$ & $\mathrm{g} / \mathrm{cm}^{3}$ & \\
\hline \multirow[t]{17}{*}{ Silver } & $95.5 \mathrm{Sn} 4 \mathrm{Ag} 0.5 \mathrm{Cu}$ & $217-350$ & 7.4 & [26] \\
\hline & $\mathrm{Sn} 2.5 \mathrm{Ag} 0.8 \mathrm{Cu} 0.5 \mathrm{Sb}$ & $217-225$ & 7.37 & [26] \\
\hline & Sn2.8Ag20In & $175-186$ & 7.39 & [49] \\
\hline & $98 \mathrm{Sn} 2 \mathrm{Ag}$ & $221-226$ & 7.45 & [26] \\
\hline & $93 \mathrm{Sn} 3 \mathrm{Ag} 4 \mathrm{Cu}$ & 221 & 7.56 & [26] \\
\hline & 94Sn2.5Ag2Bi1.5Sb & $219-226$ & 7.42 & [26] \\
\hline & 93.5Sn3Ag1Cu1Bi1.5Sb & $220-224$ & 7.4 & [26] \\
\hline & 78.4Sn2Ag9.8Bi9.8In & $163-195$ & 7.54 & [26] \\
\hline & $40.5 \mathrm{Sn} 2 \mathrm{Ag} 56 \mathrm{Bi} 1.5 \mathrm{Sb}$ & $137-145$ & 8.59 & [44] \\
\hline & $95 \mathrm{Sn} 3 \mathrm{Ag} 2 \mathrm{Sb}$ & $225-228$ & 7.35 & [44] \\
\hline & 93.5Sn2Ag8Cu & $206-215$ & 7.34 & [26] \\
\hline & 86.4Sn5Ag8.6In2Sb & $200-205$ & 7.41 & [26] \\
\hline & $96.1 \mathrm{Sn} 2.6 \mathrm{Ag} 0.8 \mathrm{Cu} 0.5 \mathrm{Sb}$ & $211-226$ & 7.37 & [26] \\
\hline & 78.4Sn9.8Bi9.8In2Ag & $163-195$ & 7.34 & [26] \\
\hline & $\mathrm{Sn} 3 \mathrm{Ag} 0.5 \mathrm{Cu}$ & $217-229$ & 7.4 & [26] \\
\hline & 39Sn3Ag54Bi2In2Sb & $99-138$ & 8.54 & [26] \\
\hline & Sn3.5Ag5Bi0.7Cu & $198-213$ & 7.38 & [26] \\
\hline
\end{tabular}


Table 2.6 (continued): Physical properties of the low melting non- eutectic alloy systems

\begin{tabular}{|c|c|c|c|c|}
\hline \multirow[t]{2}{*}{ Alloy } & \multirow[t]{2}{*}{ Name } & $\begin{array}{c}\text { Melting } \\
\text { Temperature }\end{array}$ & Density & \multirow[t]{2}{*}{ References } \\
\hline & & ${ }^{\circ} \mathbf{C}$ & $\mathrm{g} / \mathrm{m}^{3}$ & \\
\hline \multirow[t]{4}{*}{ Silver } & $\mathrm{Sn} 4 \mathrm{Ag} 0.5 \mathrm{Cu}$ & $217-219$ & 7.47 & {$[26]$} \\
\hline & 94Sn6Ag & $221-280$ & 7.43 & {$[26]$} \\
\hline & $95 \mathrm{Sn} 5 \mathrm{Ag}$ & $221-245$ & 7.39 & {$[26]$} \\
\hline & $\mathrm{Sn} 0.2 \mathrm{Ag} 2 \mathrm{Cu} 0.8 \mathrm{Sb}$ & $218-287$ & 7.36 & {$[26]$} \\
\hline \multirow[t]{2}{*}{ Lead } & $95 \mathrm{Sn} 5 \mathrm{~Pb}$ & $233-240$ & 7.42 & {$[26]$} \\
\hline & 90Sn6Pb2Sb2Cd & $268.33-304.444$ & 7.473 & {$[48]$} \\
\hline
\end{tabular}

The onset point for the bismuth material system occurs at temperature ranges of $126-206^{\circ} \mathrm{C}$ depending on the composition of the alloy. Lower onset point temperatures of $126-141^{\circ} \mathrm{C}$ are found to occur in alloys having a balance between the tin and bismuth element compositions. Alloys having a higher composition of the tin element in comparison to bismuth are found to start melting at temperatures higher than $150^{\circ} \mathrm{C}$. Melting ranges of bismuth alloys are not too broad, bismuth-tin-silver alloy with $2 \%$ silver exhibiting the lowest temperature range of $7^{\circ} \mathrm{C}$ and bismuth-tin alloy with $60 \%$ tin going up to intervals of $32^{\circ} \mathrm{C}$. Indium alloys follow similar melting behavior as that of the bismuth alloys. The onset temperature of melting of the indium alloys is typically below $150^{\circ} \mathrm{C}$. The melting ranges vary according to the percentage composition of the elements in the indium alloy. The indium-tin alloy has a melting interval of $10^{\circ} \mathrm{C}$, and the indium-silver alloy exhibits a higher melting interval of $97^{\circ} \mathrm{C}$. The alloys of antimony, cadmium, silver, and lead are 
found to exhibit higher values of the onset melting temperature. The minimum onset melting temperature of the antimony alloys is $232^{\circ} \mathrm{C}$ for the tin-antimony alloy with $95 \%$ composition of tin. The cadmium-zinc alloy starts melting at a temperature of $249^{\circ} \mathrm{C}$ and melts entirely at $316^{\circ} \mathrm{C}$. The melting temperature ranges of the silver alloy varies over a series of values owing to the array of elements in the alloy. The onset point is as low as $99^{\circ} \mathrm{C}$ for the silver-tin alloy exhibiting lower compositions of tin $39 \%$, in this case, and as high as $225^{\circ} \mathrm{C}$ for the tin-silver-antimony alloy with $95 \%$ tin composition. The minimum onset temperature for the lead alloy is $233^{\circ} \mathrm{C}$ for the tin-lead allow with $95 \%$ composition of tin.

The average densities of the bismuth non-eutectic system are found to be the highest in the group, ranging from $7.34 \mathrm{~g} / \mathrm{cm}^{3}$ to $8.6 \mathrm{~g} / \mathrm{cm}^{3}$. Lower densities of bismuth alloys are the bismuth alloys having a higher composition of the tin element in comparison to the bismuth material. Indium and antimony alloys have lower mean densities of $7.42 \mathrm{~g} / \mathrm{cm}^{3}$ and g/cm respectively. The densities of silver alloys range in between $7.3 \mathrm{~g} / \mathrm{cm}^{3}$ and $8.59 \mathrm{~g} / \mathrm{cm}^{3}$ and have a mean density of $7.51 \pm 0.34 \mathrm{~g} / \mathrm{cm}^{3}$. The densities of the silver system increase to values above 8.5 when silver forms alloys with lower compositions of tin. The tin-silver alloy with $40.5 \%$ tin and $56 \%$ bismuth shows the highest density of all the material systems with a density of $8.59 \mathrm{~g} / \mathrm{cm}^{3}$. Cadmium is highly toxic and won't be considered for the study.

A pictorial representation of the density of the non-eutectic alloy systems is shown in Figure 2.18. 


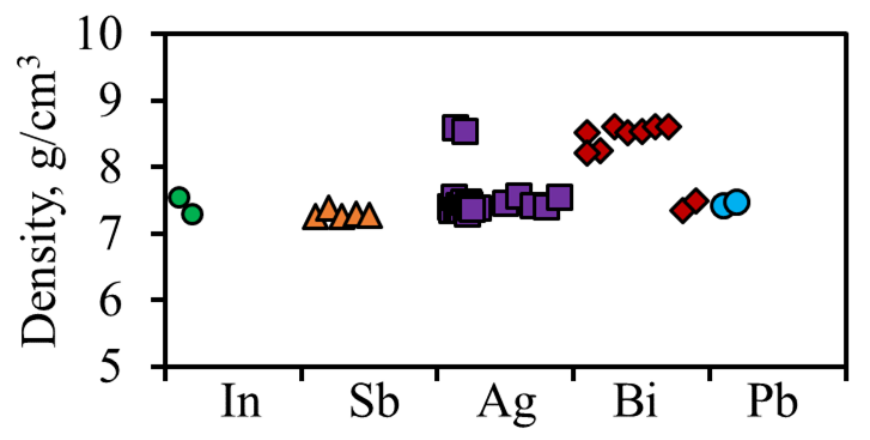

Figure 2.18: Density of the low melting non- eutectic alloy systems

Figure 2.18 shows that out of all the material systems, bismuth alloys exhibit the highest density in ranges of 7-8.5 g/ $\mathrm{cm}^{3}$, most of the alloys falling in scales of $8 \mathrm{~g} / \mathrm{cm}^{3}$ and above. The density of silver range in between $7-8.5 \mathrm{~g} / \mathrm{cm}^{3}$ with most of them in intervals of 7.5 $\mathrm{g} / \mathrm{cm}^{3}$ and below. The alloys of indium, antimony, and lead consistently fall in scales of 7$7.5 \mathrm{~g} / \mathrm{cm}^{3}$.

\subsubsection{Mechanical properties}

Mechanical properties for low melting non-eutectic alloys of bismuth, indium, antimony, silver, and lead along are shown in Table 2.7 
Table 2.7: Mechanical properties of the low melting non-eutectic alloy systems

\begin{tabular}{|c|c|c|c|c|c|}
\hline \multirow[t]{2}{*}{ Alloy } & \multirow[t]{2}{*}{ Name } & UTS & Elongation & Hardness & \multirow[t]{2}{*}{ References } \\
\hline & & MPa & $\%$ & HV5(RT) & \\
\hline \multirow[t]{7}{*}{ Bismuth } & 48Sn46Bi2In & & 53 & & [44] \\
\hline & 41Sn57Bi2Ag & 71.6 & 31 & & [44] \\
\hline & 41Sn57Bi2Sb & 66.1 & 47 & & [44] \\
\hline & 42Sn57Bi1Ag & & & & [44] \\
\hline & 41Sn57Bi2In & 58.2 & 72 & & [44] \\
\hline & 90Sn2Bi8In & 55 & 25 & & [44] \\
\hline & Sn6040Bi & 62.5 & 35 & & {$[26],[50]$} \\
\hline \multirow[t]{2}{*}{ Indium } & 90In10Ag & 11.37 & 61 & 2.7 & [33] \\
\hline & $50 \operatorname{In} 50 \mathrm{Sn}$ & 11.86 & 83 & 4.5 & [50] \\
\hline \multirow[t]{4}{*}{ Antimony } & $89 \mathrm{Sn} 7.5 \mathrm{Sb} 3.5 \mathrm{Cu}$ & 90 & 10 & 32 & [40] \\
\hline & $95 \mathrm{Sn} 5 \mathrm{Sb}$ & 40.67 & 38 & 30.3 & [33] \\
\hline & $91.75 \mathrm{Sn} 8 \mathrm{Sb} 0.25 \mathrm{Cu}$ & 49.64 & & 20 & [45] \\
\hline & $92 \mathrm{Sn} 4 \mathrm{Sb} 4 \mathrm{~Pb}$ & 46.88 & & 16 & [44] \\
\hline \multirow[t]{5}{*}{ Silver } & $95.5 \mathrm{Sn} 4 \mathrm{Ag} 0.5 \mathrm{Cu}$ & 51.503 & 47 & 27 & [26] \\
\hline & $\mathrm{Sn} 2.5 \mathrm{Ag} 0.8 \mathrm{Cu} 0.5 \mathrm{Sb}$ & 39.5 & 50 & 9 & {$[26],[44]$} \\
\hline & Sn2.8Ag20In & 68.94 & 47 & 17 & [33], [45] \\
\hline & $93 \mathrm{Sn} 3 \mathrm{Ag} 4 \mathrm{Cu}$ & 92.7 & 12 & & [44] \\
\hline & 94Sn2.5Ag2Bi1.5Sb & 48.3 & 22 & & [26] \\
\hline
\end{tabular}


Table 2.7(continued):Mechanical properties of the low melting non-eutectic alloy systems

\begin{tabular}{|c|c|c|c|c|c|}
\hline \multirow[t]{2}{*}{ Alloy } & \multirow[t]{2}{*}{ Name } & UTS & Elongation & Hardness & \multirow[t]{2}{*}{ References } \\
\hline & & Mpa & $\%$ & HV5(RT) & \\
\hline \multirow[t]{10}{*}{ Silver } & 93.5Sn3Ag1Cu1Bi1.5Sb & 56 & 21 & & [26] \\
\hline & 78.4Sn2Ag9.8Bi9.8In & 106 & 7 & & [44] \\
\hline & $40.5 \mathrm{Sn} 2 \mathrm{Ag} 56 \mathrm{Bi} 1.5 \mathrm{Sb}$ & 68.6 & 27 & & [44] \\
\hline & $96.1 \mathrm{Sn} 2.6 \mathrm{Ag} 0.8 \mathrm{Cu} 0.5 \mathrm{Sb}$ & 25.8 & 9 & & [44] \\
\hline & 78.4Sn9.8Bi9.8In2Ag & 63.8 & 21 & & [26] \\
\hline & $\mathrm{Sn} 3 \mathrm{Ag} 0.5 \mathrm{Cu}$ & 49.64 & 19.3 & & [26] \\
\hline & 39Sn3Ag54Bi2In2Sb & 80.3 & 13 & & [44] \\
\hline & Sn3.5Ag5Bi0.7Cu & 48 & & & {$[44],[33]$} \\
\hline & $95 \mathrm{Sn} 5 \mathrm{Ag}$ & 55.16 & 30 & 13.7 & [33] \\
\hline & $\mathrm{Sn} 0.2 \mathrm{Ag} 2 \mathrm{Cu} 0.8 \mathrm{Sb}$ & 29.8 & 27 & & [44] \\
\hline \multirow[t]{2}{*}{ Lead } & $95 \mathrm{Sn} 5 \mathrm{~Pb}$ & 27.45 & 45 & 8 & {$[37],[51]$} \\
\hline & 90Sn6Pb2Sb2Cd & 46.88 & & 18 & [44] \\
\hline
\end{tabular}

The ultimate tensile strength (UTS) of the bismuth alloys ranges from 55MPa to 71.6MPa, with a mean UTS value of $62.68 \mathrm{MPa}$. The tensile strength of both the indium alloys is nearly five times lesser than the bismuth alloys, with a maximum UTS value $11.86 \mathrm{MPa}$ for the alloy with composition of 50\% tin and 50\% indium. Antimony alloys have UTS values in the ranges of $40-50 \mathrm{MPa}$, with an average UTS of $45.73 \pm 3.75 \mathrm{MPa}$. The values of UTS 
in silver alloys varies broadly from 25.8MPa to 106MPa. The UTS value of the lead alloys is below $50 \mathrm{MPa}$ in general.

A representative graph of the ultimate tensile strength of the low melting non-eutectic alloy systems is plotted in Figure 2.19.

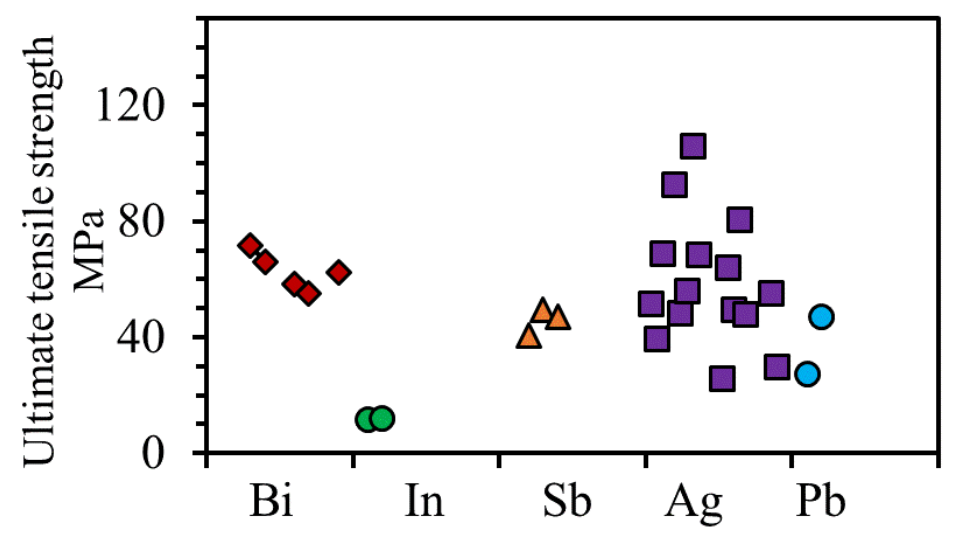

Figure 2.19: Ultimate tensile strength (UTS) of the low melting non-eutectic alloy systems

Figure 2.19 shows that bismuth alloys exhibit the highest tensile strength among all the non-eutectic alloy systems. Bismuth alloys exhibit tensile strengths ranging anywhere between $45-75 \mathrm{MPa}$. The UTS values of antimony alloys fall in close ranges of each other and are typically consistent with their scales of 40-50MPa. This is closely followed by two alloys of silver and one lead alloy, in the scales of 20-30MPa.In fact, the silver alloys have a wide scale of UTS values owing to the array of compositions involved and occupy a wide area in UTS chart. The scales range from just above the lowest values of indium and overshoots the scales of bismuth as well. Indium alloys have the lowest tensile strengths among all the non-eutectic alloy systems. 
The percentage elongation of the non-eutectic bismuth alloy systems falls in narrow ranges of $45 \%$ to $53 \%$. The percentage elongation of pure indium is comparatively higher, with values of $61 \%$ for the indium-silver alloy and increases to a value of $83 \%$ when indium forms an alloy with $50 \%$ composition of tin. The percent elongation of the antimony alloy with $95 \%$ composition of tin is $38 \%$. The elongation values of the silver alloys fall in moderately broad ranges of $7 \%$ to $50 \%$. The lowest value is exhibited by tin-silver alloy with 9.8 percent compositions of bismuth and indium materials. The lead alloy with $95 \%$ tin is found to have percentage elongation values of $45 \%$, similar to the lowest elongation values of the bismuth alloy system.

A representative graph of percentage elongations of the low melting eutectic alloy systems is plotted in Figure 2.20.

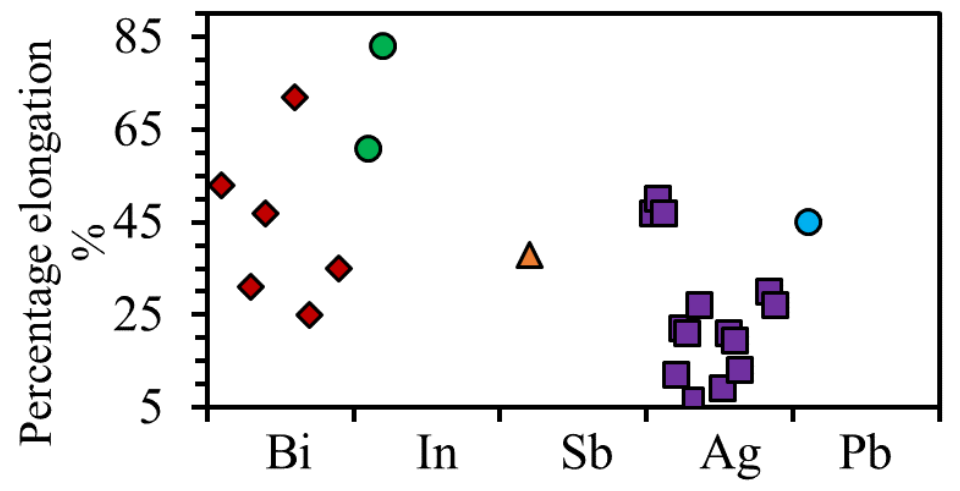

Figure 2.20: Percentage elongation of the non-eutectic alloy systems

As shown in Figure 2.20, indium alloys exhibit the highest range of percentage elongations among all the low melting non-eutectic systems considered. Bismuth alloys exhibit percentage elongation values in the ranges of $75 \%$ and up to lower ranges of $25 \%$, over a moderately broad scale. The percentage values of antimony appear within this scale of bismuth alloys. The percentage elongation values of the silver alloys fall over a broad 
range of values, predominantly under scales of $35 \%$. The lead-tin alloy exhibits a moderate value of elongation when compared to the other material systems. Thus the indium-tin alloy with $50 \%$ compositions of tin and indium is found to exhibit the highest elongation value among all the low melting eutectic alloy systems considered.

\subsubsection{Thermal properties}

Thermal properties for low melting non-eutectic alloys of bismuth, indium, silver, and lead along are shown in Table $\mathbf{2 . 8}$ 
Table 2.8: Thermal properties of the low melting non-eutectic alloys

\begin{tabular}{|c|c|c|c|c|c|}
\hline \multirow[t]{2}{*}{ Alloy } & \multirow[t]{2}{*}{ Name } & CTE & $\mathbf{k}$ & Cp & \multirow[t]{2}{*}{ References } \\
\hline & & $10^{-6} \mathrm{~K}$ & W/m.K & $\mathrm{J} / \mathrm{Kg}, \mathrm{K}$ & \\
\hline \multirow[t]{7}{*}{ Bismuth } & 48Sn46Bi2In & 16.01 & & 45 & [44] \\
\hline & 41Sn57Bi2Ag & 14.39 & & 44 & [44] \\
\hline & 41Sn57Bi2Sb & 15.8 & & 45 & [44] \\
\hline & 41Sn57Bi2In & 15.85 & & 44 & [44] \\
\hline & 90Sn2Bi8In & 20.73 & & 49 & [44] \\
\hline & 80Sn10Bi10In & 19.68 & & 38 & [44] \\
\hline & Sn6040Bi & 15 & 29.71 & 213.52 & {$[26],[50]$} \\
\hline \multirow[t]{3}{*}{ Indium } & 90In10Ag & 15 & 73 & & [33] \\
\hline & $50 \operatorname{In} 50 \mathrm{Sn}$ & 20 & 34 & & [50] \\
\hline & $95 \mathrm{Sn} 5 \mathrm{Sb}$ & 31 & 28 & & [33] \\
\hline \multirow[t]{8}{*}{ Silver } & $95.5 \mathrm{Sn} 4 \mathrm{Ag} 0.5 \mathrm{Cu}$ & 26.2 & & & [26] \\
\hline & $\mathrm{Sn} 2.5 \mathrm{Ag} 0.8 \mathrm{Cu} 0.5 \mathrm{Sb}$ & & 57.26 & & [26] \\
\hline & Sn2.8Ag20In & 28 & & 218.99 & [45] \\
\hline & $93 \mathrm{Sn} 3 \mathrm{Ag} 4 \mathrm{Cu}$ & & & 61 & [26] \\
\hline & $94 \mathrm{Sn} 2.5 \mathrm{Ag} 2 \mathrm{Bi} 1.5 \mathrm{Sb}$ & 14.83 & & 59 & [26] \\
\hline & 93.5Sn3Ag1Cu1Bi1.5Sb & & & 65 & [26] \\
\hline & 78.4Sn2Ag9.8Bi9.8In & 11.86 & & 46 & [44] \\
\hline & $40.5 \mathrm{Sn} 2 \mathrm{Ag} 56 \mathrm{Bi} 1.5 \mathrm{Sb}$ & 13.15 & & 44 & [44] \\
\hline
\end{tabular}


Table 2.8 (continued): Thermal properties of the low melting non-eutectic alloys

\begin{tabular}{|c|c|c|c|c|c|}
\hline \multirow[t]{2}{*}{ Alloy } & \multirow[t]{2}{*}{ Name } & CTE & $\mathbf{k}$ & Cp & \multirow[t]{2}{*}{ References } \\
\hline & & $10(-6) K$ & $\mathbf{W} / \mathbf{m} \cdot \mathbf{K}$ & $\mathbf{J} / \mathbf{K g}, \mathbf{K}$ & \\
\hline \multirow[t]{11}{*}{ Silver } & 95Sn3Ag2Sb & 13.44 & & 62 & [44] \\
\hline & 93.5 $\mathrm{Sn} 2 \mathrm{Ag} 8 \mathrm{Cu}$ & 16.81 & & 57 & [44] \\
\hline & 86.4Sn5Ag8.6In2Sb & & & 54 & [44] \\
\hline & $96.1 \mathrm{Sn} 2.6 \mathrm{Ag} 0.8 \mathrm{Cu} 0.5 \mathrm{Sb}$ & 26.2 & & & [44] \\
\hline & 78.4Sn9.8Bi9.8In2Ag & 19.9 & & 46 & [26] \\
\hline & $\mathrm{Sn} 3 \mathrm{Ag} 0.5 \mathrm{Cu}$ & 11.86 & & & [26] \\
\hline & 39Sn3Ag54Bi2In2Sb & 15.25 & & 40 & [44] \\
\hline & Sn3Ag3Bi & & 60 & & [26], [45] \\
\hline & $\mathrm{Sn} 4 \mathrm{Ag} 0.5 \mathrm{Cu}$ & 22.3 & & & [44], [33] \\
\hline & 95Sn5Ag & 23 & & 230 & [33] \\
\hline & $\mathrm{Sn} 0.2 \mathrm{Ag} 2 \mathrm{Cu} 0.8 \mathrm{Sb}$ & 23.1 & & & [26] \\
\hline Lead & $95 \mathrm{Sn} 5 \mathrm{~Pb}$ & & 23 & & {$[37],[51]$} \\
\hline
\end{tabular}

As shown in Table 2.8, the coefficient of thermal expansion (CTE) of both the bismuth and indium alloys ranges in between 14.39E-06 K and 20.73E-06 K. The CTE of the antimony material with $95 \%$ composition of tin is at a higher value of $31 \mathrm{E}-06 \mathrm{~K}$. Silver alloys have CTE values in broader ranges of $11.86 \mathrm{E}-06 \mathrm{~K}$ to $28 \mathrm{E}-06 \mathrm{~K}$, with a mean value of $19.54 \pm 5.39 \mathrm{E}-06 \mathrm{~K}$. A pictorial representation of Coefficient of thermal expansion (CTE) of the low melting non-eutectic alloy systems is shown in Figure 2.21 


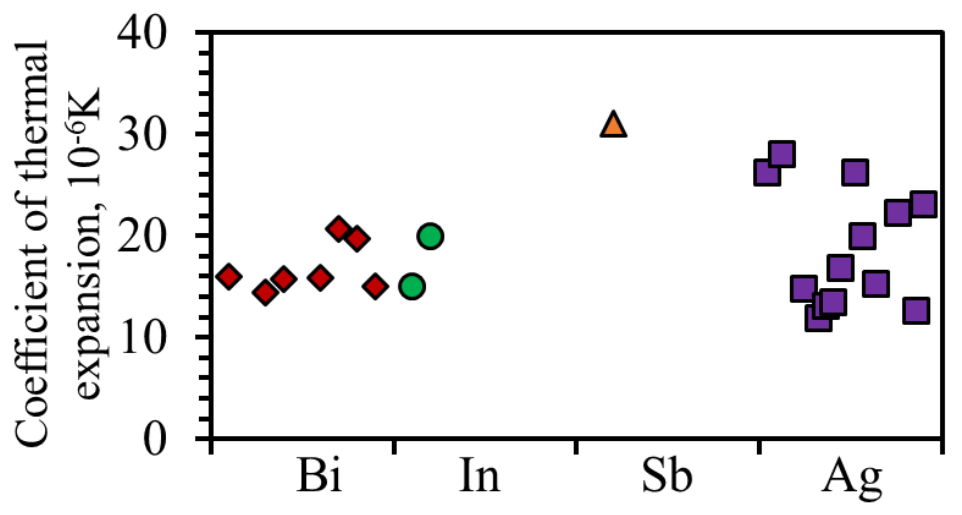

Figure 2.21: Coefficient of thermal expansion (CTE) of the low melting non-eutectic alloy systems

Figure 2.21 shows that silver alloys exhibit the antimony alloy exhibits the highest coefficient of thermal expansion among all the non-eutectic alloys considered. CTE of bismuth and indium lies in the range of $15-25 \mathrm{E}-06 \mathrm{~K}$. The conductivity of silver alloys ranges in broader ranges of 10-30 E-06K.

The thermal conductivity values of the indium with $10 \%$ composition of silver were found to be the highest at $73 \mathrm{~W} / \mathrm{mK}$. The lead alloy with $95 \%$ tin has the lowest value of 23 $\mathrm{W} / \mathrm{mK}$. The conductivity of all the other alloys ranges between these values, with bismuth and antimony alloys in the lower ranges of $29.71 \mathrm{~W} / \mathrm{m} . \mathrm{K}$ and $31 \mathrm{~W} / \mathrm{m} . \mathrm{K}$ respectively. Silver alloys had thermal conductivity values in higher ranges, with values of $57.26 \mathrm{~W} / \mathrm{m} . \mathrm{K}$ for the alloy with $96.2 \%$ tin and a value of $60 \mathrm{~W} / \mathrm{m} . \mathrm{K}$ for the alloy with $94 \%$ tin and 3\% silver.

The specific heat values of the bismuth alloys vary in between $21.35-49 \mathrm{~J} / \mathrm{Kg}, \mathrm{K}$, with most of them lying in the ranges of $40 \mathrm{~J} / \mathrm{Kg}, \mathrm{K}$ and above. Heat capacities were lowest for the alloy with $60 \%$ composition of tin; the highest value was exhibited by the alloy having the 
highest percentage of tin, with $90 \%$ tin composition. The specific heat values of the silver alloy ranges in between $23-62 \mathrm{~J} / \mathrm{Kg}, \mathrm{K}$, with a mean value of $50.63 \mathrm{~J} / \mathrm{Kg}, \mathrm{K}$.

A representative graph of specific heat with the coefficient of thermal expansion for the low melting non-eutectic bismuth and silver alloy systems are shown in Figure 2.22.

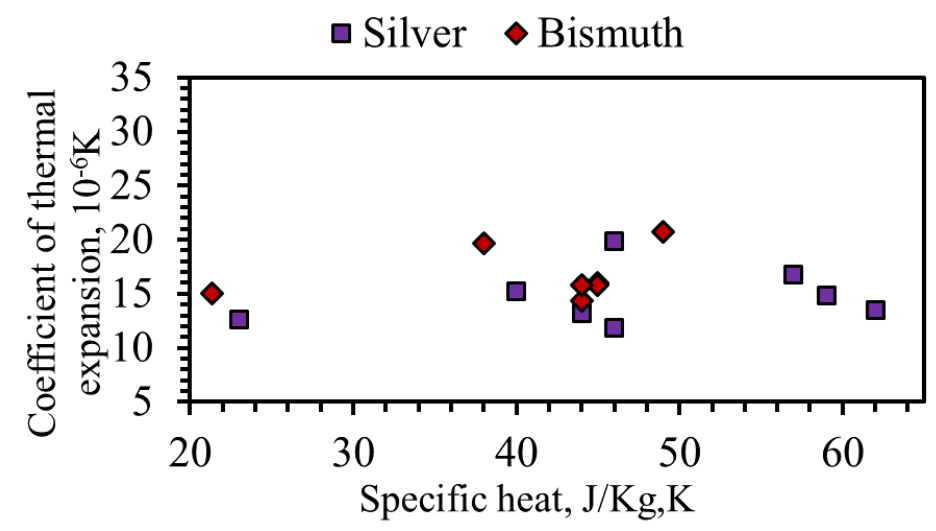

Figure 2.22: Specific heat vs. CTE of the non-eutectic bismuth and silver alloy systems

Figure 2.22shows that the specific heat capacities of the majority of bismuth alloys lie between the ranges of $35-50 \mathrm{~J} / \mathrm{Kg}, \mathrm{K}$. The heat capacities of silver vary broadly between the ranges of 35-65 J/Kg, K. The CTE of both the alloy systems lies in ranges of 13-23 10${ }^{6} \mathrm{~K}$. 


\subsection{Thermoplastic materials used in 3D printing}

The most common thermoplastic materials currently used in FFF 3D printing are; PA6, PLA, TPU, PMMA and ABS. The physical properties, mechanical properties and thermal properties of these thermoplastic materials are analyzed using CES selector and described in this section.

\subsubsection{Physical properties}

Figure 2.23 shows the physical properties of popular 3D printing thermoplastic materials.



Figure 2.23 Physical properties of popular 3D printing thermoplastic materials

Figure 2.23 shows that ABS exhibits the lowest values of density and highest values of glass temperatures ranging from $1.0-1.08 \mathrm{~g} / \mathrm{cm}^{3}$ and $88^{\circ} \mathrm{C}-120{ }^{\circ} \mathrm{C}$ respectively. The glass temperatures of the PA6 system ranges from $44^{\circ} \mathrm{C}-56^{\circ} \mathrm{C}$. This is closely followed by PLA with glass temperatures ranging from $52^{\circ} \mathrm{C}-60^{\circ} \mathrm{C}$. TPU and PMMA materials exhibits higher glass temperatures ranging from $77{ }^{\circ} \mathrm{C}-107{ }^{\circ} \mathrm{C}$ and $100{ }^{\circ} \mathrm{C}-110{ }^{\circ} \mathrm{C}$ respectively. 
PLA exhibits the highest density of $1.24 \mathrm{~g} / \mathrm{cm}^{3}-1.27 \mathrm{~g} / \mathrm{cm}^{3}$ followed by TPU with densities of $1.12 \mathrm{~g} / \mathrm{cm}^{3}-1.24 \mathrm{~g} / \mathrm{cm}^{3}$. PA6 and PMMA exhibits densities of $1.13 \mathrm{~g} / \mathrm{cm}^{3}-1.15 \mathrm{~g} / \mathrm{cm}^{3}$ and $1.17-1.20 \mathrm{~g} / \mathrm{cm}^{3}$ respectively.

The average densities of all the thermoplastic materials accounts to a value of $1.19 \mathrm{~g} / \mathrm{cm}^{3}$ and is less by a percentage difference of $84 \%$ when compared with that of the low melting alloys (sections 2.5.1.1 and 2.5.2.1), whose densities account to average values of $7-7.5$ $\mathrm{g} / \mathrm{cm}^{3}$. Moreover, the maximum service temperatures of PA6, PLA, TPU, PMMA and ABS are limited to temperatures of $130^{\circ} \mathrm{C}, 55^{\circ} \mathrm{C}, 78^{\circ} \mathrm{C}, 56^{\circ} \mathrm{C}$ and $77^{\circ} \mathrm{C}$, which makes them very vulnerable to high temperature and high strength applications.

\subsubsection{Mechanical properties}

Figure 2.24 shows the mechanical properties of popular 3D printing thermoplastic materials.

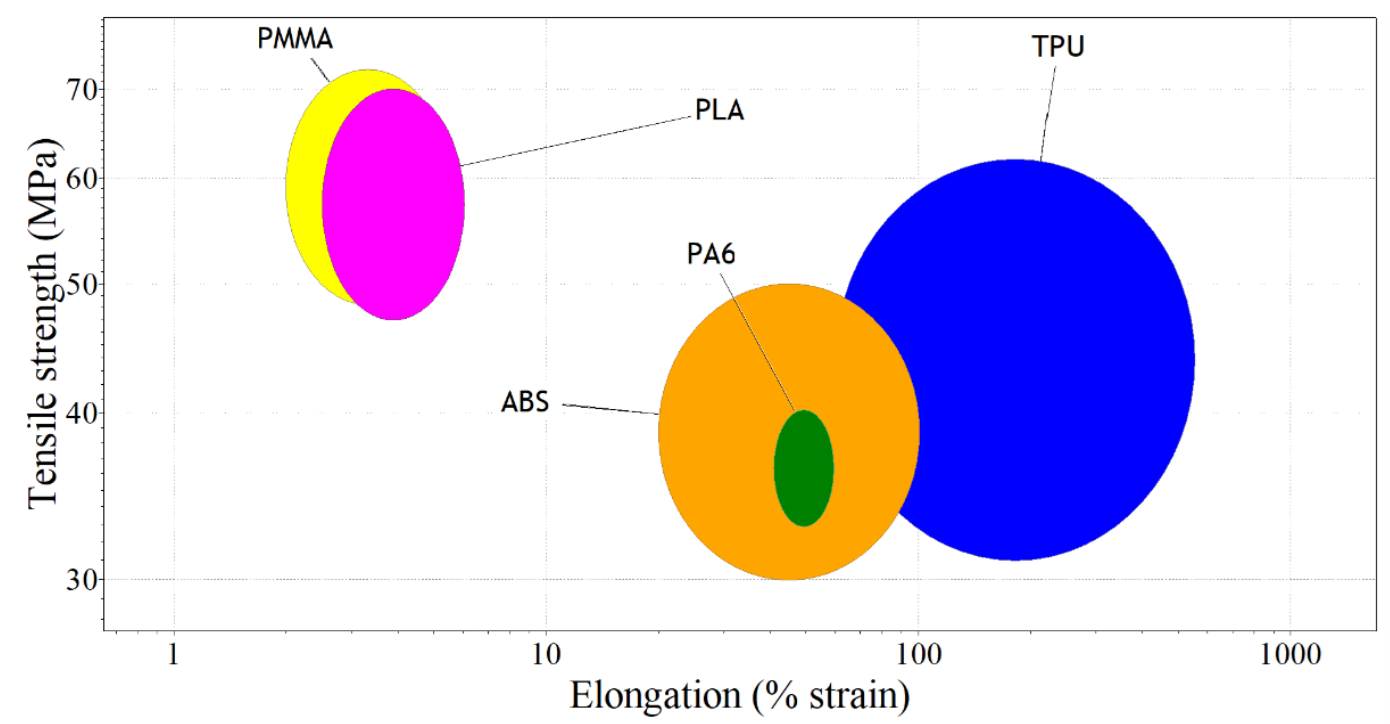

Figure 2.24: Mechanical properties of popular 3D printing thermoplastic materials 
Figure 2.24 shows that out of all the 3D printing thermoplastic materials, PMMA and PLA exhibits the lowest elongations of $2.5-6 \%$ and $2-5.5 \%$ respectively, and is the most brittle of all the thermoplastic materials considered. TPU is the most ductile with elongations of $60-550 \%$ and exhibits commendable tensile strength of $31-62$ MPa. PMMA and PLA exhibits the highest tensile strength in ranges $47-70 \mathrm{MPa}$ and 48 - $73 \mathrm{MPa}$ respectively. ABS exhibits $20-100 \%$ elongations and tensile strengths of $30-50 \mathrm{MPa}$. PA6 forms a subset of ABS with percentage elongation values of $41-59 \%$ and tensile strengths of 40 $\mathrm{MPa}$.

The tensile strength falls in ranges of 31-73 MPa and falls below the generic tensile strength range of low melting alloys (sections 2.5.1.2 and 2.5.2.2), The average percentage elongations are in general lesser than that of low melting alloys expect for TPU, which exhibits very large elongations of $500 \%$. Thus, thermoplastics, in general, exhibits lesser mechanical strength values and percentage elongations as compared to metals. 


\subsubsection{Thermal properties}

Figure 2.25 shows the thermal properties of popular 3D printing thermoplastic materials.

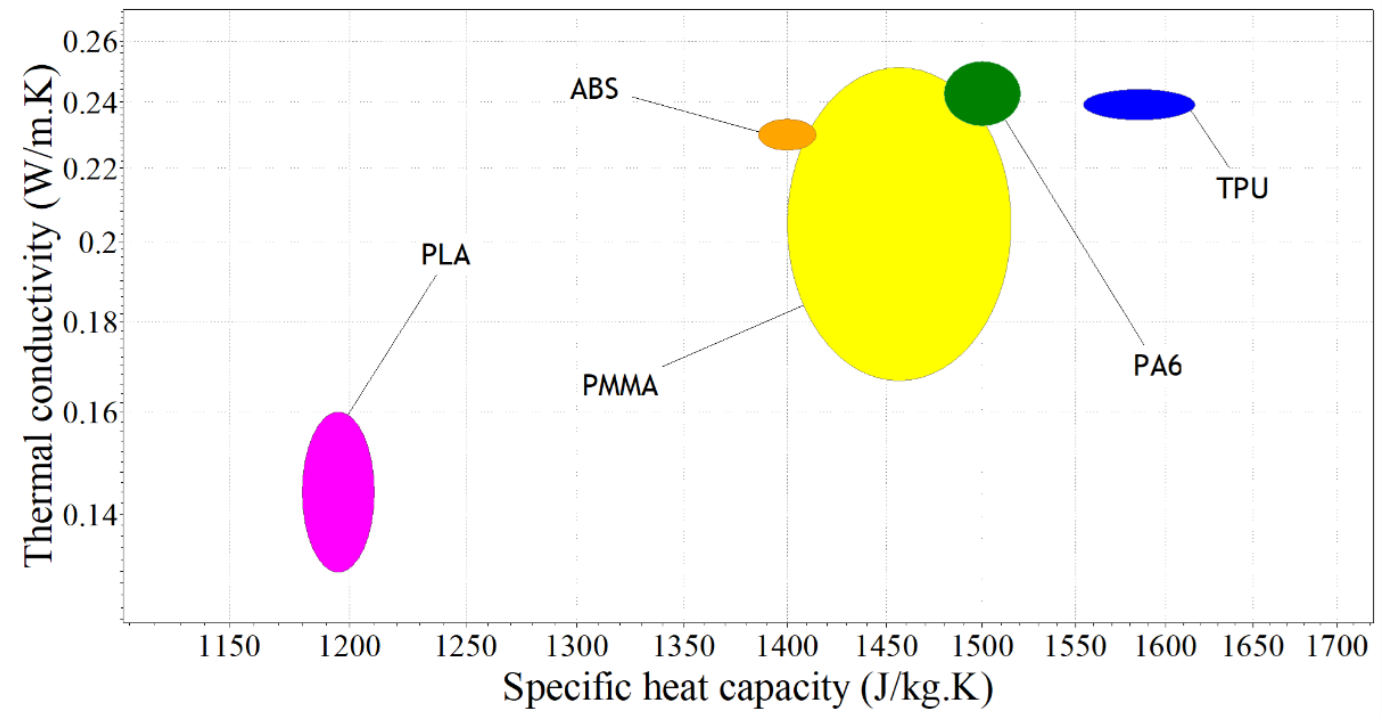

Figure 2.25: Thermal properties of popular 3D printing thermoplastic materials

From Figure 2.25, it can be stated that PLA exhibits the least thermal expansion as well as specific heat capacities among all the 3D printing thermoplastic materials considered and accounts to average values of $0.15 \mathrm{~W} / \mathrm{m} . \mathrm{K}$ and $1195 \mathrm{~J} / \mathrm{kg} . \mathrm{K}$ respectively .TPU exhibits the highest specific heat value of $1640 \mathrm{~J} / \mathrm{kg} . \mathrm{K}$ with average thermal conductivity values accounting to $0.24 \mathrm{~W} / \mathrm{m} . \mathrm{K}$. TPU is closely followed by PMMA, which exhibits a broad spectrum of thermal conductivity values ranging from $0 / .16 \mathrm{~W} / \mathrm{m} . \mathrm{K}-0.25 \mathrm{~W} / \mathrm{m}$. K and accounts to an average of $0.20 \mathrm{~W} / \mathrm{m} . \mathrm{K}$. ABS and PA6, exhibits average thermal conductivity values of $\mathrm{W} / \mathrm{m} . \mathrm{K}$ and $\mathrm{W} / \mathrm{m} . \mathrm{K}$ respectively and exhibits specific heat values of $\mathrm{J} / \mathrm{kg} . \mathrm{K}$ and $\mathrm{J} / \mathrm{kg} . \mathrm{K}$ respectively.

Thus, thermoplastics, in general, exhibits lesser thermal conductivity values and higher specific heat capacities as compared to metals. 


\subsection{Conclusions}

Among the eutectic alloy systems, bismuth alloy system is best suited for 3D printing using FFF technology owing to its convenient melting temperatures and consistently high mechanical strength. Among the non-eutectic materials, alloy systems of bismuth, silver, and antimony exhibit commendable properties and are hence suited for 3D printing using FFF . Silver alloys has to be avoided due to its tendency to agglomerate at high temperatures, which could lead to clogging of the extruder nozzle and discontinuity in the3D printing process. Thermoplastics in general exhibit low density and melting temperatures than those of metals. Metals in general exhibits high thermal conductivities, high mechanical strength and elongations and thus has the ability to be deformed into complex shapes without breaking.

It is expected that such a study will form a basis to use low melting alloys for 3D printing prototypes and on demand metal parts for a variety of applications which are currently unachievable using the current materials used for FFF 3D printing. 


\section{CHAPTER 3}

\section{FUSED FILAMENT FABRICATION 3D PRINTING AND CASTING WITH LOW- MELTING ALLOYS}

3D printing polymers using Fused Filament Fabrication (FFF) technology has shown to fabricate complex functional parts for electronic, automotive, and biomedical applications. However, there is limited knowledge and understanding of 3D printing metals using FFF technology. The use of 3D printing of metals and alloys using FFF technology can provide low-cost alternatives and solutions to the Laser-Powder Bed Fusion Process (L-PBF). In current work, low melting eutectic alloy of bismuth $(58 \% \mathrm{Bi}, 42 \% \mathrm{Sn})$, non-eutectic alloy of bismuth $(40 \% \mathrm{Bi}, 60 \% \mathrm{Sn})$, and a non-eutectic alloy of antimony $(7.5 \% \mathrm{Sb}, 89 \% \mathrm{Sn})$ have been used as a starting material and evaluated for FFF 3D printing using two approaches. Both approaches were used to fabricate a prototype specimen such as a souvenir and a prototype wrench. It is expected that such a technology will pave the way for the affordable fabrication of metal prototypes and alternatively on-demand custom metal spare parts for in space applications and future space missions. 


\subsection{Introduction}

3D printing can be used to manufacture custom products and has gained a lot of attention due to its flexibility to design complex geometries with metals, polymers, and ceramics [52]. According to the research and advisory board of Gartner Inc., $97.5 \%$ of all the 3D printers sold worldwide are Fused filament fabrication (FFF) 3D printers [40]. However, FFF 3D printers are typically limited to 3D print various polymers whereas metals 3D printed parts are typically made from 3D printing technologies such as laser powder bed fusion (L-PBF), direct metal laser sintering (DMLS), electron beam melting (EBM), and binder jetting. These metal 3D printing technologies can often take up a lot of space, are expensive and requires regular maintenance compared to FFF 3D printing technology [52]. Successful fabrication of metals products using FFF can reduce the price point of metal printers from approximately $500,000 \$$ to just $500 \$$, paving the way for an affordable desktop metal 3D printer [45]. FFF is an additive manufacturing process in which typically thermoplastic polymers in the form of filaments are fed through an extruder into a heated nozzle where it is melted and extruded layer-by-layer onto a heated bed platform to fabricate a 3D geometry. Once a layer is fabricated, the nozzle moves up in the z-direction (or, the base is lowered) to accommodate the subsequent layers. This process continues until the desired 3D structure is fabricated [53]. The capability to fabricate metals using FFF technology calls for applications in various fields such as the production of prototypes in industries, disposable single-use surgical instruments in healthcare and manufacturing metal spare parts in the international space station (ISS) and for future space missions such as Mars One. 
In a recent study of using FFF technology to print metal performed by P.C. Hsieh et al, low melting Sn99.3Cu0.7 and Sn60Pb40 alloys were extruded in a continuous linear shape with excellent formability [2]. Ten layer stacking of Sn99.3Cu0.7 and five layer stacking of Sn60Pb40 was achieved at nozzle temperatures of $220-240^{\circ} \mathrm{C}$. However, attempts to print in 2D was not successful at print separations of less than $0.75 \mathrm{~mm}$. In another study performed by Jorge Mireles et al, a redefined extrusion head was used to fabricate 2D spiral maze and a 3D wall with six stacked layers [54]. However, there is not a lot of work in literature that demonstrates successful 3D printing of filled metal 3D structures.

In this study, 3D geometries using low-melt alloys were fabricated using FFF technology using two approaches. In the first approach, a tin-bismuth alloy wire was used as a feedstock for the FFF 3D printer to fabricate tensile specimens. In the second approach, tensile molds were 3D printed using polymer using and low melt alloys of tin-bismuth and antimony-tin were cast into them. Additionally, the FFF 3D cast and FFF 3D printed samples were characterized for physical and mechanical properties and microstructure analysis. This work also demonstrates the use of FFF technology to fabricate low-melt alloys for applications such as affordable souvenirs and rapid production of metal spare parts for in-space applications.

\subsection{Materials and methods}

As a part of studying the feasibility of 3D printing metals using an FFF 3D printer, material search was conducted on low melting alloys through metal reference books, research papers, and commercial websites. Due to the temperature limitations of an FFF 3D printer, only low melting alloy systems with onset melting temperatures ranging from of 100$300^{\circ} \mathrm{C}$ were considered. Additionally, the lead content was limited to a maximum 
composition of $10 \%$. Using this twenty-one eutectic alloys systems of bismuth, indium, and tin, and fifty-five non-eutectic alloy systems of bismuth, indium, tin, antimony, cadmium, silver and lead were evaluated [22-41]

\subsubsection{Materials for FFF casting and printing}

A low melting eutectic alloy of bismuth $(58 \% \mathrm{Bi}, 42 \% \mathrm{Sn})$, non-eutectic alloy of bismuth $(40 \% \mathrm{Bi}, 60 \% \mathrm{Sn})$, and a non-eutectic alloy of antimony $(7.5 \% \mathrm{Sb}, 89 \% \mathrm{Sn})$ were selected for the study on the basis of their physical and mechanical properties. Sn42Bi58, also known by its trade name 'Cerrotru,' and Sn60Bi40, are both shiny in appearance and exhibits low viscosity values, making them good candidates for casting application [55]. The typical applications of the bismuth-tin alloy include lead-free soldering, metal spraying, proof casting, prototyping, and radiation shielding. [56] Sn89Sb7.5, commonly known as 'Babbitt' is white and shiny in appearance, soft, readily conformable and hence easily cast. The material also exhibits excellent corrosion resistance properties and resilience under a wide range of conditions. It is widely used as a bearing material [57].

Table 3.1 shows the physical and mechanical properties of $\operatorname{Sn} 42 \mathrm{Bi} 58, \mathrm{Sn} 60 \mathrm{Bi} 40$ and Sn89Sb7.5. All of these materials were used to fabricate and test 3D tensile bars with method II called FFF casting whereas Sn60Bi40 alloy was used to fabricate and test 3D tensile bars with method I called FFF printing. 
Table 3.1: Physical and mechanical properties of the low melting alloys selected for the evaluation of metal fabrication using FFF 3D printing technology[40, 58-60].

\begin{tabular}{|c|c|c|c|c|}
\hline Specimen & MP & Density & UTS & Elongation \\
& $\left({ }^{\circ} \mathbf{C}\right)$ & $(\mathbf{g} / \mathbf{c c})$ & $(\mathbf{M P a})$ & $\%$ \\
\hline Sn42Bi58 & 138 & 8.58 & 55.41 & 46 \\
\hline Sn60Bi40 & $138-170$ & 8.21 & 62.5 & 35 \\
\hline Sn89Sb7.5 & $241-354$ & 7.38 & 90 & 10 \\
\hline
\end{tabular}

\subsubsection{Method I - FFF 3D printing}

In this methodology, the low melting Sn60Bi40 alloy in the form of a wire was fed into the FFF 3D printer and heated in the nozzle to deposit material layer by layer to fabricate a 3D geometry. Since the extrusion characteristics of metals are different from that of polymers, optimization of the printer process parameters was necessary for the uninterrupted printing of the low-melting Sn60Bi40 material.

A 2D geometry, square toolpath, was designed to investigate the linear deposition characteristics of Sn60Bi40. Multiple trials were performed in order to achieve continuous deposition. This was followed by attempts to fabricate a 3D geometry, dog bone specimen. Printrbot Simple 1403 with a build volume of 6" x 6" x 6"was used for the fabrications. Figure 3.1 shows the SolidWorks models of the 2D tool path, and the dog bone specimen used for the development of process parameters. 


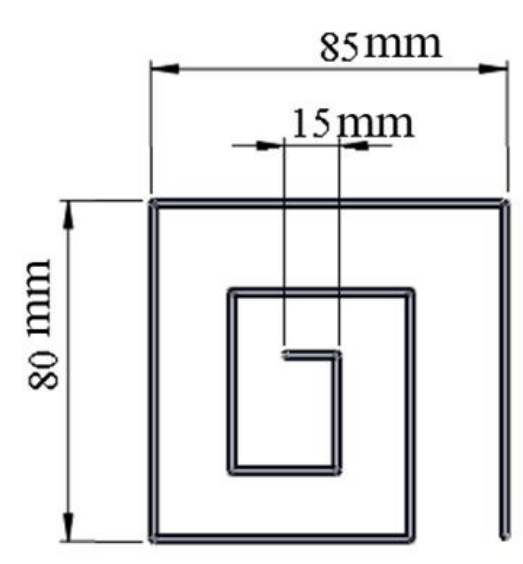

(a)

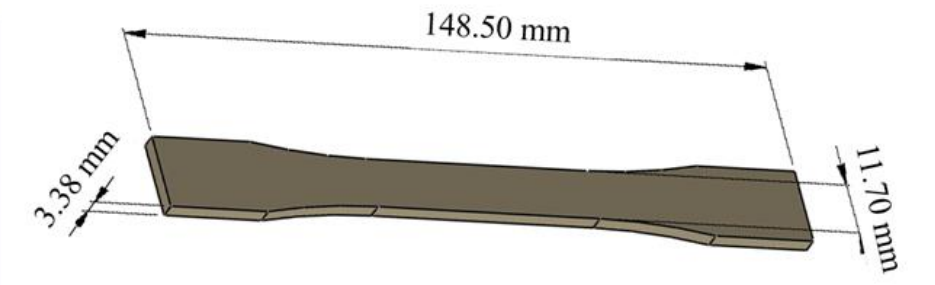

(b)

Figure 3.1: SolidWorks designs for the development of printing process parameters of low melting alloy, Sn60Bi40, using FFF 3D printing technology (a) 2D - Square toolpath (b) $3 \mathrm{D}-\mathrm{dog}$ bone specimen

FFF printing process parameters for fabricating low-melt Sn60Bi40 was successfully developed. ASTM E8 standard tensile coupons were fabricated using the parameters as per the dimensions shown in Figure 3.2. The specimens were subsequently tested for its physical properties such as mass, volume, and density, mechanical properties such as ultimate tensile strength, yield strength, and percent elongation as well as microstructure. 



Figure 3.2: SolidWorks design of the ASTM E8 standard tensile specimen for FFF 3D printing with Sn60Bi40 alloy

\subsubsection{Method-II: FFF casting}

In this methodology, the mold of the specimens to be fabricated was designed in SolidWorks, and 3D printed using an FFF 3D printer. The low melting alloys of Sn60Bi40, $\mathrm{Sn} 42 \mathrm{Bi} 58$ and $\mathrm{Sn} 89 \mathrm{Sb} 7.5$ were heated in a hotplate to its pouring temperatures and poured into the mold cavity to cool and solidify at room temperature. The solidified part was removed from the mold and post-processed to obtain the final part.

The top and isometric views of the tensile molds designed for fabrication is shown in

Figure 3.3.

(a)

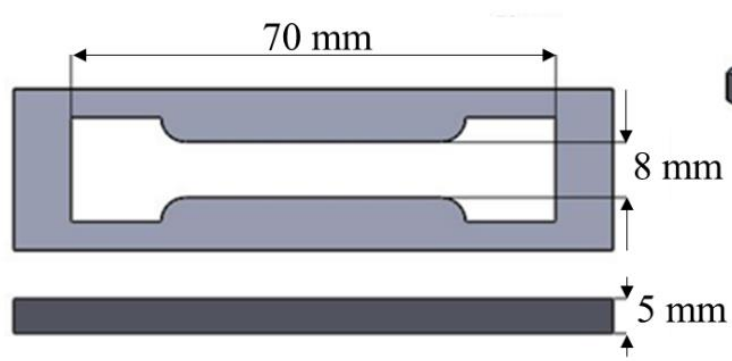

(b)

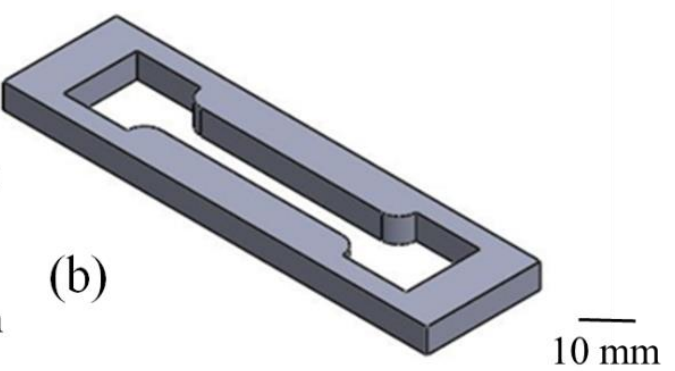

Figure 3.3: SolidWorks design of the tensile specimen mold. (a) Top view (b) Isometric view 
The model was saved in '. STL' format and imported into the 3D printing software, Repetier. The mold was 3D printed using an FFF 3D Printer, Printrbot simple 1403, in polylactic acid (PLA) material. Printing process parameters included nozzle temperature of $215{ }^{\circ} \mathrm{C}$, bed temperature of $65^{\circ} \mathrm{C}$ and infill percentage of $40 \%$. Infill percentage was set to $40 \%$ to aid the easy removal of the part from the mold with minimum damage.

The low melting alloys were heated to its pouring temperatures of $250^{\circ} \mathrm{C}(\mathrm{Sn} 60 \mathrm{Bi} 40$, $\mathrm{Sn} 42 \mathrm{Bi} 58)$ and $420^{\circ} \mathrm{C}(\mathrm{Sn} 89 \mathrm{Sb} 7.5)$ in a hotplate. The molten metal was then poured into the $3 \mathrm{D}$ printed tensile molds and cooled to room temperatures. The solidified metal part was removed from the mold.

Additionally, to investigate the effect of mold cooling times on the mechanical properties and microstructure of the fabricated part, additional specimens of Sn60Bi40 were cast at different cooling rates. The cast was cooled in two different states viz. slow cooled, at room temperature (cooling time $=15$ seconds) and fast cooled under the presence of an external fan (cooling time $=5$ seconds).

This methodology was used to create four ASTM E8 standard tensile specimens as shown in Figure 3.2. The specimens were subsequently characterized for its dimensions, and physical properties such as mass, volume, and density, mechanical properties such as ultimate tensile strength, yield strength, and percent elongation as well as microstructure.

\subsection{Characterization}

Samples fabricated using both methods I and II were further post-processed. ALO papers with grits P120, P240, was used as the abrasive surface and the specimen was polished on a water lubricated abrasive wheel. The dimensions and mass of the samples were noted. 
The volume and density were calculated based on Archimedes' principle, with the liquid of submersion being water. Uniaxial tensile testing was performed using an Instron MTI 10,000 lbs. benchtop tension testing machine. Stress-strain curves were plotted, and materials properties such as ultimate tensile strength, percent elongation, and yield strength were calculated.

The fabricated specimens were then carefully sectioned using a metal pressed diamond wafering blade to a convenient size along its z-axis. After sectioning, the sample was mounted in an epoxy compression mounting resin material to facilitate handling during the subsequent grinding and polishing steps. The sample was then ground and polished using P240, P400 and P1200 grit ALO papers [22]. This was followed by polishing them on an abrasive surface of $1 \mu \mathrm{m}$ diamond. Further fine polishing was performed on the abrasive surface of $0.25 \mu \mathrm{m}$ with a speed of $100 \mathrm{rpm}$. Polishing was performed for a duration of 1800 seconds at a rate of $100 \mathrm{rpm}$ and a force of approximately 10 pounds. [23]

Sn60Bi40 and Sn42Bi58 alloys were etched using 95\% methanol, 3\% $\mathrm{HCl}$ and 2\% $\mathrm{HNO} 3$ to reveal the true microstructure. Sn89Sb7.5 alloy was subjected to chemical etching with a $5 \%$ solution of $\mathrm{HCl}$ in ethanol.

\subsection{Results and Discussion}

\subsubsection{FFF 3D Printing of Sn60Bi40 alloy}

The printing parameters such as the velocity of extrusion, rate of feeding, temperature of the nozzle, print bed temperature and layer height play a significant role in the continuous deposition of the material, adherence to the bed (and subsequent layers) and build quality of the fabricated part. Each of these parameters was iterated in order to successfully $3 \mathrm{D}$ print Sn60Bi40 alloy using the FFF technology. Table 3.2 shows the process parameters 
that were developed for the fabrication of 2D and 3D geometries of the Sn60Bi40 alloy using the FFF 3D printing technology.

Table 3.2: Printing process parameters developed for fabricating low-melting Sn60Bi40 alloy using FFF 3D printing technology.

\begin{tabular}{|c|c|c|c|c|c|}
\hline \multirow{2}{*}{ Printing Parameters } & \multicolumn{2}{|c|}{ 2D } & \multicolumn{3}{c|}{ 3D } \\
\cline { 2 - 6 } & Trial 1 & Trial2 & Trial 1 & Trial2 & Trial 3 \\
\hline Nozzle temperature $\left({ }^{\circ} \mathrm{C}\right)$ & 220 & 220 & 220 & 220 & 220 \\
\hline Bed temperature $\left({ }^{\circ} \mathrm{C}\right)$ & 40 & 40 & 40 & 40 & 40 \\
\hline Extrusion velocity (mm/s) & 14 & 7 & 7 & 5 & 1 \\
\hline Feed rate (mm/s) & 150 & 200 & 200 & 250 & 250 \\
\hline Layer height (mm) & 0.3 & 0.3 & 0.3 & 0.3 & 0.3 \\
\hline Infill (\%) & NA & NA & 80 & 80 & 80 \\
\hline
\end{tabular}

All the trials were conducted at nozzle temperature of $220^{\circ} \mathrm{C}$, bed temperature of $40^{\circ} \mathrm{C}$, layer height of $0.3 \mathrm{~mm}$ and build direction of ' $\mathrm{y}$ '. Initial trials of fabricating the 2D geometry at extrusion velocities of $14 \mathrm{~mm} / \mathrm{s}$ and feed rate of $150 \mathrm{~mm} / \mathrm{s}$ deposited discontinuous tracks with a gap of approximately $7 \mathrm{~mm}$ between extrusions as shown in Figure 3.4 (a). Reducing the extrusion velocities to $7 \mathrm{~mm} / \mathrm{s}$ provided additional time for depositing the material on to the print bed. Consequently, increasing the feed rate to a higher value of $200 \mathrm{~mm} / \mathrm{s}$ assisted in the faster extrusion of the material. Thus the coupled effect of reducing the extrusion velocity by $50 \%$ and increasing the feed rate by $25 \%$ 
resulted in successful fabrication of the Sn60Bi40 alloy in 2D as shown in Figure 3.4 (b). The perimeter of the $2 \mathrm{D}$ square tool path spans a total length of $320 \mathrm{~mm}$.
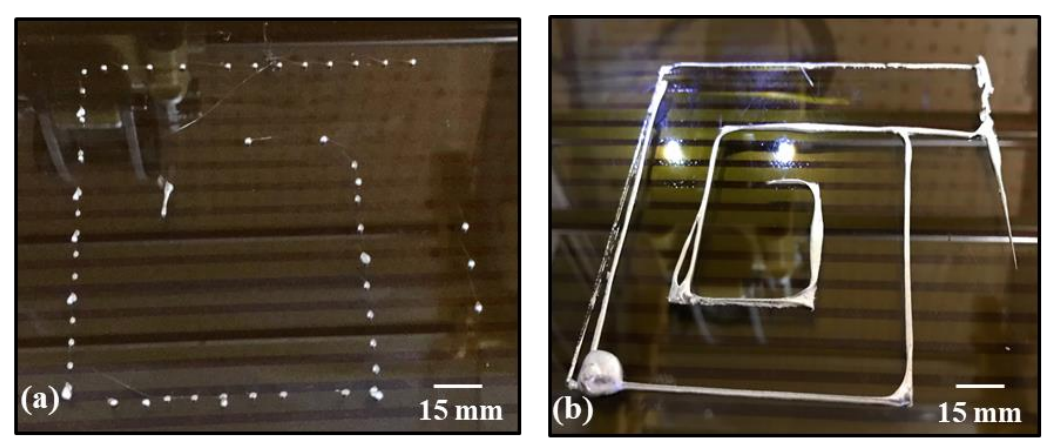

Figure 3.4: (a) Trial 1- 2D Square maze toolpath with discontinuity between depositions (b) Trial 2- Successful fabrication of 2D square maze toolpath

Attempts to fabricate the $3 \mathrm{D}$ geometry using the parameters developed for $2 \mathrm{D}$ created irregular intervals of separations as shown in Figure 3.4 (a) probably due to the lack of molten material available for immediate extrusion. Increasing the feed rate by a percentage of $20 \%$ along with a decrease in $28.57 \%$ in the extrusion velocity addressed this issue reducing the discontinuities over the entire area of the geometry as shown in Figure 3.5 (b).Reducing the extrusion velocity further to an allowed minimum of $1 \mathrm{~mm} / \mathrm{s}$ further reduced the voids and discontinuities between the layers and paved the way for the successful fabrication of Sn60Bi40 using FFF technology as shown in Figure 3.5 (c) The structure exhibits nearly complete fill with sufficient interlayer bonding. 

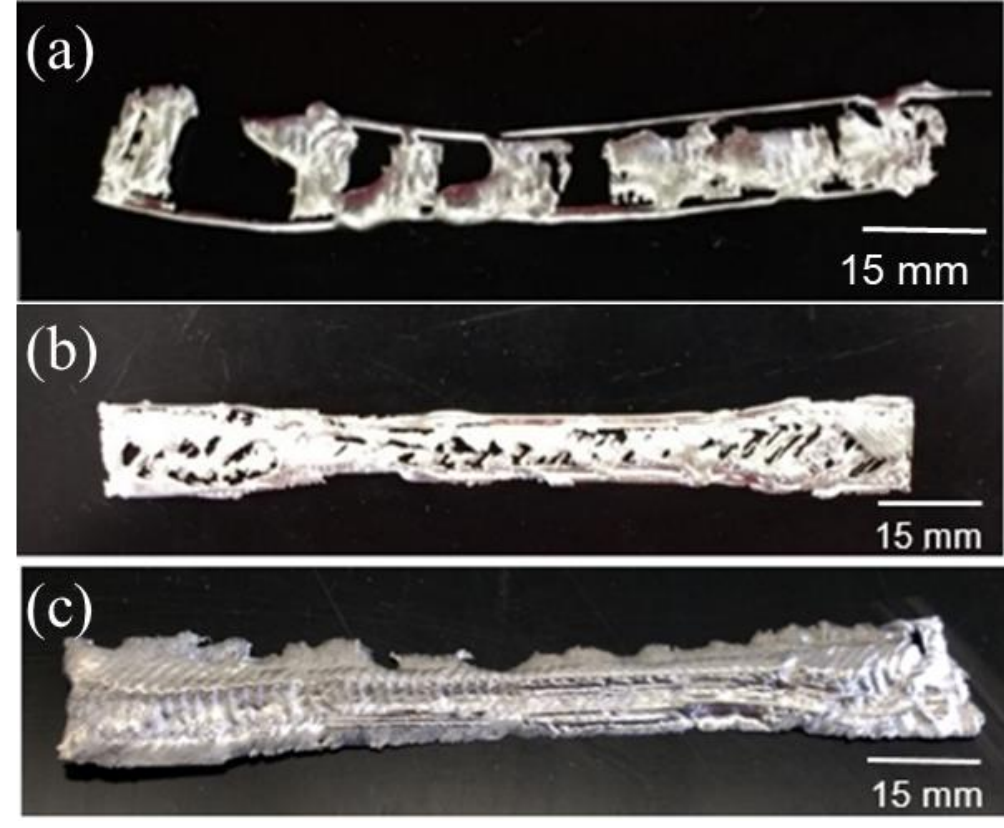

Figure 3.5: FFF 3D printing of 3D geometry using Sn60Bi40 alloy (a) Trial 1 (b) Trial 2 (c) Trial 3

Finally, ASTM E8 standard tensile specimens were fabricated (see Figure 3.6) as per the print parameters developed as given in Table 3.2 (3D, Trial3).

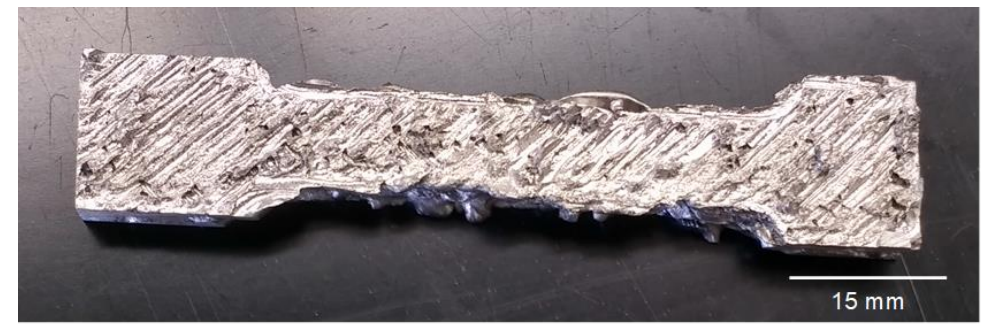

Figure 3.6: FFF 3D printed ASTM E8 standard tensile specimen of Sn60Bi40 alloy 
Table 3.3 shows the dimensions and physical properties of the post-processed FFF 3D printed part of the Sn60Bi40 alloy.

Table 3.3: Dimensions and physical properties of the post-processed FFF 3D printed part of the Sn60Bi40 alloy

\begin{tabular}{|c|c|c|c|c|c|}
\hline $\begin{array}{c}\text { Length } \\
(\mathbf{m m})\end{array}$ & Width & Thickness & Mass $(\mathbf{g})$ & Volume & Density (g/cc) \\
& $(\mathbf{m m})$ & $(\mathbf{m m})$ & & \\
\hline $69.19 \pm 0.69$ & $7.99 \pm 0.35$ & $4.88 \pm 0.15$ & $21.31 \pm 2.05$ & $2.75 \pm 0.25$ & $7.71 \pm 0.11$ \\
\hline
\end{tabular}

Table 3.3 shows that the length of the fabricated samples is smaller than the true length of $70 \mathrm{~mm}$, with an average dimension of $69.19 \pm 0.69 \mathrm{~mm}$ and a percentage error of $1.16 \%$. The fabricated samples had an average width of $7.99 \pm 0.35 \mathrm{~mm}$ and percentage error value of $0.13 \%$. The greatest variation in dimensions was found to occur in the thickness of the specimen, with an average thickness of $4.88 \pm 0.15 \mathrm{~mm}$ and percentage error values of 2.43 .

$\%$. The volume of the fabricated specimens is lesser than the expected volume derived from the SolidWorks, $3.762 \mathrm{~g} / \mathrm{cc}$, by a percentage of $31.08 \%$. Consequently, the mass of fabricated specimens had a percentage error of $35.63 \%$. The densities of the fabricated specimens are smaller than the true density values of the material and accounted to relative densities of $93.91 \%$ and porosity of $6.09 \%$.

The ultimate tensile strength, yield strength and percent elongation of the FFF 3D printed ASTM E8 tensile specimen of Sn60Bi40 is shown in Figure 3.7. 


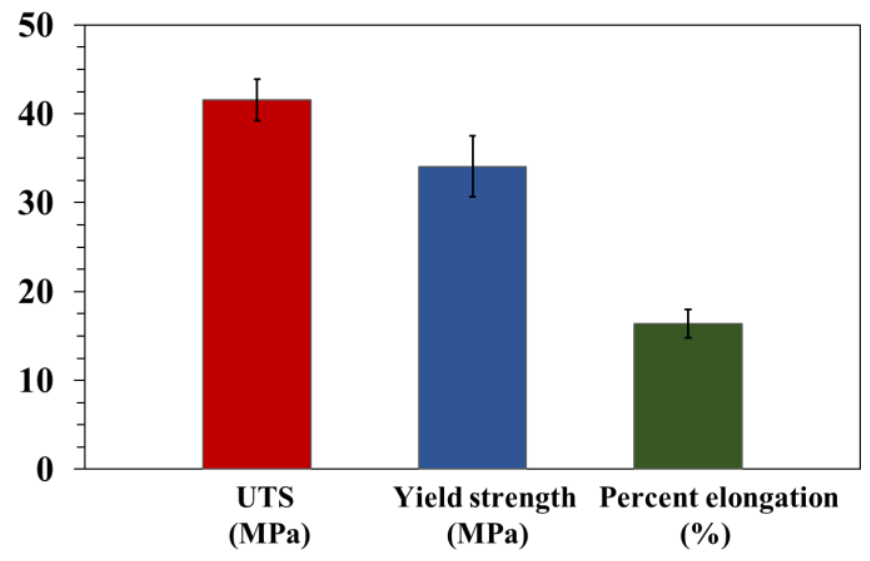

Figure 3.7: Ultimate tensile strength, yield strength and percent elongation of the FFF 3D printed ASTM E8 tensile specimen of Sn60Bi40

The ultimate tensile strength of the FFF 3D printed tensile specimen accounts to an average value of $41.55 \pm 2.30 \mathrm{MPa}$. This is a percentage decrease of $33.52 \%$ with respect to the estimated values of the UTS of the Sn60Bi40 alloy (see Table 3.1). Similarly, the percent elongation of the FFF 3D printed tensile specimen accounts to an average value of $16.38 \pm$ 1.59 MPa. This is a percentage decrease of $53.21 \%$ with respect to the estimated values of the percent elongation of the Sn60Bi40 alloy (see Table 3.1). This could be due to the lower volume percentages and lower relative densities of the fabricated part as depicted in Table 3.3. The yield stress of the samples was calculated using the $0.2 \%$ offset method[61] and accounts for a value of $34.06 \pm 3.43 \mathrm{MPa}$.

The optical microscopy images of post-processed FFF 3D printed part of Sn60Bi40 alloy is shown in Figure 3.8. 


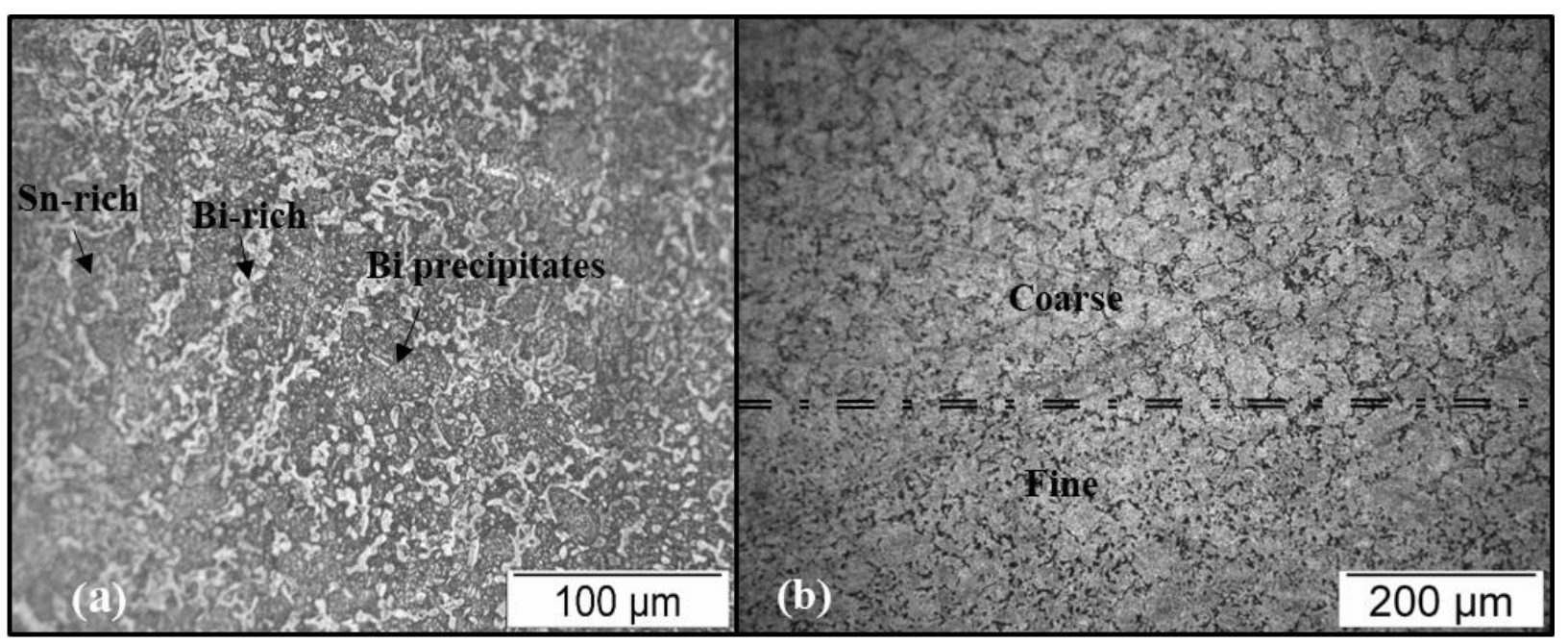

Figure 3.8: (a) Bright Field (BF) Image of FFF 3D printed Sn60Bi40 alloy showing the primary tin-rich phase surrounded by eutectic structure. (50X) (b) Dark Field (DF) Image of FFF 3D printed Sn60Bi40 alloy which shows the layering of fine and coarse microstructure

Figure 3.8 (a) shows that microstructure of the FFF 3D printed Sn60Bi40 alloy consists of bismuth-rich phases, tin-rich phases and fine granules of bismuth precipitates in the tinrich phase and is comparable with the microstructure of the wrought sample. [62]. The light grey pattern in Figure 3.8 (a) represent the bismuth-rich phase; the dark grey background represents the tin-rich phase and the fine light colored particles on the tin-rich matrix represent the bismuth precipitates. The precipitation of bismuth occurs due to the lower solubility of bismuth in tin at low temperatures, leading to the segregation of bismuth from the tin. However, at a higher magnification of $20 \mathrm{X}$, layering of fine and coarse microstructure was observed as shown in the Figure 3.8 (b). The coarsening of the lamellar 
could be attributed to the reheating of the previous build layer by the subsequent layer and explains the reduced mechanical properties [47].

For metals with moderate ductility, relationship between yield strength and porosity can be expressed by the empirical relation[63],

$$
\sigma_{y}=K(1-\theta)^{1.25} \sigma_{0}
$$

where $\sigma_{y}$ is the yield strength and $\theta$ is the porosity from 0 to 1 and $\sigma_{0}$ is the material constant.

Thus, higher the relative density, lower the porosity and higher the yield strength.

\subsubsection{FFF 3D Casting of Sn60Bi40, Sn42Bi58 and Sn89Sb7.5 alloys}

The process of fabricating specimens using FFF cast methodology and the samples of ASTM E8 tensile specimens fabricated using the technique are shown in Figure 3.9.

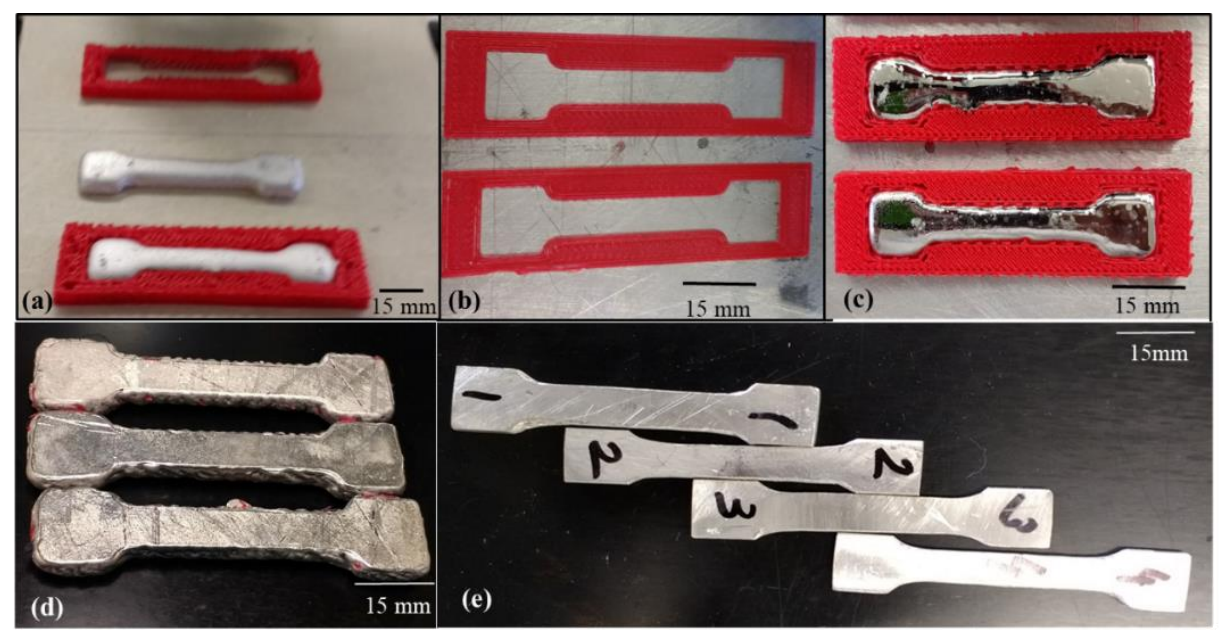

Figure 3.9: (a) Process summary of the FFF cast methodology (b) Tensile molds 3D printed using PLA (c) Molten material cast onto the 3D printed mold (d) As-cast tensile specimens (e) Post-processed tensile specimens 
The dimensions of the post-processed specimens were evaluated to understand the geometric tolerances of the fabricated part.

Table 3.4 shows the dimensions and tolerances of the post-processed FFF 3D cast parts of Sn60Bi40, Sn42Bi58 and Sn89Sb7.5 alloys.

Table 3.4: Dimensions of the post-processed FFF 3D cast parts of Sn60Bi40, Sn42Bi58 and $\mathrm{Sn} 89 \mathrm{Sb} 7.5$ alloys

\begin{tabular}{|c|c|c|c|}
\hline Specimen & Length $(\mathbf{m m})$ & Width $(\mathbf{m m})$ & $\begin{array}{c}\text { Thickness } \\
(\mathbf{m m})\end{array}$ \\
\hline Sn60Bi40 & $69.36 \pm 0.20$ & $7.97 \pm 0.23$ & $4.73 \pm 0.31$ \\
\hline Sn42Bi58 & $69.10 \pm 0.44$ & $8.14 \pm 0.12$ & $4.64 \pm 0.49$ \\
\hline Sn89Sb7.5 & $68.81 \pm 0.39$ & $8.32 \pm 0.20$ & $5.55 \pm 0.37$ \\
\hline
\end{tabular}

Table 3.4 shows that the length of the fabricated samples is larger than the true length of $70 \mathrm{~mm}$, with an average dimension of $69.9 \pm 0.34 \mathrm{~mm}$. The width of the samples was found to vary in ranges of $7.97 \mathrm{~mm}$ to $8.32 \mathrm{~mm}$, with an average value of $8.15 \pm 0.21 \mathrm{~mm}$. The thickness of the samples was found to lie between values of $4.64 \mathrm{~mm}$ to $5.55 \mathrm{~mm}$ with an average value of $4.98 \pm 0.39 \mathrm{~mm}$. The greatest variation in dimensions was found to occur in the width of the specimen, with a percentage error of $1.80 \%$. The least variation in dimension occurred in the thickness of the specimen, with a percentage difference value of $0.48 \%$. The length measurements had a percentage error value of $1.31 \%$.

Table 3.5 shows the physical properties of the post-processed FFF 3D cast parts of Sn60Bi40, Sn42Bi58 and Sn89Sb7.5 alloys. 
Table 3.5: Physical properties of the post-processed FFF 3D cast parts of Sn60Bi40, Sn42Bi58 and Sn89Sb7.5 alloys

\begin{tabular}{|c|c|c|c|}
\hline Specimen & Mass (g) & Volume (cc) & Density \\
& & & $(\mathrm{g} / \mathbf{c c})$ \\
\hline Sn60Bi40 & $25.57 \pm 1.385$ & $3.207 \pm 0.180$ & $7.97 \pm 0.206$ \\
\hline Sn42Bi58 & $25.27 \pm 2.538$ & $2.94 \pm 0.289$ & $8.58 \pm 0.027$ \\
\hline Sn89Sb7.5 & $32.18 \pm 2.54$ & $4.47 \pm 0.251$ & $7.17 \pm 0.243$ \\
\hline
\end{tabular}

Table 3.5 shows that the volume of the fabricated specimens is greater than the expected volume derived from the SolidWorks, $3.762 \mathrm{~g} / \mathrm{cc}$, by a percentage of $19.22 \%$. The greatest percent error in volume was for the parts fabricated in Sn42Bi58, with a percentage error of $24.53 \%$. Parts fabricated in Sn89Sb7.5 and Sn60Bi40 exhibited percentage differences of $17.2 \%$ and $15.93 \%$ respectively. Consequently, the mass of the fabricated specimens was found to greatly vary for the parts fabricated in $\mathrm{Sn} 42 \mathrm{Bi} 58$, with a percentage error of 24.36\%. Parts fabricated in Sn89Sb7.5 and Sn60Bi40 exhibited percentage differences of $17.74 \%$ and $14.74 \%$ respectively.

The densities of the fabricated specimens are in close correlation with the true density values of the materials and accounted to relative densities of $98.15 \%$ for the Sn60Bi40, $100 \%$ for the $\mathrm{Sn} 42 \mathrm{Bi} 58$ and $97.15 \%$ for $\mathrm{Sn} 89 \mathrm{Sb} 7.5$.

Figure 3.10 shows the relative density of the post-processed FFF 3D cast parts of Sn60Bi40, Sn42Bi58 and Sn89Sb7.5 alloys 


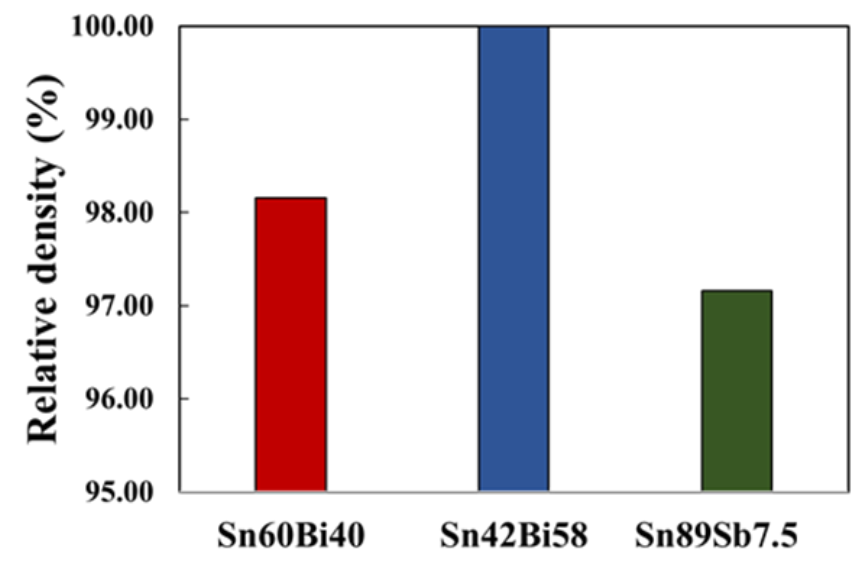

Figure 3.10: Relative densities of the post-processed FFF 3D cast parts of Sn60Bi40, Sn42Bi58 and Sn89Sb7.5 alloys

Figure 3.10 shows that the densities of the post-processed FFF 3D cast parts of Sn60Bi40, Sn42Bi58 and Sn89Sb7.5 alloys are in close correlation with the true density values of the alloys as shown in Table 3.2.

Figure 3.11 shows ultimate tensile strength of the post-processed FFF 3D cast parts for Sn60Bi40, Sn42Bi58 and Sn89Sb7.5 alloys.

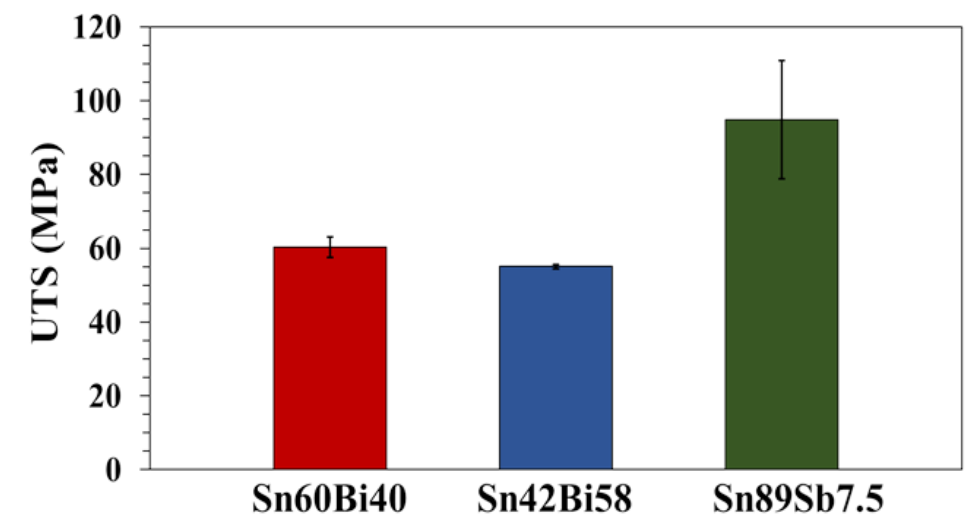

Figure 3.11: Ultimate tensile strength of the post-processed FFF 3D cast parts of Sn60Bi40, Sn42Bi58 and Sn89Sb7.5 alloys 
The ultimate tensile strength (UTS) accounts to a value of $60.29 \pm 2.79 \mathrm{MPa}, 55.08 \pm 0.58$ $\mathrm{MPa}$ and $94.81 \pm 16 \mathrm{MPa}$ for the post-processed FFF 3D cast parts of Sn60Bi40, Sn42Bi58 and Sn89Sb7.5 alloys respectively. The results are comparable with the theoretical values as shown in Table 3.2.

Figure 3.12 shows percent elongation of the post-processed FFF 3D cast parts of Sn60Bi40, Sn42Bi58 and Sn89Sb7.5 alloys.

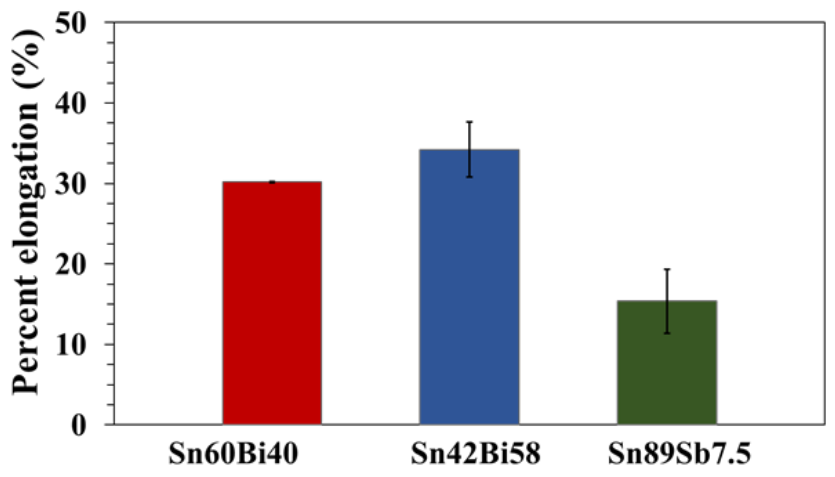

Figure 3.12: Percent elongation of the post-processed FFF 3D cast parts of Sn60Bi40, Sn42Bi58 and Sn89Sb7.5 alloys

The percentage elongation accounts to a value of $30.18 \pm 0.99 \%, 34.22 \pm 3.43 \%$ and 15.38 $\pm 4.10 \%$ for the post-processed FFF 3D cast parts of Sn60Bi40, Sn42Bi58 and Sn89Sb7.5 alloys respectively. It can be noted that $\mathrm{Sn} 42 \mathrm{Bi} 58$ has higher percentage elongation compared to that of Sn60Bi40. This can be attributed to higher percentage composition of bismuth in the alloy.At higher concentrations of bismuth , more number of bismuth particles are non-soluble and thus precipitated and accumulated at the grain boundaries, leading to a decrease in the overall stiffness of the material[64].Sn89Sb7.5 has low values of percentage elongations and is hence comparatively brittle. 
Figure 3.13 shows yield strengths of the post-processed FFF 3D cast parts of Sn60Bi40, Sn42Bi58 and Sn89Sb7.5 alloys.

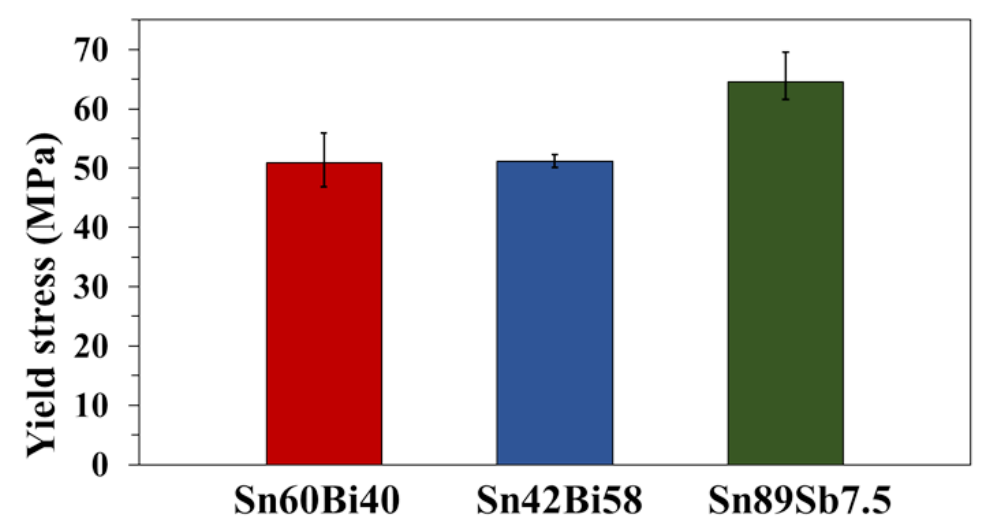

Figure 3.13: Strengths of the post-processed FFF 3D cast parts of Sn60Bi40, Sn42Bi58 and $\mathrm{Sn} 89 \mathrm{Sb} 7.5$ alloys

The yield stress of the samples was calculated using the $0.2 \%$ offset method[61]. The average and standard deviation of the yield stress accounts to a value of $50.90 \pm 4.32 \mathrm{MPa}$, $51.19 \pm 1.12 \mathrm{MPa}$ and $64.54 \pm 7.35 \mathrm{MPa}$ for Sn60Bi40, Sn42Bi58 and Sn89Sb7.5 alloys respectively.

The optical microscopy images of the post-processed FFF 3D cast parts of Sn42Bi58, and Sn60Bi40 alloy is shown in Figure 3.14 


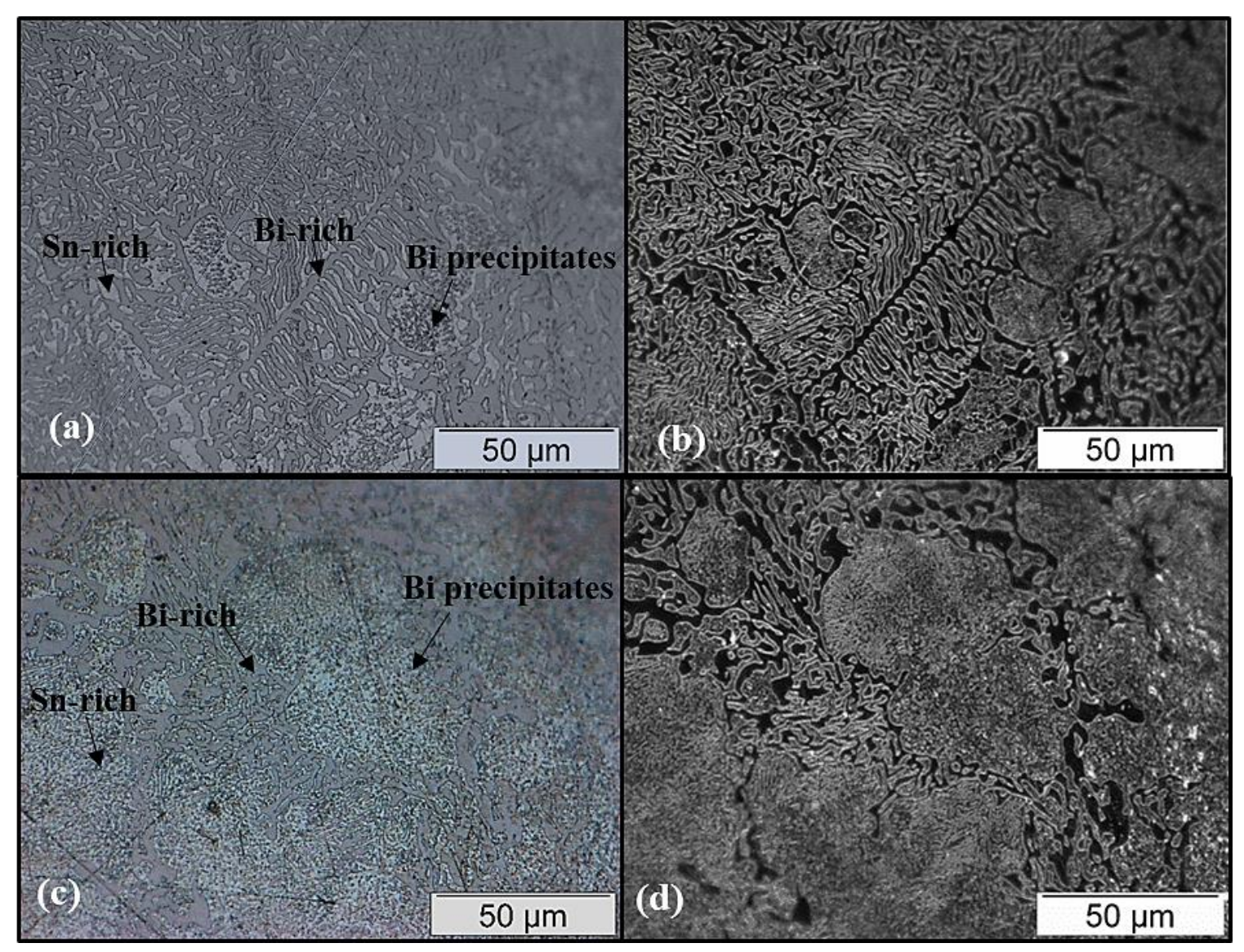

Figure 3.14: Optical microscopy images of the post-processed FFF 3D cast Sn42Bi58 (eutectic) and Sn60Bi40(non-eutectic) alloys (a) Bright field image of Sn42Bi58 showing bismuth and tin phases in the microstructure (b) Dark field image of Sn42Bi58 showing the eutectic structure (c) Bright field image of Sn60Bi40 showing bismuth and tin phases in the microstructure (d) Dark field image of Sn60Bi40 which shows the primary Sn-rich phase surrounded by eutectic structure

Figure 3.14 (a), (c) shows that microstructure of a bismuth-tin alloy consists of bismuthrich phases, tin-rich phases and fine granules of bismuth precipitates in the tin-rich phase. [62]. The dark grey pattern in the bright field images represent the bismuth-rich phase, the light grey background represents the tin-rich phase, and the fine dark particles on the tin- 
rich matrix represent the bismuth precipitates. The precipitation of bismuth occurs due to the lower solubility of bismuth in tin at low temperatures, leading to the segregation of bismuth from the tin. [65]. As the concentration of bismuth content in the alloy increases from $40 \%$ in Sn60Bi40 to 58\% in Sn42Bi58, bismuth particles segregate significantly and accumulates on the tin-rich phase[66].

Figure 3.14 (b), (d) which are the corresponding dark field images, clearly distinguishes the lamellar structure of the eutectic and non-eutectic bismuth-tin alloys. It can be observed that in the eutectic alloy $(\operatorname{Sn} 42 \mathrm{Bi} 58)$, the bismuth phase, as well as the tin phase, forms a continuous network in the form of a dendrite, also referred to as the fishbone eutectics. The microstructure of the non-eutectic alloy(Sn60Bi40) consists of a continuous network of bismuth surrounded by the tin-rich matrix[64].

Figure 3.15 shows the optical microscopy images of the post-processed FFF 3D cast parts of the $\mathrm{Sn} 89 \mathrm{Sb} 7.5$ alloy.

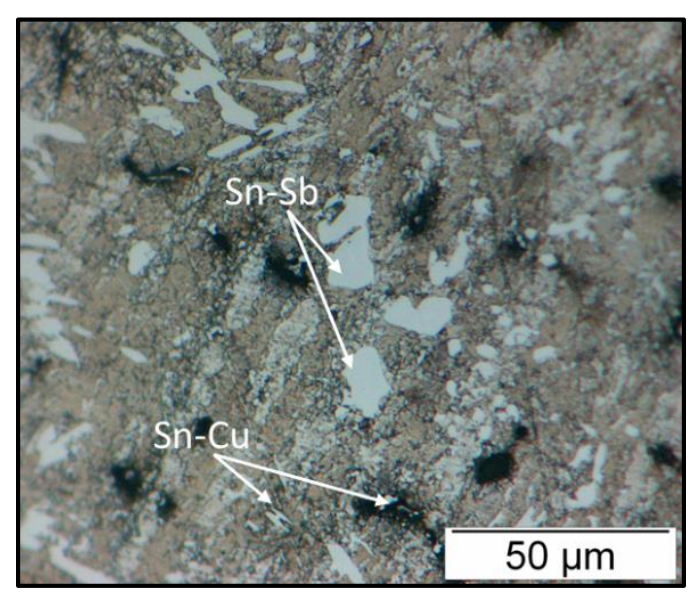

Figure 3.15: Optical microscopy image of the post-processed FFF 3D cast part of the Sn89Sb7.5 alloy 
Figure 3.15 shows that the microstructure of the $\mathrm{Sn} 89 \mathrm{Sb} 7.5$ alloy consists of $\mathrm{Sn}-\mathrm{Sb}$ phase surrounded by $\mathrm{Sn}$-rich phase and $\mathrm{Cu}-\mathrm{Sn}$ phase. $\mathrm{Sn}-\mathrm{Sb}$ phases are square in shape, and the $\mathrm{Cu}-\mathrm{Sn}$ phases are the long and irregular shaped phases in the background of the Sn-rich phase Figure 39 [67, 68].

\subsubsection{Effect of cooling rate on the FFF 3D casting of Sn60Bi40 alloy}

The dimensions of the post-processed specimens were evaluated to understand the geometric tolerances of the fabricated part. Table 3.6 shows the dimensions and tolerances of the post-processed FFF 3D cast parts of Sn60Bi40 at slow and fast rates of cooling.

Table 3.6: Dimensions and tolerances of the post-processed FFF 3D cast parts of Sn60Bi40 at slow and fast rates of cooling

\begin{tabular}{|c|c|c|c|}
\hline Rate of cooling & Length $(\mathbf{m m})$ & Width $(\mathbf{m m})$ & Thickness \\
& & & $(\mathbf{m m})$ \\
\hline Slow cooled & $68.79 \pm 0.22$ & $7.56 \pm 0.22$ & $5.23 \pm 0.63$ \\
\hline Fast cooled & $68.98 \pm 0.72$ & $8.01 \pm 0.37$ & $4.98 \pm 0.25$ \\
\hline
\end{tabular}

Table 3.6 shows that the length of the fabricated samples is smaller than the true length of $70 \mathrm{~mm}$, with an average dimension of $68.88 \pm 0.47 \mathrm{~mm}$ and a percentage error of $1.61 \%$. The fabricated samples had an average width of $7.78 \pm 0.29 \mathrm{~mm}$ and a percentage error of $2.77 \%$. The greatest variation in dimensions was found to occur in the thickness of the specimen, with an average thickness of $5.11 \pm 0.44 \mathrm{~mm}$ and percentage error value of 2.08 \%. Table 3.7 shows the physical properties of the post-processed FFF 3D cast parts of Sn60Bi40 at slow and fast rates of cooling. 
Table 3.7: Physical properties of the post-processed FFF 3D cast parts of Sn60Bi40 at slow and fast rates of cooling

\begin{tabular}{|c|c|c|c|}
\hline Rate of cooling & Mass $(\mathbf{g})$ & Volume $(\mathbf{c c})$ & Density (g/cc) \\
\hline Slow cooled & $27.84 \pm 2.52$ & $3.43 \pm 0.161$ & $8.09 \pm 0.009$ \\
\hline Fast cooled & $27.92 \pm 2.34$ & $3.29 \pm 1.56$ & $8.10 \pm 0.057$ \\
\hline
\end{tabular}

Table 3.7 shows that the volume of the fabricated specimens is greater than the expected volume derived from the SolidWorks, $3.762 \mathrm{~g} / \mathrm{cc}$, by a percentage of $11.31 \%$. The parts fabricated in slowly cooled condition under ambient temperature exhibited percentage differences of $9.23 \%$ and the percent volume error percent for the fast cooled specimen was $13.39 \%$. Consequently, the mass of the specimens fabricated in the slow and fast cooling conditions exhibited percentage error values of $9.27 \%$ and $8.99 \%$ respectively.

The densities of the fabricated specimens are found to be in close correlation with the true density value of the Sn60Bi40 alloys as shown in Table 3.2. Figure 3.16 shows the relative density of the post-processed FFF 3D cast parts of Sn60Bi40 at slow and fast rates of cooling, which account for percentage differences of $98.53 \%$ for the slowly cooled specimens and $98.66 \%$ for the fast cooled specimens. 


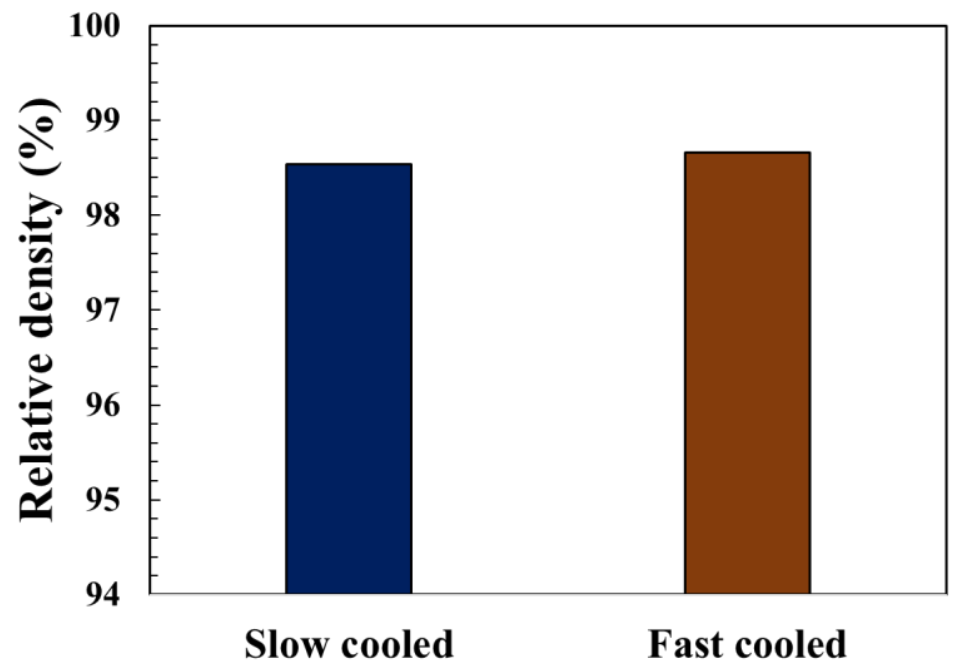

Figure 3.16: Relative densities of the post-processed FFF 3D cast parts of Sn60Bi40 at slow and fast rates of cooling

Figure 3.16 shows that the densities of the post-processed FFF 3D cast parts of Sn60Bi40 at slow and rapid rates of cooling is in close correlation with the true density value of the Sn60Bi40 alloy as shown in Table 3.2. Figure 3.17 shows ultimate tensile strengths of the post-processed FFF 3D cast parts of Sn60Bi40 at slow and fast rates of cooling.

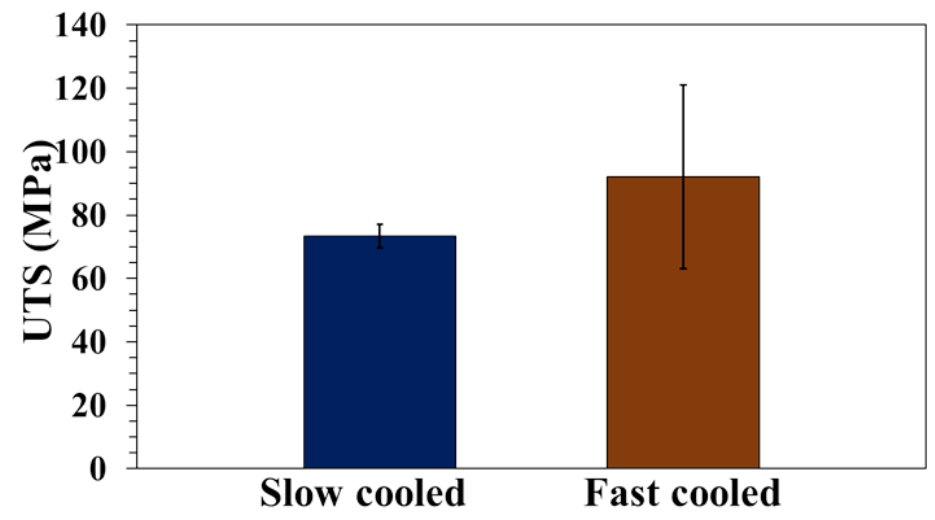

Figure 3.17: Ultimate Tensile Strengths of the post-processed FFF 3D cast parts of Sn60Bi40 at slow and fast rates of cooling 
Figure 3.17 represents the average ultimate tensile strength of the post-processed FFF 3D cast parts of Sn60Bi40 at slow and fast rates of cooling which accounts for values of $73.35 \pm$ 3.69 $\mathrm{MPa}$ and $92.10 \pm 0.58 \mathrm{MPa}$ respectively. This is a percentage increase of $15.97 \%$ for the slow-cooled specimen and $47.36 \%$ for the fast-cooled specimen with respect to the estimated values of the UTS for the Sn60Bi40 alloy as shown in Table 3.2. Fast cooled specimens exhibit higher ultimate tensile strengths.

Figure 3.18 shows percentage elongation values of the post-processed FFF 3D cast parts of Sn60Bi40 at slow and fast rates of cooling.

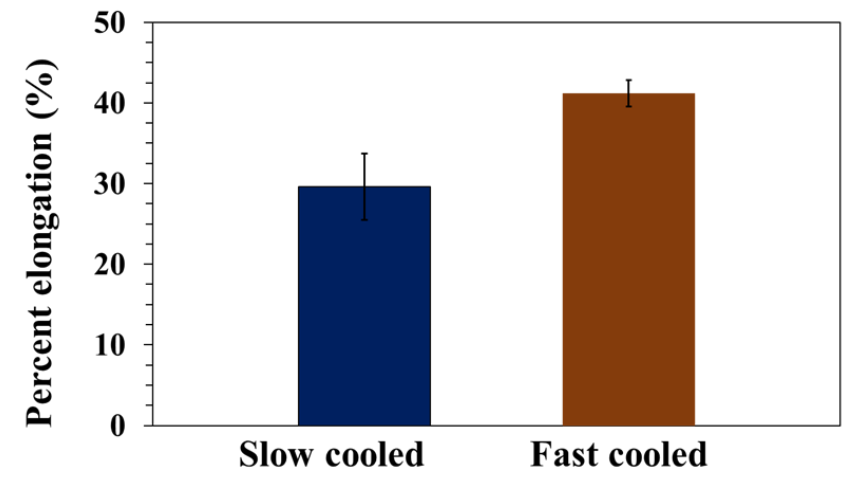

Figure 3.18: Percentage elongation of the post-processed FFF 3D cast parts of Sn60Bi40 at slow and fast rates of cooling

Percentage elongation of the post-processed FFF 3D cast parts of Sn60Bi40 at slow and fast rates of cooling accounts to a value of $29.62 \pm 4.11 \%$ and $41.17 \pm 1.64 \%$ respectively. Fast cooled specimens clearly exhibit higher percentage elongation, with an increase of $17.61 \%$ as compared to the estimated value (see Table 3.2), and hence higher ductility.

Figure 3.19 shows yield strength of the post-processed FFF 3D cast parts of Sn60Bi40 at slow and fast rates of cooling 


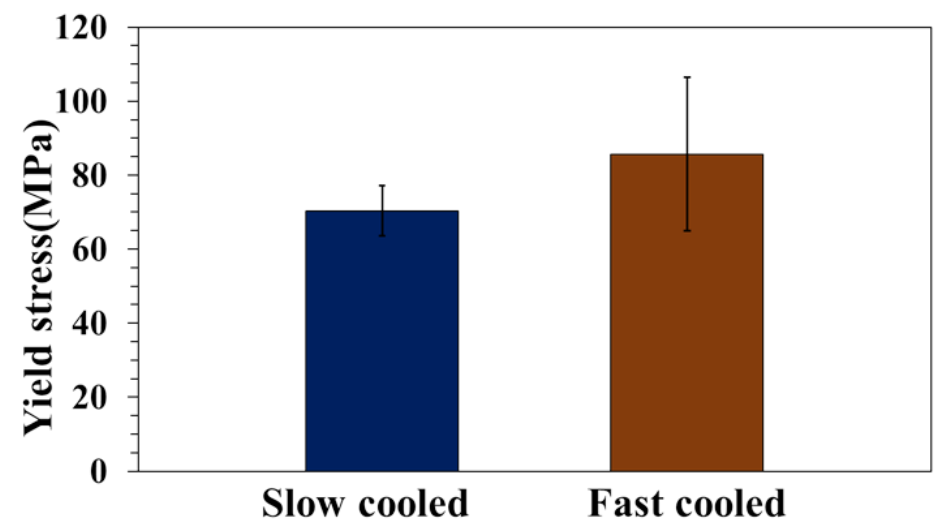

Figure 3.19: Strengths of the post-processed FFF 3D cast parts of Sn60Bi40 at slow and fast rates of cooling

The yield stress of the FFF 3D cast samples was calculated using the $0.2 \%$ offset method [61].The average and standard deviations were taken for those calculations which accounts to a value of $70.37 \pm 6.70 \mathrm{MPa}$ and $87.68 \pm 20.46 \mathrm{MPa}$ for Sn60Bi40 for the slow cooled fast cooled respectively. Fast cooled samples exhibit higher yield strength.

The optical microscopy images of post-processed FFF 3D cast parts of Sn60Bi40 at slow and fast rates of cooling is shown in Figure 3.20
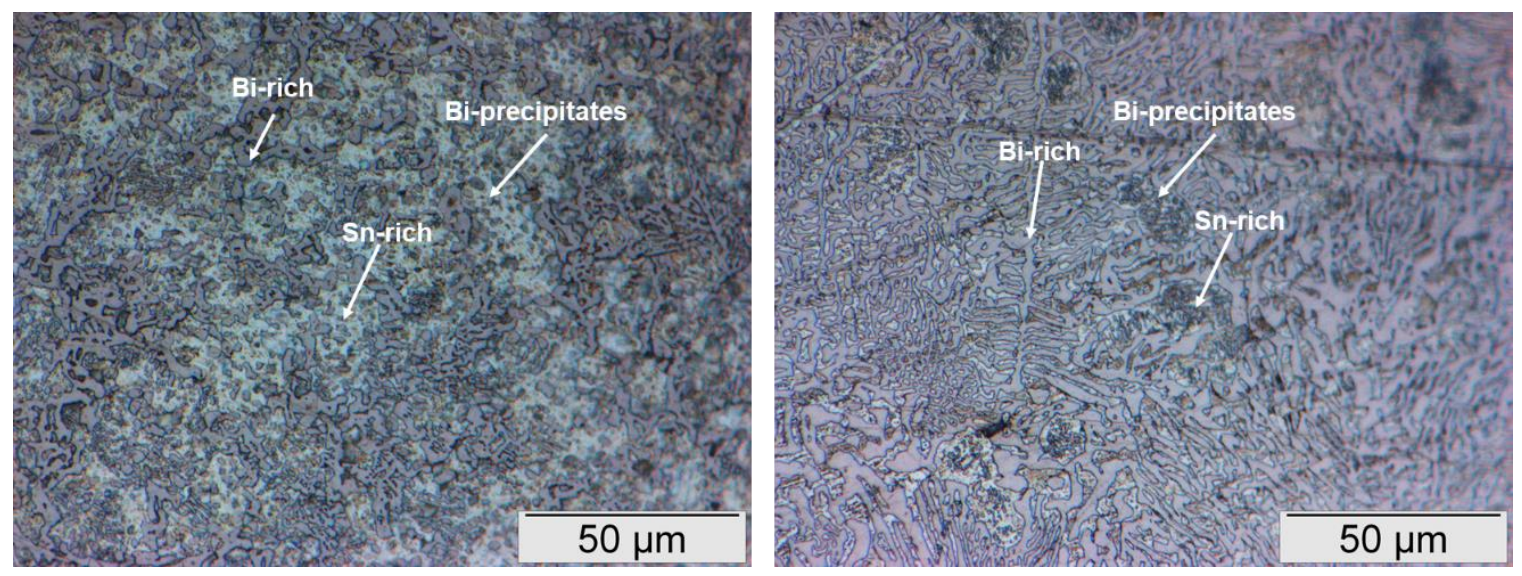

Figure 3.20: (a) Optical microscopy image of the slow cooled non-eutectic Sn60Bi40 material (b) Optical microscopy image of the fast cooled non-eutectic Sn60Bi40 material 
Figure 3.20 shows that the microstructure of the slowly cooled specimen is comparable with that of the literature and consists of a continuous network of bismuth in the form of a lamellar structure surrounded by tin-rich phase containing Bi precipitates.

For most metallic materials [27], the yield strength is related to the grain size through the Hall-Petch relationship expressed by the equation,

$$
\sigma_{y}=\sigma_{0}+\frac{k_{y}}{\sqrt{d}}
$$

Where $\sigma_{y}$ is the yield strength, $\sigma_{0}$ is a materials constant for the resistance of the lattice to dislocation movement, $k_{y}$ is the strengthening coefficient and $d$ is the grain diameter .

So, by changing the grain size, one can influence dislocation movement and yield strength. Grain size reduction is also a means to increase the toughness of a metal. For example, heat treatment after plastic deformation and changing the rate of solidification are ways to alter grain size.

As the rate of cooling is increased, the microstructure forms closed colonies with finer grain structures and closer grain boundaries as shown in Figure 3.20 (b). This leads to ductility enhancement and explains the higher values of percentage elongation of the fast cooled specimens as compared to the slow cooled specimens as shown in Figure 3.20 (a) [69]. 


\subsection{Applications}

The capability of fabricating metals using an FFF 3D printing paves the way for the fabrication of prototypes for applications in fields such as automobile, aerospace, healthcare, and consumer. The International Space Station houses a 3D printer, however, it is limited to fabricating parts only in thermoplastic material, and not in metals [70].Using the FFF 3D printing methodology, prototype of a mechanical spanner was 3D printed in Sn60Bi40 alloy. Figure 3.21 (a) shows the prototype of mechanical spanner 3D printed using FFF 3D printing technology. Using the FFF 3D casting methodology, a customized souvenir of UofL (University of Louisville) logo was fabricated. Figure 3.21 (b) shows the customized UofL souvenir fabricated using the FFF 3D casting methodology.

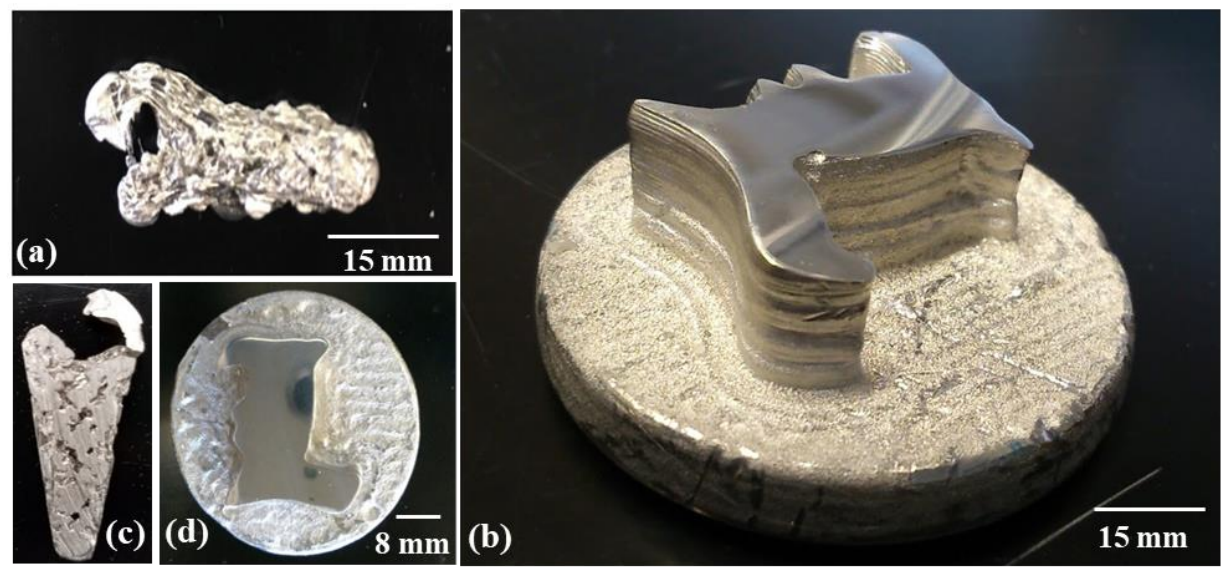

Figure 3.21: Metal prototypes fabricated using an FFF 3D printer. (a), (c) Mechanical wrench fabricated using FFF 3D printing methodology (b), (d)Customized UofL (University of Louisville) souvenir logo fabricated using FFF 3D casting methodology

FFF casting exhibits higher dimensional accuracy, 100\% relative density and 99.4\% UTS for the eutectic Sn-Bi material and can thus be used to cast a similar wrench design or any other tooling equipment in space application for on-demand and custom 3D printing. Other 
possibilities include the fabrication of customizable single-use disposable surgical instruments in healthcare, which can be customized according to the patient's physique, and rapid production of customized jewelry.

\subsection{Conclusion}

The research showcases the feasibility of fabricating low melting metals using the FFF 3D printing technology. The coupled effect of reducing the extrusion velocity and increasing the feed rate resulted in successful fabrication of the Sn60Bi40 alloy using FFF 3D Printing methodology. For the FFF 3D cast technology, material properties such as the pouring temperature and the cooling rate determine the dimensional tolerances and the quality of the part 3D printed. FFF casting methodology exhibits comparable dimensional accuracies relative densities and mechanical properties. Fast cooled specimens exhibit enhanced densities and mechanical properties in comparison to the slow-cooled specimens. This work paves the potentiality of FFF in the rapid production of affordable metal prototypes and fully functional parts in industries, and on-demand 3D printing of metals in space. 


\section{CHAPTER 4}

\section{CONCLUSIONS AND FUTURE WORK}

Eutectic low melting alloys of bismuth and non-eutectic low melting alloys of bismuth and antimony are suitable for FFF metal 3D printing using FFF 3D printing and FFF casting, methodology. The coupled effect of reducing the extrusion velocity and increasing the feed rate resulted in successful fabrication of the Sn60Bi40 alloy using FFF 3D Printing methodology. FFF casting methodology provides comparable dimensional accuracies, relative densities and mechanical properties. Fast cooled specimens exhibit higher dimensional accuracies, relative densities and mechanical strength as compared to the slow cooled specimens.

Future work will focus on optimizing the process parameters of the FFF 3D printing approach for improving the geometric tolerances and densities of the fabricated part to improve the mechanical properties of the product. The setup will be placed in a controlled atmosphere to reduce the possibility of oxidation and contamination during the fabrication process. Characterization will be performed on the FFF 3D printed specimens to study the internal cracks within the specimen. Furthermore, the feasibility of fabricating eutectic alloys using FFF 3Dprinter will be investigated.

FFF 3D Casting will be performed using an SLA 3D printer to obtain finer resolution of the cast parts. The effect of cooling at higher mold temperatures will be analyzed. Slow 
cooling of the casting at a mold temperature of $120^{\circ} \mathrm{C}$ has already been analyzed (See Appendix L), fast cooling for the same will be performed. 


\section{REFERENCES}

1. Ding, D., et al., Wire-feed additive manufacturing of metal components: technologies, developments and future interests. The International Journal of Advanced Manufacturing Technology, 2015. 81(1-4): p. 465-481.

2. Hsieh, P., et al. 3D printing of low melting temperature alloys by fused deposition modeling. in Industrial Technology (ICIT), 2016 IEEE International Conference on. 2016. IEEE.

3. Mireles, J., et al. Fused deposition modeling of metals. in Proceedings of the Solid Freeform Fabrication Symposium, Austin, TX, USA. 2012.

4. Anzalone, G.C., et al., A low-cost open-source metal 3-D printer. IEEE Access, 2013. 1: p. 803-810.

5. Panchagnula, J.S. and S. Simhambhatla. Additive Manufacturing of Complex Shapes Through Weld-Deposition and Feature Based Slicing. in ASME 2015 International Mechanical Engineering Congress and Exposition. 2015. American Society of Mechanical Engineers.

6. Zhang, Y., et al., Weld deposition-based rapid prototyping: a preliminary study. Journal of Materials Processing Technology, 2003. 135(2): p. 347-357.

7. Weiss, L.E., et al., Shape deposition manufacturing of heterogeneous structures. Journal of Manufacturing Systems, 1997. 16(4): p. 239-248. 
8. Das, S., D.L. Bourell, and S. Babu, Metallic materials for 3D printing. MRS Bulletin, 2016. 41(10): p. 729-741.

9. Heralić, A., A.-K. Christiansson, and B. Lennartson, Height control of laser metal-wire deposition based on iterative learning control and 3D scanning. Optics and lasers in engineering, 2012. 50(9): p. 1230-1241.

10. Taminger, K. and R.A. Hafley, Electron beam freeform fabrication: a rapid metal deposition process. 2003.

11. Taminger, K.M. and R.A. Hafley, Electron beam freeform fabrication for cost effective near-net shape manufacturing. 2006.

12. Groover, M.P., Fundamentals of modern manufacturing: materials processes, and systems. 2007: John Wiley \& Sons.

13. manufacturing, T.1.o., Basics of casting.

14. companies, M.f.g., OPen molding process.

15. Snelling, D., et al. The effects of 3D printed molds on metal castings. in International solid freeform fabrication symposium. 2013.

16. Bak, D., Rapid prototyping or rapid production? 3D printing processes move industry towards the latter. Assembly Automation, 2003. 23(4): p. 340-345.

17. Lim, K.W., Using Ultimaker 3D printers for manufacturing at Siemens. 2015.

18. Smeekes, I., Jewelers use 3D printing to prototype custom rings. 2015.

19. Wee, A.G., R.L. Schneider, and S.A. Aquilino, Use of low fusing alloy in dentistry. The Journal of prosthetic dentistry, 1998. 80(5): p. 540-545.

20. Autocart, Car keychain in chrome-plated zinc alloy versus polished aluminum alloy 2014 . 
21. Belmont, Safe sparklers: Using lead-free pewter alloys for making jewelry helps alleviate health concerns. 2016.

22. Composition and Physical Properties of Alloys. August 18, 2007

23. 5NPLUS, Product data sheet MCP 137/Metspec 281 Alloy. 2012.

24. 5NPLUS, Product Data Sheet MCP 150/ Metspec 281/338 Alloy. 2012.

25. Belmont, Material Data Sheet 7881 Genuine Babbitt.

26. Bolotoff, P., Solder Alloys: Physical and Mechanical Properties. Alasir Enterprises, 2010.

27. Briggs, E. Advantages of bismuth-based alloys for low temperature $\mathrm{Pb}$-free soldering and rework. in International conference on soldering \& reliability, surface mount technology association (SMTA), Toronto. 2011.

28. catalog, E.m.o., Indium/Specialty Alloys.

29. corp, I., Product data sheet, Eutectic gold tin solder. 2015.

30. corporation, I., Bismuth Solders.

31. Cverna, F., ASM ready reference: thermal properties of metals. 2002: ASM International.

32. Inc, K.a.a.w., Kapp Cadmium-Zinc Multipurpose Solders.

33. Lee, N.-C., Getting ready for lead-free solders. Soldering \& Surface Mount Technology, 1997. 9(2): p. 65-69.

34. Materia, T., The world's most comprehensive materials database.

35. Meilunas, M., A. Primavera, and S.O. Dunford. Reliability and failure analysis of lead-free solder joints. in Proceedings, IPC Conference. 2002.

36. metals, B., Low Melting (Fusible) Alloys. 
37. Sheet, P.D., Solder Wire. Indium Corporation of America, Utica, NY, 1997.

38. Siewert, T., et al., Properties of lead-free solders. Database for solder properties with emphasis on new lead-free solders, Release, 2002. 4.

39. Siewert, T., et al., Database for solder properties with emphasis on new lead-free solders. NIST \& Colorado School of Mines, Release, 2002. 4: p. 1-77.

40. Smithells, C.J., Metals reference book. Vol. 1. 1967: Butterworth.

41. Thompson, J., Properties of Lead-Bismuth, Lead-Tin, Type Metal and Fusible Alloys. 1930: Department od Commerce.

42. Solder Alloys. Total meteria, 2009(Oct).

43. Inc., B.M., Data sheet.

44. http://www.totalmateria.com, Solder Alloys. Total Materia, 2009.

45. Smith, D.R., et al., Database for Solder Properties With Emphasis on New LeadFree Solders. Electronic Publication, 2002.

46. metals, B., Casting alloys for rubber molds.

47. metals, B., Babbit metals- Genuine Babbitt alloy. 2012.

48. corporation, I., Solder alloy directory.

49. Wilson, J., Thermal conductivity of solders. 2006.

50. Metals, B., Babbitt metals data sheet. (L1015B).

51. metals, E., Indium/speciality alloys. online catalog.

52. Wong, K.V. and A. Hernandez, A review of additive manufacturing. ISRN Mechanical Engineering, 2012. 2012.

53. Gibson, I., D. Rosen, and B. Stucker, Additive manufacturing technologies: 3D printing, rapid prototyping, and direct digital manufacturing. 2014: Springer. 
54. Mireles, J., et al., Development of a fused deposition modeling system for low melting temperature metal alloys. Journal of Electronic Packaging, 2013. 135(1): p. 011008.

55. PLUS, N. Product Data Sheet MCP/137. 2012-07; Available from: http://www.5nplus.com/files/10/Alloy\%20137\%20Tech\%20Data\%20Sheet_2016 $-07-22-15-34 . p d f$.

56. 5NPLUS, Product Data Sheet MCP/150. 2012.

57. Belmont, Product Data Sheet Genuine Babbit.

58. Bauccio, M., ASM metals reference book. 1993: ASM international.

59. solder, D., Technical datasheet-Sn42/Bi58 SOLID SOLDER WIRE. (C).

60. Belmont, Casting alloys for rubber molds. (RM-1097).

61. Beer, F.P., et al., Mechanics of Materials, McGraw-Hill. 2006, Boston.

62. Mei, Z. and J.W. Morris, Characterization of eutectic Sn-Bi solder joints. Journal of Electronic Materials, 1992. 21(6): p. 599-607.

63. Liu, P., et al., Relationship between tensile strength and porosity for high porosity metals. Science in China Series E: Technological Sciences, 1999. 42(1): p. 100107.

64. Shen, L., et al., Creep behavior of Sn-Bi solder alloys at elevated temperatures studied by nanoindentation. Journal of Materials Science: Materials in Electronics, 2017. 28(5): p. 4114-4124.

65. Lai, Z. and D. Ye, Microstructure and fracture behavior of non eutectic Sn-Bi solder alloys. Journal of Materials Science: Materials in Electronics, 2016. 27(4): p. $3182-3192$. 
66. Spinelli, J., Microstructural development and mechanical properties of a neareutectic directionally solidified Sn-Bi solder alloy. Materials Characterization, 2015. 107: p. 43-53.

67. Leszczynska-Madej, B. and M. Madej, Effect of the heat treatment on the microstructure and properties of tin babbitt. KOVOVE MATERIALYMETALLIC MATERIALS, 2013. 51(2): p. 101-110.

68. Korobov, Y.S., et al., Effect of production methods on tribological characteristics of babbitt coatings. Journal of Friction and Wear, 2012. 33(3): p. 190-194.

69. Morris, J.W., J.L.F. Goldstein, and Z. Mei, Microstructure and mechanical properties of Sn-In and Sn-Bi solders. JOM, 1993. 45(7): p. 25-27.

70. Space Station 3-D Printer Builds Ratchet Wrench To Complete First Phase Of Operations. 2014. 
APPENDICES 
APPENDIX A

\section{PHASE DIAGRAMS}

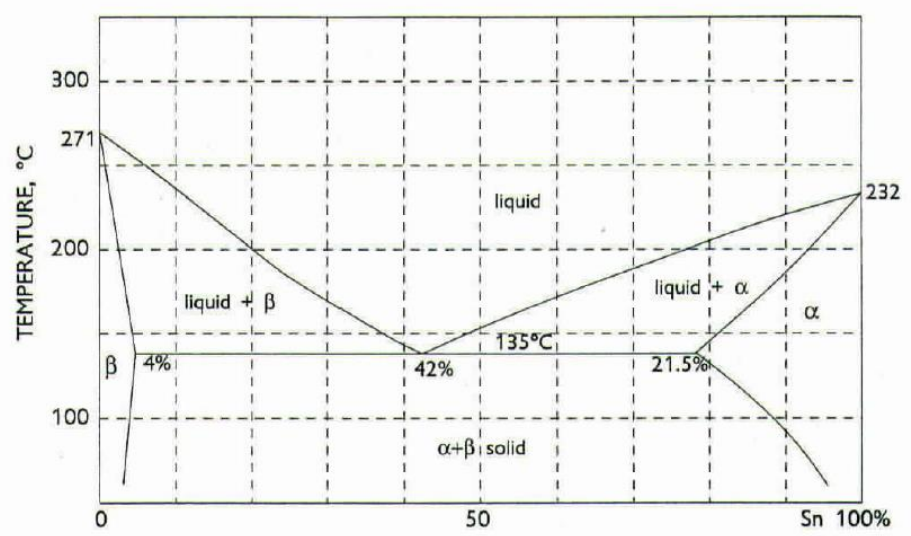

Figure A.1: Binary phase diagram of Sn60Bi40

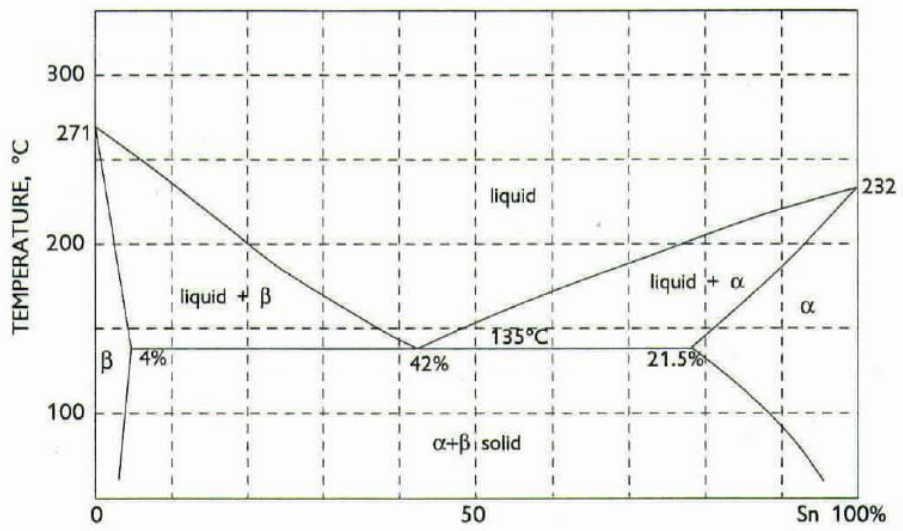

Figure A.2: Binary phase diagram of $\mathrm{Sn} 42 \mathrm{Bi} 58$ 

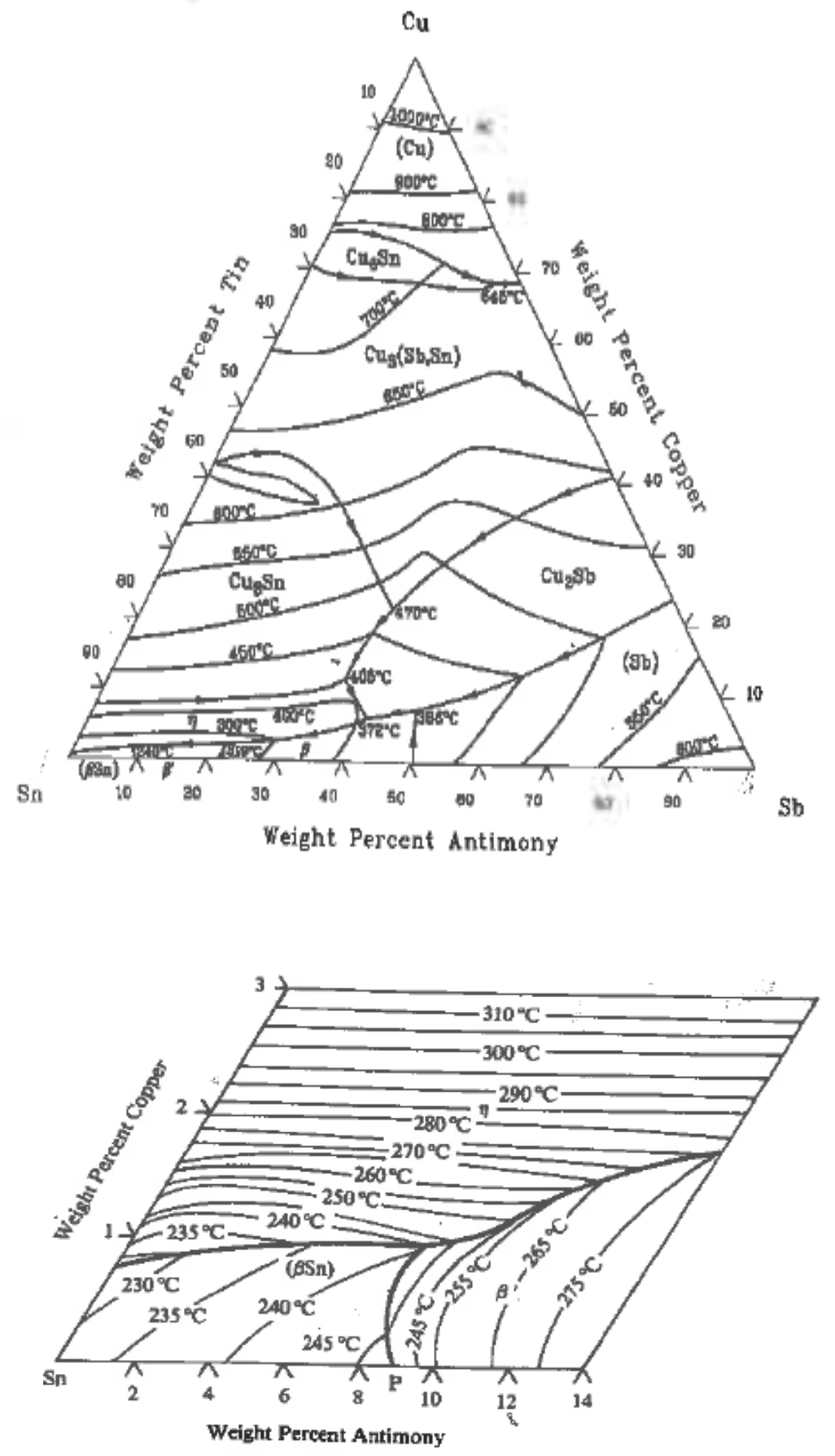

Figure A.3: Ternary phase diagram and Liquids projection of $\mathrm{Cu}-\mathrm{Sb}-\mathrm{Sn}$ 


\section{APPENDIX B}

\section{EXPERIMENT TO ESTIMATE MELTING BEHAVIOUR}

Purpose: To determine the melting ranges and melting behavior of Sn60Bi40 alloy experimentally. This range can be used as the starting temperature for FFF extrusion.

Procedure: The theoretical melting range of the Sn60Bi40 alloy was derived from the phase diagram (see Figure A.4) and used as the temperature input data for the experiment. The Sn60Bi40 alloy wire was cut into eight specimens of approximately $1 \mathrm{gm}$ each and placed in aluminum pans. This setup was placed onto the hotplate, and heated, starting from the onset melting temperature of $135^{\circ} \mathrm{C}$ to $170^{\circ} \mathrm{C}$, with an interval of $5^{\circ} \mathrm{C}$. A thermometer was used to cross-check the temperature at the bottom surface of the aluminum pan. The physical changes to the alloy at the specified temperatures were observed and the time taken was recorded. Table 16 shows the experimental data showing the stages of melting. 
Table A.1: Experimental data showing the stages of melting for 8 samples

\begin{tabular}{|c|c|c|c|c|c|}
\hline Weight of & Tempe & rature $\left({ }^{\circ} \mathrm{C}\right)$ & & Telting Stages- T & e taken $(\mathrm{s})$ \\
\hline sample(g) & Hotplate & Thermometer & Warping & Softening time & Complete melting \\
\hline 0.9913 & 155 & 135 & $1: 50$ & $2: 15$ & $3: 10$ \\
\hline 1.0066 & 163 & 140 & $1: 31$ & $1: 58$ & $3: 03$ \\
\hline 0.9912 & 169 & 145 & 35 & $1: 08$ & $1: 30$ \\
\hline 1.0016 & 171 & 150 & 27 & 49 & $1: 28$ \\
\hline 0.9946 & 174 & 155 & 18 & 38 & $1: 16$ \\
\hline 0.9982 & 176 & 160 & 20 & 32 & 54 \\
\hline 1.0012 & 180 & 165 & 14 & 20 & 33 \\
\hline 0.9986 & 184 & 170 & 8 & 16 & 31 \\
\hline
\end{tabular}

The process of melting was visible in specified steps as As the temperature progressed, the process of melting was noticed to occur in certain specified steps as observed by the naked eye. The first step was warping, followed by softening of the metal, followed by complete melting.

At lower temperatures the metal took considerable amount of time to warp. Even though the metal melted completely, it was still considerably viscous. As the temperature rose to 
higher levels, it took lesser time for the alloy to warp and soften. Complete melting with lesser viscosity started occurring at temperature ranges of $155^{\circ} \mathrm{C}$.

Instantaneous melting was observed when the temperatures raised to $160^{\circ} \mathrm{C} .165^{\circ} \mathrm{C}$ and $170^{\circ} \mathrm{C}$ all showed considerably short times to melt completely. For $170^{\circ} \mathrm{C}$, the warping and softening were instantaneous. Figure A.4 shows the samples of the molten alloys.

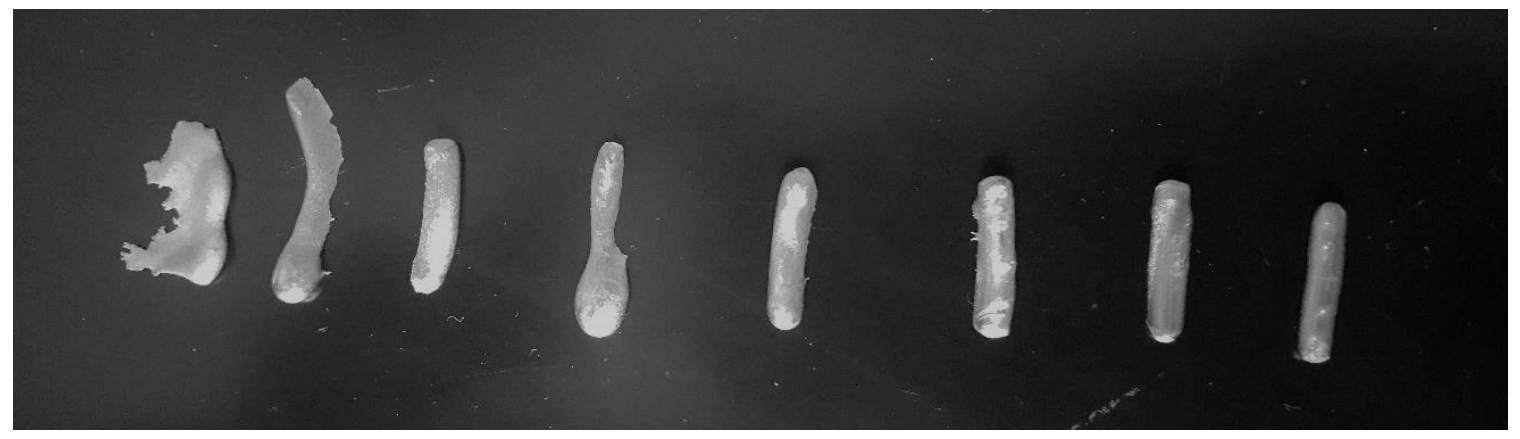

Figure A.4: Samples of the melted alloys over the temperature range of $135^{\circ} \mathrm{C}$ (left-most) to $170^{\circ} \mathrm{C}$ (right-most) at increments of $5^{\circ} \mathrm{C}$.

In conclusion, since FFF is a layer by layer process, the extrusion should be consistent and continuous. It wouldn't be desirable to set the hot end to the lower ranges of temperature $\left(135^{\circ} \mathrm{C}\right.$ to $\left.150^{\circ} \mathrm{C}\right)$ as it takes considerable amount of time to melt. $160^{\circ} \mathrm{C}$ and $165^{\circ} \mathrm{C}$ seems to provide a continuous extrusion. However, $155^{\circ} \mathrm{C}$ would be a good temperature range to start with, since it was the onset of faster warping. When the metal is surrounded by a temperature of $155^{\circ} \mathrm{C}$, it is expected to show better properties. Extrusion at $170^{\circ} \mathrm{C}$ is not desirable as the extrusion can turn out to be less viscous and flowy. This could lead to difficulty in controlling the flow. the process of melting occurred in specified steps. 


\section{APPENDIX C}

\section{DIFFERENTIAL SCANNING CALORIMETRY (DSC) ANALYSIS ON SN60BI40}

Purpose: To find the melting temperature range and to find the energy required to melt 1 gm of Bi-Sn alloy

Apparatus used: DSC analysis machine Q600

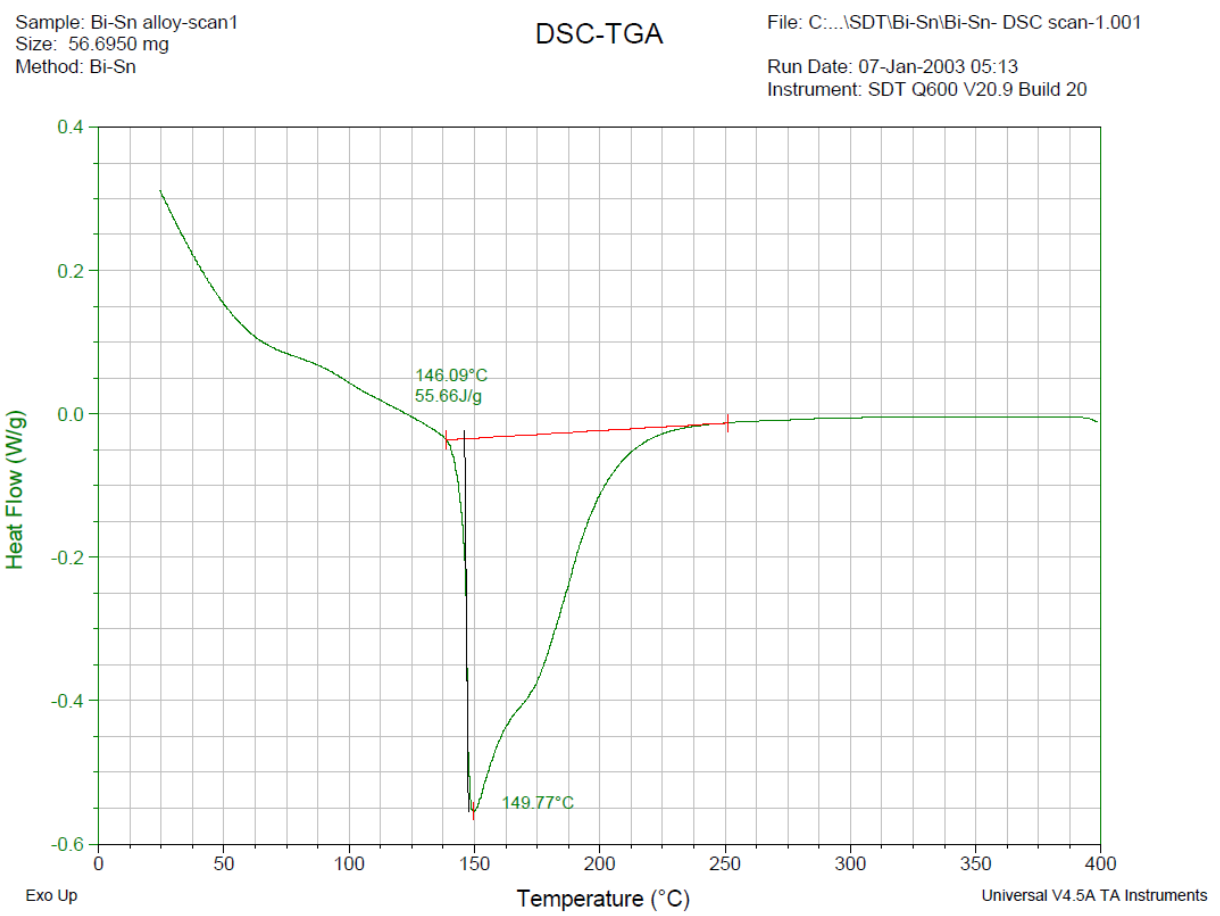

Figure A.5: DSC results for $\mathrm{Sn60Bi40}$ 


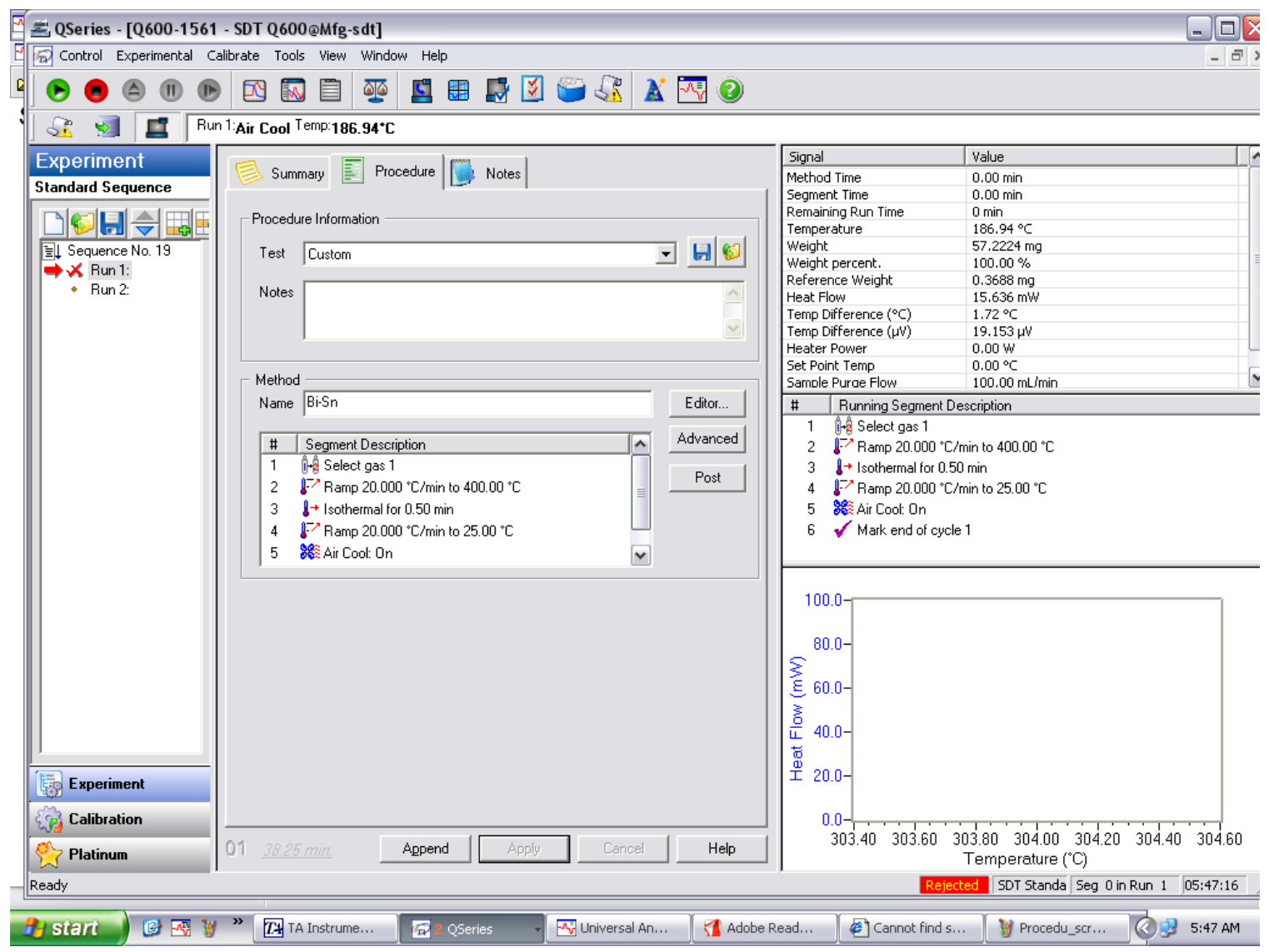

Figure A.6: Screenshot of the procedure followed for DSC analysis 


\section{APPENDIX D}

MAGNIFIED IMAGES OF THE 3D PRINTED WRENCH
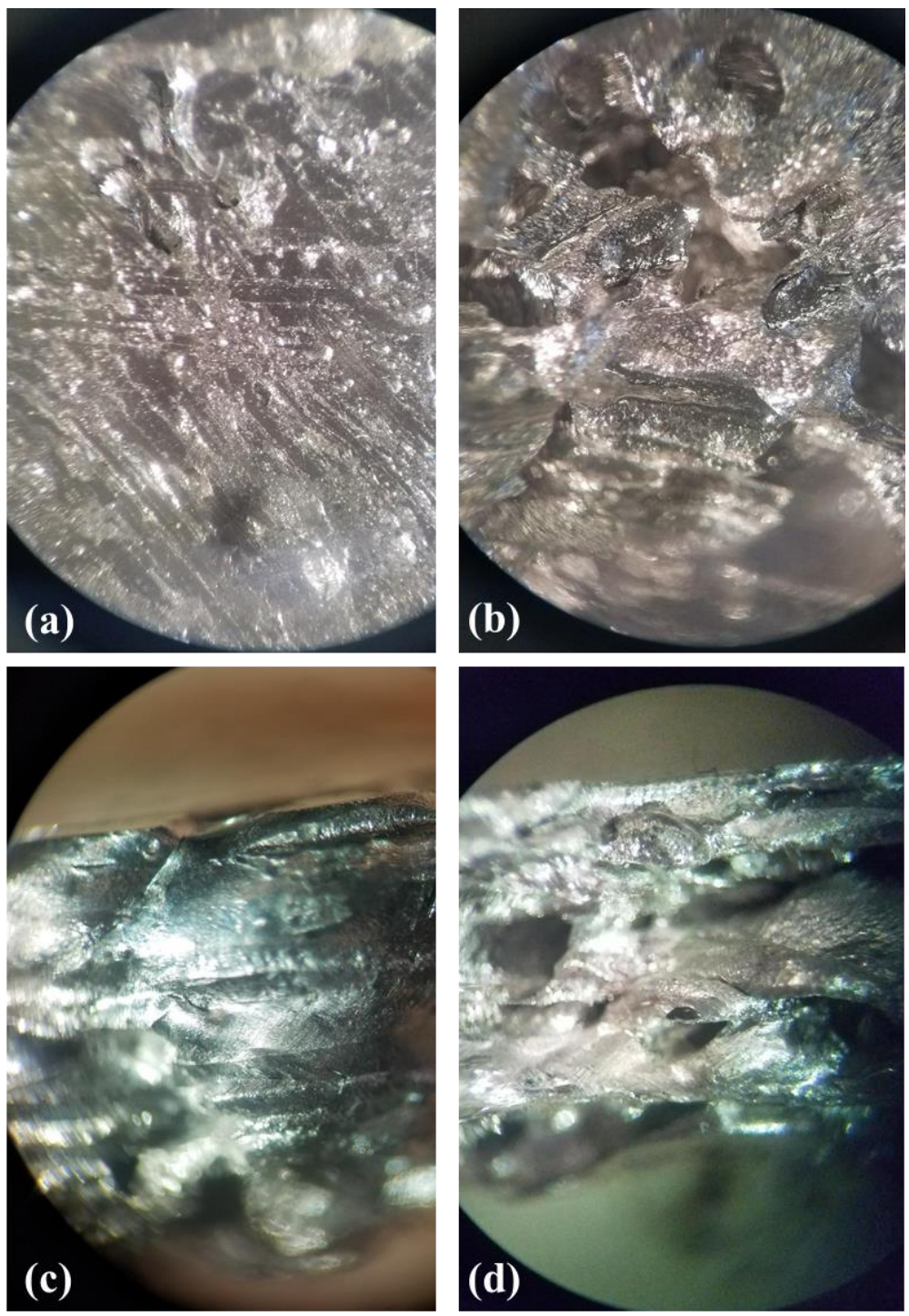

Figure A.7: (a) Bottom surface (b) Top surface (c) Side profile (d) Rear end 


\section{APPENDIX E}

COMPARISON OF DIMENSIONAL TOLERNACES - FFF 3D PRINTED AND FFF 3D

\section{CAST PARTS}

Figure A.8 shows the SolidWorks design of the tensile mold and the tensile specimens fabricated using FFF 3D printing and FFF casting methodologies.
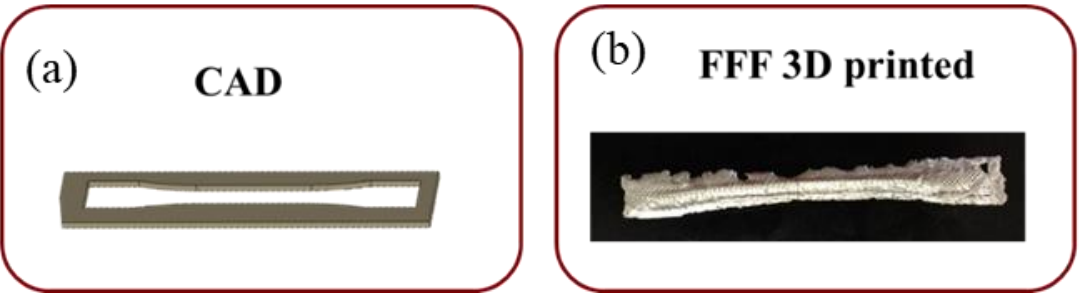

\section{(c) FFF 3D cast}

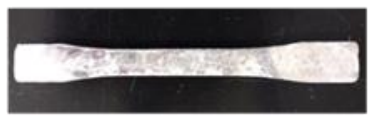

Figure A.8: (a) SolidWorks design of the tensile mold (b) FFF 3D Printed tensile specimen (c) FFF 3D Cast tensile specimen

Table A.2 shows the dimensional comparison of the SolidWorks design of the tensile mold and the tensile specimens fabricated using FFF 3D printing and FFF casting methodologies.

Table A.2:Dimensional comparison of the SolidWorks design of the tensile mold and the tensile specimens fabricated using FFF 3D printing and FFF casting methodologies.

\begin{tabular}{|c|c|c|c|}
\hline & Design & FFF 3D printed & FFF 3D cast \\
\hline Length (mm) & 150 & $149 \pm 0.33$ & $149 \pm 0.17$ \\
\hline Width (mm) & 12 & $12 \pm 0.18$ & $12 \pm 0.51$ \\
\hline Thicnkess (mm) & 3 & $3 \pm 0.21$ & $4 \pm 0.20$ \\
\hline
\end{tabular}


Figure A.9 shows the SolidWorks design of the mechanical wrench and the wrench fabricated using FFF 3D printing and FFF casting methodologies.
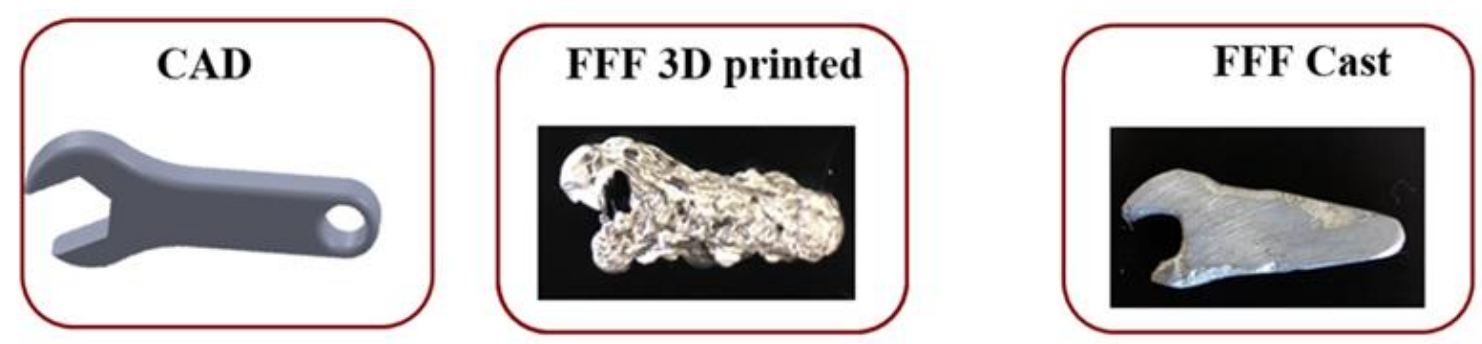

Figure A.9: (a) SolidWorks design of the mechanical wrench(b) FFF 3D Printed wrench prototype (c) FFF 3D Cast wrench prototype

Table A.3 shows the dimensional comparison of the SolidWorks design of the mechanical wrench and the wrench fabricated using FFF 3D printing and FFF casting methodologies

Table A.3: Dimensional comparison of the SolidWorks design of the mechanical wrench and the wrench fabricated using FFF 3D printing and FFF casting methodologies

\begin{tabular}{|c|c|c|c|}
\hline & Design & FFF 3D printed & FFF 3D cast \\
\hline Length (mm) & 40 & $40 \pm 0.47$ & $39 \pm 0.33$ \\
\hline Width (mm) & 9 & $10 \pm 0.82$ & $9 \pm 0.51$ \\
\hline Thicnkess (mm) & 5 & $6 \pm 0.63$ & $5 \pm 0.17$ \\
\hline
\end{tabular}




\section{APPENDIX F}

\section{STRESS-STRAIN CURVES}

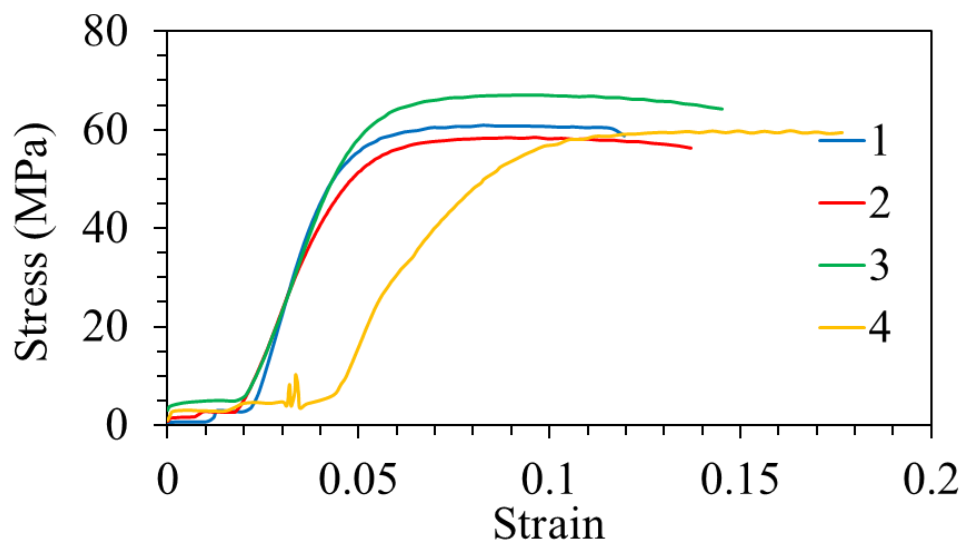

Figure A.10:Stress-strain curve of 4 specimens of Sn60Bi40 using FFF cast methodology

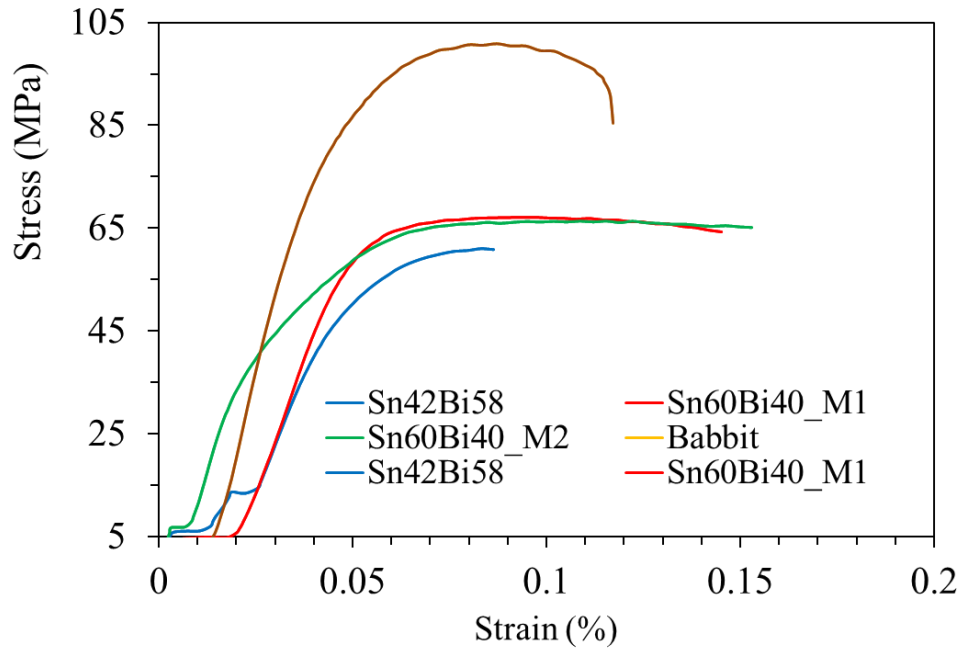

Figure A.11: Stress-strain curve of both the Sn60Bi40, Sn42Bi58 and Babbitt 
APPENDIX G

COMPARISON OF ULTIMATE TENSILE STRENGTH - FFF 3D PRINTING AND FFF 3D CASTING TECHNOLOGIES

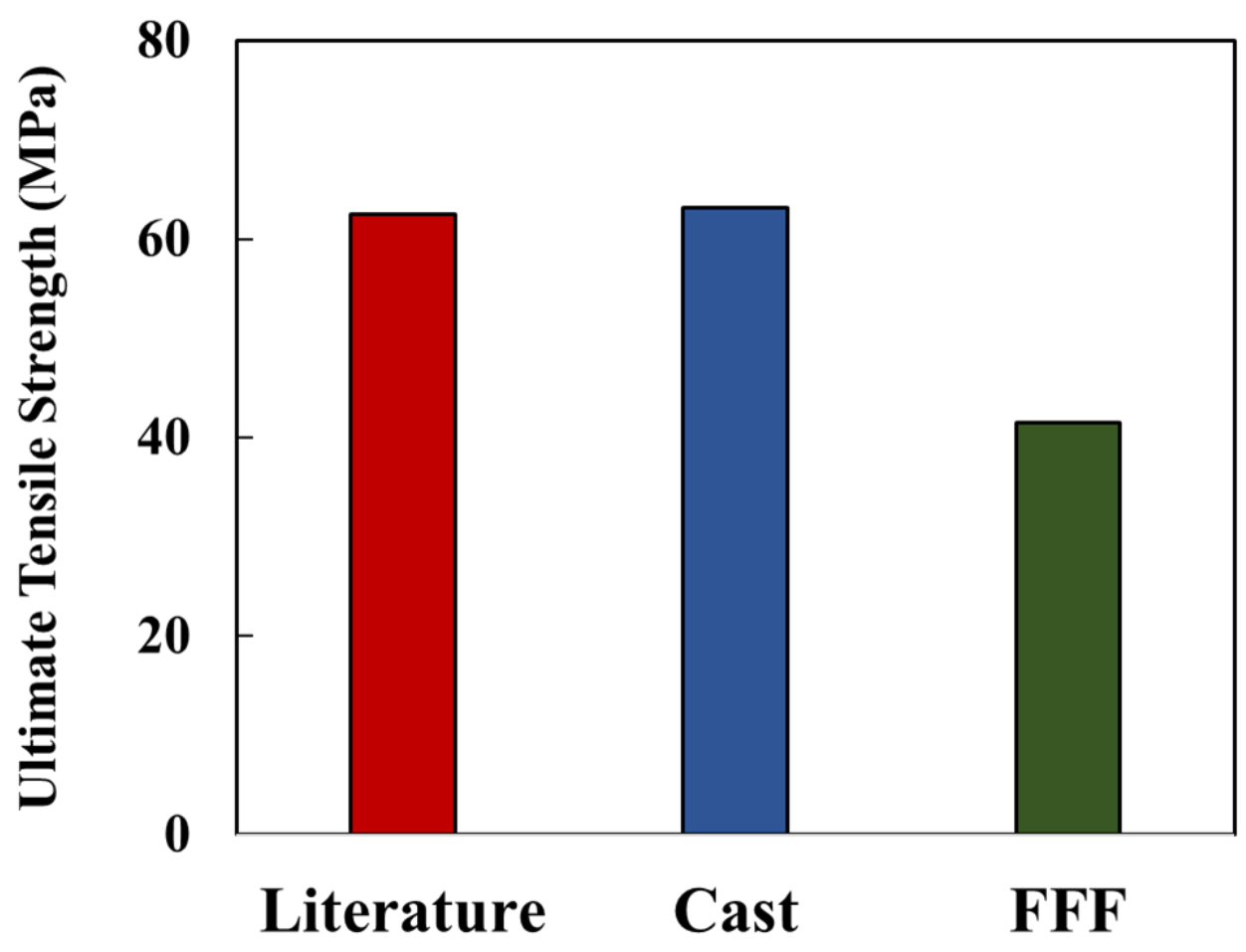

Figure A.12: Comparison of ultimate tensile strength(UTS) of specimens fabricated using FFF 3D printing and FFF 3D casting methodologies, with respect to the literature value. 


\section{APPENDIX H}

\section{CALCULATIONS - PHYSICAL PROPERTIES}

The density and volume of the sampled were calculated using the following set of

formulae:

$$
\begin{aligned}
& \text { Density: } \rho=\frac{A}{A-B}\left(\rho_{0}-\rho_{L}\right)+\rho_{L} \\
& \text { Volume: } V=\alpha \frac{A-B}{\rho_{0}-\rho_{L}}
\end{aligned}
$$$$
\rho=\text { Density of sample }
$$$$
A=\text { Weight of sample in air }
$$$$
B=\text { Weight of sample in the auxiliary liquid }
$$$$
\rho_{0}=\text { Density of the auxiliary liquid }
$$$$
\rho_{\mathrm{L}}=\text { Air density }\left(0.0012 \mathrm{~g} / \mathrm{cm}^{3}\right)
$$

$\alpha=$ Balance correction factor (0.99985), takes air buoyancy of the adjustment weight into account.

Table A.4: Density of the auxiliary liquid(water) with respect to temperature.

\begin{tabular}{|c|c|c|c|c|c|c|c|c|c|c|}
\hline T $\boldsymbol{C} \mathbf{C}$ & $\mathbf{0 . 0}$ & $\mathbf{0 . 1}$ & $\mathbf{0 . 2}$ & $\mathbf{0 . 3}$ & $\mathbf{0 . 4}$ & $\mathbf{0 . 5}$ & $\mathbf{0 . 6}$ & $\mathbf{0 . 7}$ & $\mathbf{0 . 8}$ & $\mathbf{0 . 9}$ \\
\hline 10. & 0.99973 & 0.99972 & 0.99971 & 0.99970 & 0.99969 & 0.99968 & 0.99967 & 0.99966 & 0.99965 & 0.99964 \\
\hline 11. & 0.99963 & 0.99962 & 0.99961 & 0.99960 & 0.99959 & 0.99958 & 0.99957 & 0.99956 & 0.99955 & 0.99954 \\
\hline 12. & 0.99953 & 0.99951 & 0.99950 & 0.99949 & 0.99948 & 0.99947 & 0.99946 & 0.99944 & 0.99943 & 0.99942 \\
\hline $\mathbf{1 3 .}$ & 0.99941 & 0.99939 & 0.99938 & 0.99937 & 0.99935 & 0.99934 & 0.99933 & 0.99931 & 0.99930 & 0.99929 \\
\hline $\mathbf{1 4}$. & 0.99927 & 0.99926 & 0.99924 & 0.99923 & 0.99922 & 0.99920 & 0.99919 & 0.99917 & 0.99916 & 0.99914 \\
\hline 15. & 0.99913 & 0.99911 & 0.99910 & 0.99908 & 0.99907 & 0.99905 & 0.99904 & 0.99902 & 0.99900 & 0.99899 \\
\hline 16. & 0.99897 & 0.99896 & 0.99894 & 0.99892 & 0.99891 & 0.99889 & 0.99887 & 0.99885 & 0.99884 & 0.99882 \\
\hline 17. & 0.99880 & 0.99879 & 0.99877 & 0.99875 & 0.99873 & 0.99871 & 0.99870 & 0.99868 & 0.99866 & 0.99864 \\
\hline 18. & 0.99862 & 0.99860 & 0.99859 & 0.99857 & 0.99855 & 0.99853 & 0.99851 & 0.99849 & 0.99847 & 0.99845 \\
\hline 19. & 0.99843 & 0.99841 & 0.99839 & 0.99837 & 0.99835 & 0.99833 & 0.99831 & 0.99829 & 0.99827 & 0.99825 \\
\hline 20. & 0.99823 & 0.99821 & 0.99819 & 0.99817 & 0.99815 & 0.99813 & 0.99811 & 0.99808 & 0.99806 & 0.99804 \\
\hline 21. & 0.99802 & 0.99800 & 0.99798 & 0.99795 & 0.99793 & 0.99791 & 0.99789 & 0.99786 & 0.99784 & 0.99782 \\
\hline 22. & 0.99780 & 0.99777 & 0.99775 & 0.99773 & 0.99771 & 0.99768 & 0.99766 & 0.99764 & 0.99761 & 0.99759 \\
\hline 23. & 0.99756 & 0.99754 & 0.99752 & 0.99749 & 0.99747 & 0.99744 & 0.99742 & 0.99740 & 0.99737 & 0.99735 \\
\hline 24. & 0.99732 & 0.99730 & 0.99727 & 0.99725 & 0.99722 & 0.99720 & 0.99717 & 0.99715 & 0.99712 & 0.99710 \\
\hline 25. & 0.99707 & 0.99704 & 0.99702 & 0.99699 & 0.99697 & 0.99694 & 0.99691 & 0.99689 & 0.99686 & 0.99684 \\
\hline 26. & 0.99681 & 0.99678 & 0.99676 & 0.99673 & 0.99670 & 0.99668 & 0.99665 & 0.99662 & 0.99659 & 0.99657 \\
\hline 27. & 0.99654 & 0.99651 & 0.99648 & 0.99646 & 0.99643 & 0.99640 & 0.99637 & 0.99634 & 0.99632 & 0.99629 \\
\hline 28. & 0.99626 & 0.99623 & 0.99620 & 0.99617 & 0.99614 & 0.99612 & 0.99609 & 0.99606 & 0.99603 & 0.99600 \\
\hline 29. & 0.99597 & 0.99594 & 0.99591 & 0.99588 & 0.99585 & 0.99582 & 0.99579 & 0.99576 & 0.99573 & 0.99570 \\
\hline 30. & 0.99567 & 0.99564 & 0.99561 & 0.99558 & 0.99555 & 0.99552 & 0.99549 & 0.99546 & 0.99543 & 0.99540 \\
\hline
\end{tabular}




\section{APPENDIX I}

AS-CAST PROPERTIES OF THE FFF 3D CAST PARTS FOR SN60BI40, SN42BI58

\section{AND SN89SB7.5 ALLOYS}

The dimensions of the cast specimens were evaluated in-order to evaluate the geometric tolerances of the fabricated part. Table A.5 shows the dimensions and tolerances of the as-cast FFF 3D cast parts for Sn60Bi40, Sn42Bi58 and Sn89Sb7.5 alloys.

Table A.5: Dimensions of the as-cast FFF 3D cast parts for Sn60Bi40, Sn42Bi58 and Sn89Sb7.5 alloys

\begin{tabular}{|c|c|c|c|}
\hline Specimen & Length $(\mathbf{m m})$ & Width $(\mathbf{m m})$ & Thickness $(\mathbf{m m})$ \\
\hline Sn60Bi40 & $70.53 \pm .36$ & $8.47 \pm .25$ & $5.54 \pm .070$ \\
\hline Sn42Bi58 & $70.40 \pm .04$ & $8.20 \pm .12$ & $5.52 \pm .190$ \\
\hline Sn89Sb7.5 & $70.17 \pm .17$ & $8.61 \pm .25$ & $7.05 \pm .190$ \\
\hline
\end{tabular}

Table A.5 shows that the length of the fabricated samples is larger than the true length of $70 \mathrm{~mm}$, with an average dimension of $70.37 \pm .53 \mathrm{~mm}$. The width of the samples was found to vary in ranges of $8.20 \mathrm{~mm}$ to $8.61 \mathrm{~mm}$, with an average width of $8.43 \pm 0.21 \mathrm{~mm}$. The thickness of the samples was found to lie within values of $5.52 \mathrm{~mm}$ to $7.05 \mathrm{~mm}$ with an average thickness of $6.04 \pm 0.15 \mathrm{~mm}$. The greatest variation in dimensions was found to occur in the thickness of the specimen, with a percentage error of $18.79 \%$ which was due 
to the high viscosity of Sn897.5Sb. The least variation in dimension occurred in the length of the specimen, with a percentage difference value of $0.53 \%$. The width measurements had a percentage error value of $5.22 \%$. Table A.6 shows the physical properties of the ascast FFF 3D cast parts for Sn60Bi40, Sn42Bi58 and Sn89Sb7.5 alloys.

Table A.6: Physical properties of the as-cast FFF 3D cast parts for Sn60Bi40, Sn42Bi58 and $\mathrm{Sn} 89 \mathrm{Sb} 7.5$ alloys

\begin{tabular}{|c|c|c|c|}
\hline Specimen & Mass $(\mathrm{g})$ & Volume $(\mathbf{c c})$ & Density $(\mathrm{g} / \mathrm{cc})$ \\
\hline Sn60Bi40 & $31.62 \pm 0.692$ & $3.904 \pm 0.083$ & $8.09 \pm 0.003$ \\
\hline Sn42Bi58 & $33.51 \pm 2.501$ & $3.961 \pm 0.289$ & $8.54 \pm 0.027$ \\
\hline Sn89Sb7.5 & $38.55 \pm 2.81$ & $5.35 \pm 0.412$ & $7.18 \pm 0.270$ \\
& & & \\
\hline
\end{tabular}

Table A.6 shows that the volume of the fabricated specimens is greater than the expected volume derived from the Solid works, $3.762 \mathrm{~g} / \mathrm{cc}$, by a percentage of $14.57 \%$. The greatest percent error in volume were for the parts fabricated in $\mathrm{Sn} 89 \mathrm{Sb} 7.5 \mathrm{Sb}$, with a percentage error of $34.85 \%$. This can be attributed to the high viscosity, or in other terms, less fluidity of the material at the recommended pouring temperature. The parts fabricated in Sn-Bi exhibited lower percentage differences of $3.70 \%$ for the Sn60Bi40 material and $3.96 \%$ 
for the Sn42Bi58 material. Consequently, mass of the fabricated specimens was found to greatly vary for the $\mathrm{Sn} 89 \mathrm{Sb} 7.5 \mathrm{Sb}$ material with a percentage error value of $32.53 \%$. The parts fabricated in Sn-Bi had minimal percentage errors of mass with $3.45 \%$ for the Sn60Bi40 material and $3.74 \%$ for the Sn42Bi58 material. The densities of the fabricated specimens are in close correlation with the true density values of the materials and accounted to relative densities of $99.63 \%$ for Sn60Bi40, $99.53 \%$ for the Sn42Bi58 and $97.29 \%$ for the $\mathrm{Sn} 89 \mathrm{Sb} 7.5 \mathrm{Sb}$ alloys A representative graph of the relative density of the as-cast FFF 3D cast parts for Sn60Bi40, Sn42Bi58 and $\mathrm{Sn} 89 \mathrm{Sb} 7.5$ alloys is shown in Figure A.13

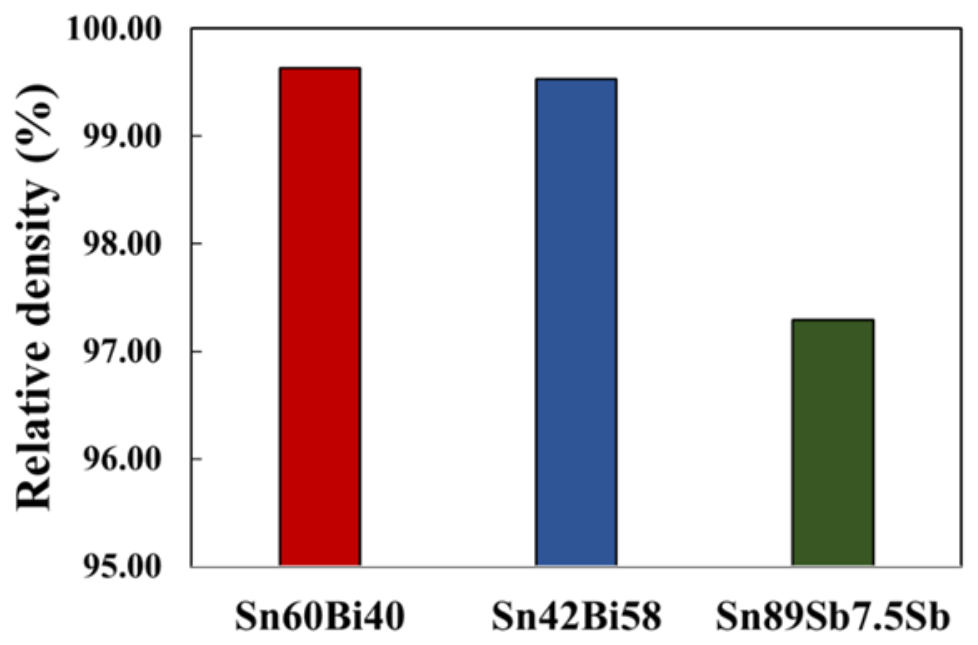

Figure A.13: Relative densities of the as-cast FFF 3D cast parts for Sn60Bi40, Sn42Bi58 and $\mathrm{Sn} 89 \mathrm{Sb} 7.5$ alloys

The densities of the fabricated specimens are in close correlation with the true density values of the materials and accounted to relative densities of $99.63 \%$ for Sn60Bi40, $99.53 \%$ for the Sn42Bi58 and $97.29 \%$ for the Sn897.5Bi alloy. 


\section{APPENDIX J}

\section{AS-CAST PROPERTIES OF THE FFF 3D CAST PARTS OF SN60BI40 AT SLOW}

\section{AND FAST RATES OF COOLING}

The dimensions of the cast specimens were evaluated in-order to evaluate the geometric tolerances of the fabricated part. Table A.7 shows the dimensions and tolerances of the ascast FFF 3D cast parts of Sn60Bi40 at slow and fast rates of cooling.

Table A.7: Dimensions of the as-cast FFF 3D cast parts of Sn60Bi40 at slow and fast rates of cooling

\begin{tabular}{|c|c|c|c|}
\hline State of cooling & Length $(\mathbf{m m})$ & Width $(\mathbf{m m})$ & Thickness $(\mathbf{m m})$ \\
\hline Slow cooled & $70.71 \pm 0.22$ & $8.36 \pm 0.36$ & $5.69 \pm 0.550$ \\
\hline Fast cooled & $70.57 \pm 0.40$ & $8.80 \pm 0.17$ & $5.64 \pm 0.130$ \\
\hline
\end{tabular}

Table A.7 shows that the length of the fabricated samples is larger than the true length of $70 \mathrm{~mm}$, with an average dimension of $70.64 \pm 0.31 \mathrm{~mm}$ and a minimal percentage error of $0.91 \%$. The fabricated samples had an average width of $8.58 \pm 0.26 \mathrm{~mm}$ and percentage error value of $6.95 \%$. The greatest variation in dimensions was found to occur in the thickness of the specimen, with an average thickness of $5.66 \pm 0.34 \mathrm{~mm}$ and percentage 
error values of $12.46 \%$ respectively. Table A.8 shows the physical properties of the ascast FFF 3D cast parts of Sn60Bi40 at slow and fast rates of cooling.

Table A.8: Physical properties s of the as-cast FFF 3D cast parts of Sn60Bi40 at slow and fast rates of cooling

\begin{tabular}{|c|c|c|c|}
\hline State of cooling & Mass $(\mathbf{g})$ & Volume $(\mathbf{c c})$ & Density $(\mathbf{g} / \mathbf{c c})$ \\
\hline Slow cooled & $34.62 \pm 1.71$ & $3.89 \pm .13$ & $8.01 \pm .004$ \\
\hline Fast cooled & $34.41 \pm 3.95$ & $4.01 \pm .012$ & $8.09 \pm .023$ \\
\hline
\end{tabular}

Table A.8 shows that the volume of the fabricated specimens is greater than the expected volume derived from the Solid works, $3.762 \mathrm{~g} / \mathrm{cc}$, by a percentage of $4.86 \%$. The parts fabricated in slow cooled state under ambient temperature exhibited percentage differences of $3.35 \%$ and the volume error percent for the fast cooled specimen was $6.38 . \%$. Consequently, mass of the specimens fabricated in the slow and fast cooled condition had percentage error values of $9.23 \%$ and $13.39 \%$ respectively.

The densities of the fabricated specimens are found to be in close correlation with the true density values. A representative graph of the relative density of the of the slow cooled and fast cooled states of the Sn60Bi40 material is shown in Figure A.14 


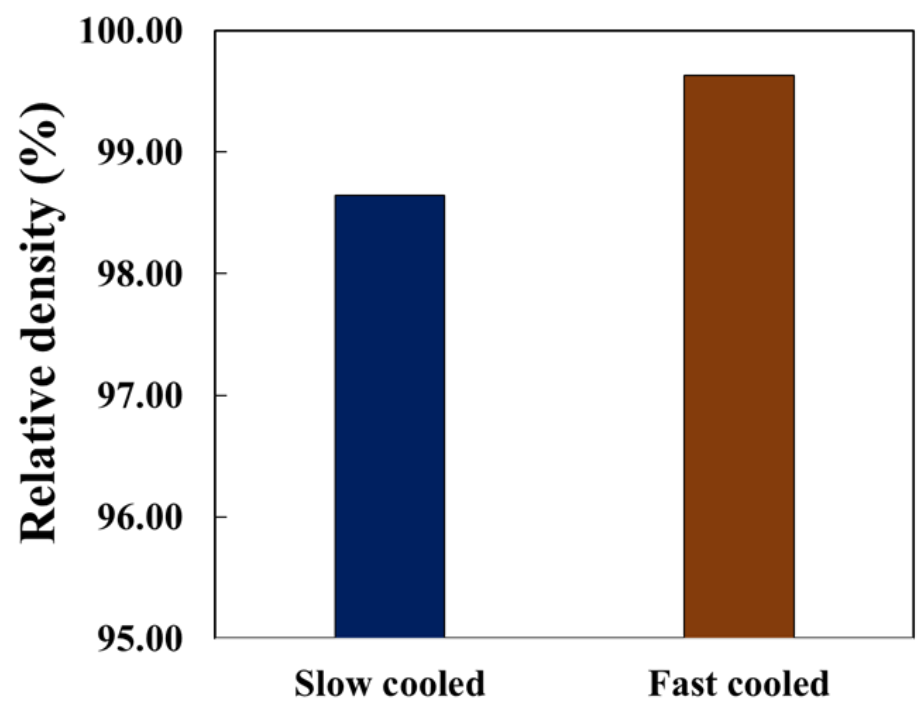

Figure A.14: Relative densities of the as-cast FFF 3D cast parts of Sn60Bi40 at slow and fast rates of cooling

The relative densities account to percentage differences of $98.64 \%$ for the slow cooled specimens and $99.63 \%$ for the fast cooled specimens of the Sn60Bi40 alloy. 


\section{APPENDIX K}

FFF CAST METHODOLOGY FOR SN60BI40 - MANUFACTURER II

These experiments were performed on Sn60Bi40 wires of diameter $3.00 \mathrm{~mm}$ purchased from the manufacturer, BELMONT METALS. The material used for the experiments as in the chapters 2 for FFF 3D printing as well as casting are from the, manufacturer, AIM solders. Belmont metals would be referred to as 'manufacturer 2/M2'. Figure A.15 shows the samples of as-cast Sn60Bi40_M2 fabricated using the FFF casting methodology.

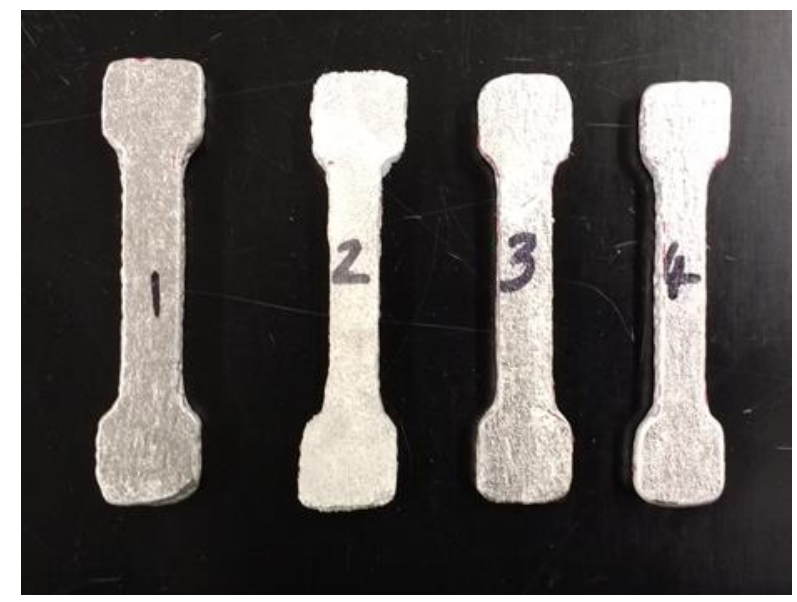

Figure A.15: Samples of Sn60Bi40_M2 as cast fabricated using the FFF casting methodology .

Table A.9 shows the dimensions and tolerances of the as-cast Sn60Bi40_M2 fabricated using the FFF casting methodology.

Table A.9: Dimensions and tolerances of the as-cast Sn60Bi40_M2 fabricated using the FFF casting methodology. 


\begin{tabular}{|c|c|c|c|}
\hline Specimen & Length & Width & Thickness \\
\hline 1 & $71.43 \pm .10$ & $9.44 \pm .03$ & $5.18 \pm .02$ \\
\hline 2 & $71.05 \pm .15$ & $8.23 \pm .23$ & $5.02 \pm .12$ \\
\hline 3 & $71.36 \pm .09$ & $9.21 \pm .04$ & $4.43 \pm .10$ \\
\hline 4 & $71.23 \pm .40$ & $8.33 \pm .24$ & $5.09 \pm .08$ \\
\hline
\end{tabular}

Table A.10 shows the physical properties of the as-cast Sn60Bi40_M2 fabricated using the FFF casting methodology.

Table A.10: Physical properties of the as-cast Sn60Bi40_M2 fabricated using the FFF casting methodology.

\begin{tabular}{|c|c|c|c|}
\hline Specimen & $\begin{array}{c}\text { Volume } \\
(\mathrm{mL})\end{array}$ & $\begin{array}{c}\text { Density } \\
\left(\mathrm{g} / \mathrm{cc}^{3}\right)\end{array}$ & $\begin{array}{c}\text { Relative } \\
\text { density }\end{array}$ \\
\hline 1 & $3.93 \pm .02$ & $8.07 \pm .040$ & 0.983 \\
\hline 2 & $3.45 \pm .03$ & $8.01 \pm .060$ & 0.976 \\
\hline 3 & $3.34 \pm .05$ & $8.18 \pm .100$ & 0.997 \\
\hline 4 & $3.43 \pm .01$ & $8.04 \pm .020$ & 0.979 \\
\hline
\end{tabular}

Figure A.16 shows the samples of post-processed Sn60Bi40_M2 fabricated using the FFF casting methodology. 


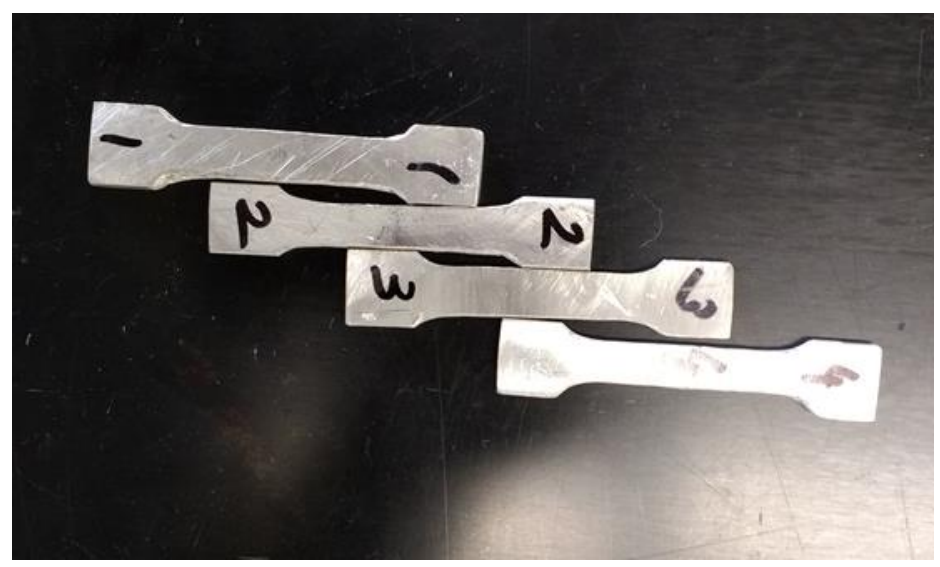

Figure A.16: Samples of post-processed Sn60Bi40_M2 fabricated using the FFF casting methodology

Table A.11 shows the dimensions and tolerances of the post-processed Sn60Bi40_M2 fabricated using the FFF casting methodology.

Table A.11: Dimensions and tolerances of the post-processed Sn60Bi40_M2 fabricated using the FFF casting methodology.

\begin{tabular}{|c|c|c|c|}
\hline Specimen & Length & Width & Thickness \\
\hline 1 & $67.62 \pm .12$ & $9.04 \pm .05$ & $4.51 \pm .04$ \\
\hline 2 & $67.59 \pm .23$ & $7.98 \pm .29$ & $4.71 \pm .29$ \\
\hline 3 & $68.97 \pm .17$ & $8.88 \pm .27$ & $4.00 \pm .05$ \\
\hline 4 & $66.64 \pm .06$ & $7.66 \pm .19$ & $4.33 \pm .11$ \\
\hline
\end{tabular}

Table A.12 shows the physical properties of the post-processed Sn60Bi40_M2 fabricated using the FFF casting methodology. 
Table A.12: Physical properties of the post-processed Sn60Bi40_M2 fabricated using the FFF casting methodology.

\begin{tabular}{|r|l|l|r|}
\hline Specimen & $\begin{array}{l}\text { Volume } \\
(\mathrm{mL})\end{array}$ & $\begin{array}{l}\text { Density } \\
\left(\mathrm{g} / \mathrm{cc}^{3}\right)\end{array}$ & $\begin{array}{l}\text { Relative } \\
\text { density }\end{array}$ \\
\hline 1 & $3.18 \pm .001$ & $8.08 \pm .003$ & 0.984 \\
\hline 2 & $2.73 \pm .003$ & $8.08 \pm .007$ & 0.984 \\
\hline 3 & $2.80 \pm .002$ & $8.09 \pm .005$ & 0.986 \\
\hline 4 & $2.62 \pm .003$ & $8.06 \pm .006$ & 0.981 \\
\hline
\end{tabular}

Table A.13 shows the ultimate tensile strength and young's modulus values of the postprocessed Sn60Bi40_M2 fabricated using the FFF casting methodology.

Table A.13: Ultimate tensile strength and Young's modulus values of the post-processed Sn60Bi40_M2 fabricated using the FFF casting methodology.

\begin{tabular}{|c|c|c|}
\hline Specimen & $\begin{array}{c}\text { Ultimate Tensile strength } \\
\text { (MPa) }\end{array}$ & $\begin{array}{c}\text { Youngs modulus } \\
(\mathbf{G P a})\end{array}$ \\
\hline 1 & 60.94 & 2.455 \\
\hline 2 & 58.41 & 1.873 \\
\hline 3 & 67.02 & 2.029 \\
\hline 4 & 59.86 & 1.036 \\
\hline
\end{tabular}




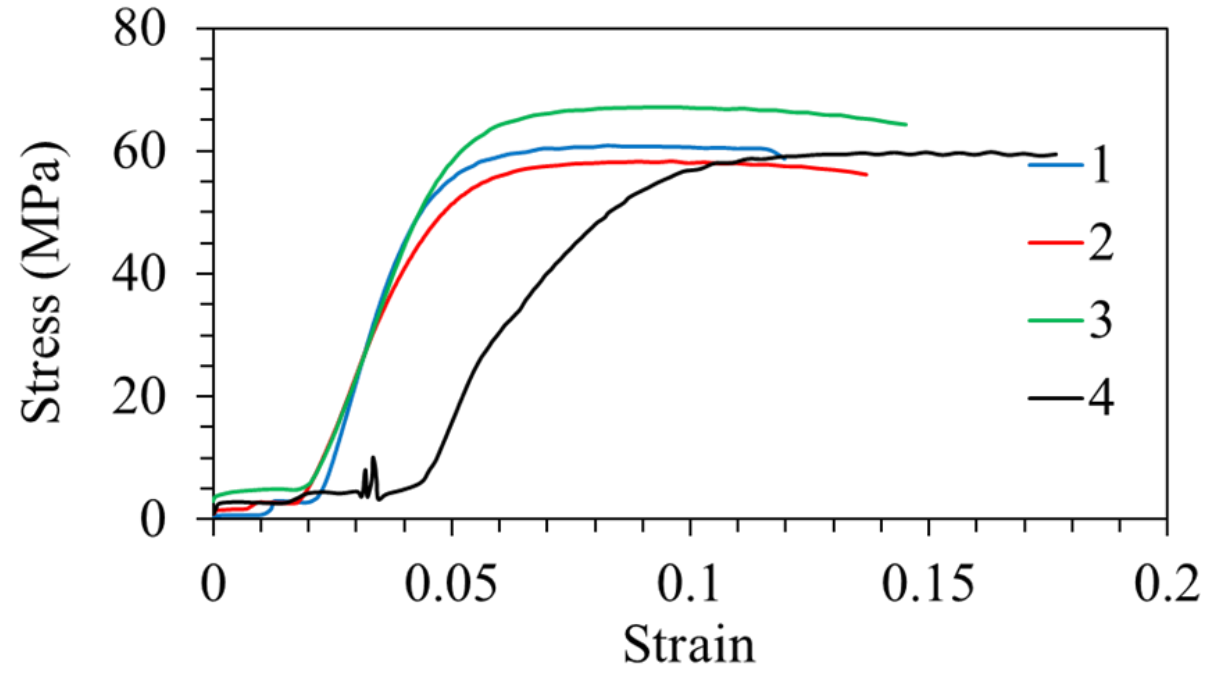

Figure A.17: Stress-strain curves for Sn60Bi40_M2 samples fabricated using the FFF casting methodology. 


\section{APPENDIX L}

\section{EXPERIEMENTAL DATA FOR HEATED MOLD}

Four tensile molds were $3 \mathrm{D}$ printed using PLA at nozzle temperatures of $210^{\circ} \mathrm{C}$ and bed temperatures of $60^{\circ} \mathrm{C}$. The printed was heated to a temperature of $120^{\circ} \mathrm{C}$ and the tensile molds were left heated as low melting non-eutectic alloy of Sn60Bi40 was melted and poured into the mold. The cast was cooled at room temperatures. Table A.14 shows the average of physical and mechanical properties of four tensile specimens fabricated using this process.

Table A.14: Physical and mechanical properties of tensile specimens fabricated using a heated mold

\begin{tabular}{|c|c|c|}
\hline & Average & Std.Dev \\
\hline Length (mm) & 68.80 & 0.81 \\
\hline Width(mm) & 8.01 & 0.32 \\
\hline Thickness(mm) & 5.24 & 0.07 \\
\hline Mass (g) & 29.30 & 1.30 \\
\hline Volume (cc) & 3.58 & 1.64 \\
\hline Density (g/cc) & 8.21 & 0.05 \\
\hline UTS (MPa) & 79.82 & 6.27 \\
\hline Yield Strength (MPa) & 71.98 & 3.45 \\
\hline
\end{tabular}


Figure A.18 and Figure A.19 shows the microstructure of the etched specimens observed using an optical microscope.

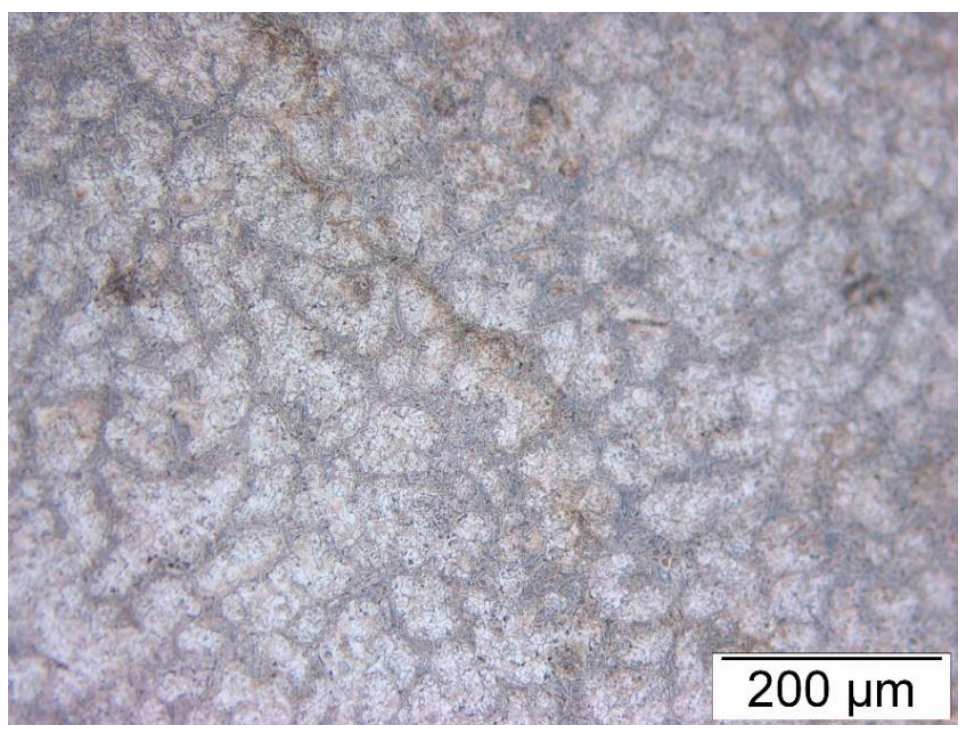

Figure A.18: Optical microscopy imaging of etched FFF 3D cast Sn60Bi40 sample fabricated using a heated mold

$$
\text { (20X, Bright field) }
$$

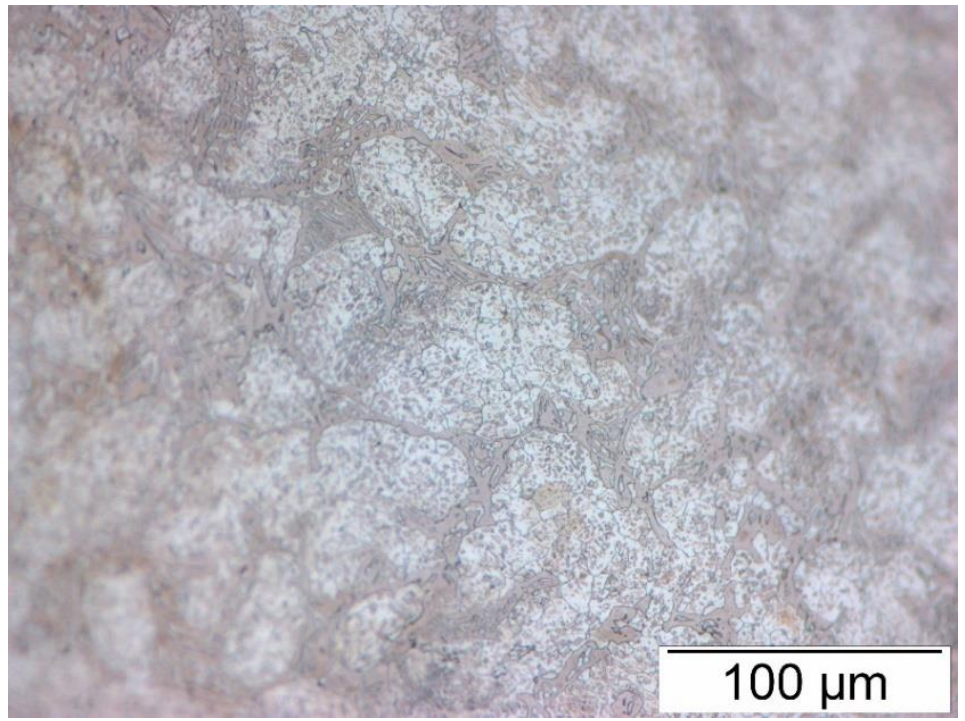

Figure A.19: Optical microscopy imaging of etched FFF 3D cast Sn60Bi40 sample fabricated using a heated mold (50X, Bright field) 


\section{APPENDIX M}

OPTICAL MICROSCOPY IMAGES

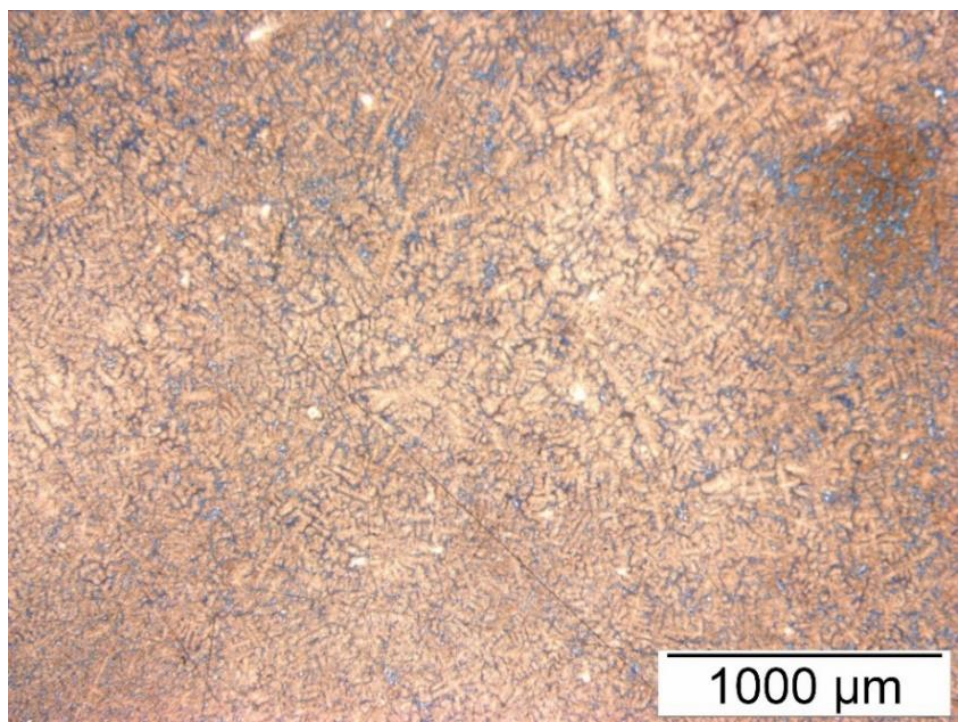

Figure A.20: Optical microscopy imaging of etched FFF 3D cast Sn60Bi40 sample (5X, Bright field)

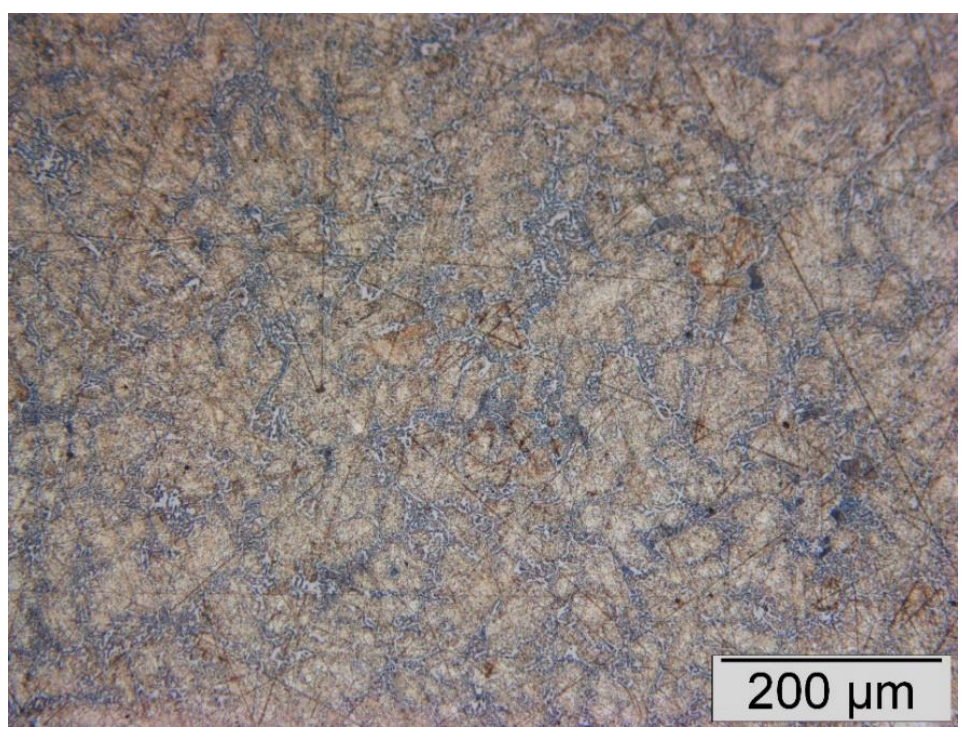

Figure A.21: Optical microscopy imaging of etched FFF 3D cast Sn60Bi40 sample (20X, Bright field) 


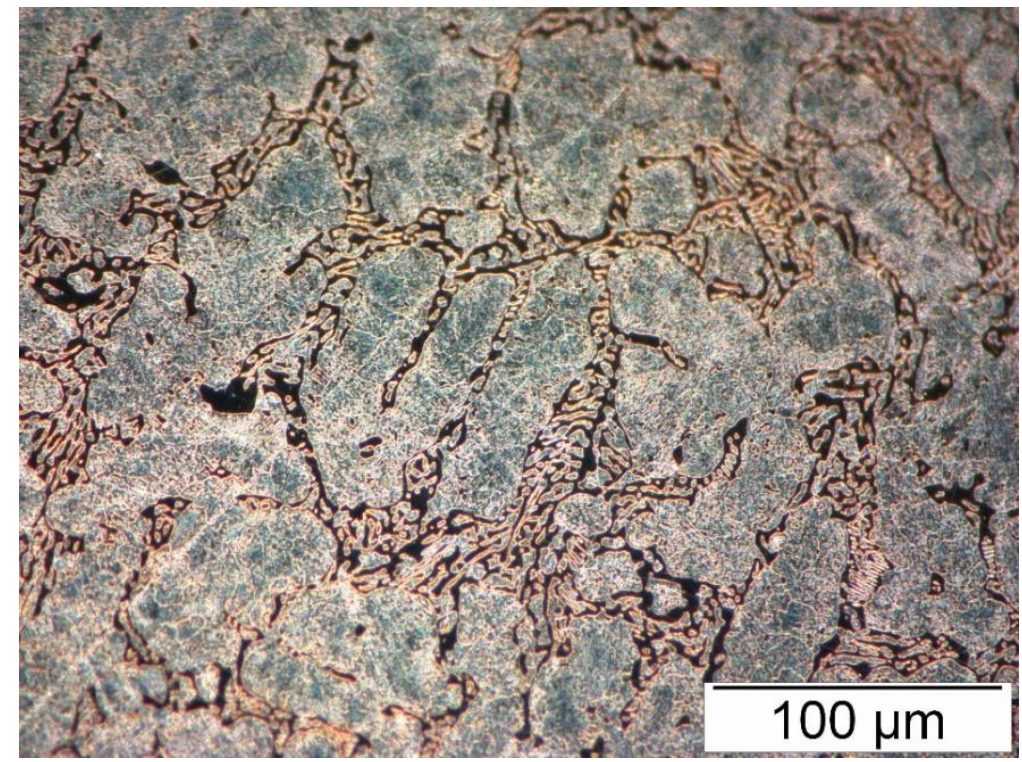

Figure A.22: Optical microscopy imaging of etched FFF 3D cast Sn60Bi40 sample (50X, Bright field)

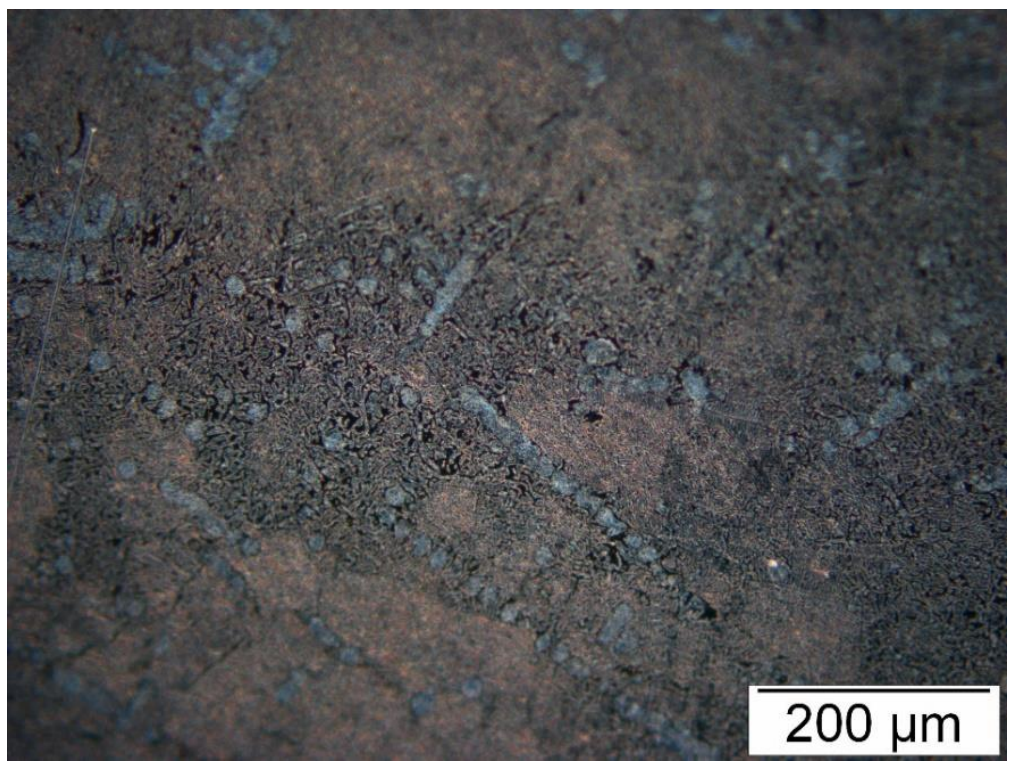

Figure A.23: Optical microscopy imaging of etched FFF 3D cast Sn42Bi58 sample (20X, Dark field ) 




Figure A.24: Optical microscopy imaging of etched FFF 3D cast Sn42Bi58 sample (50X, Dark field )

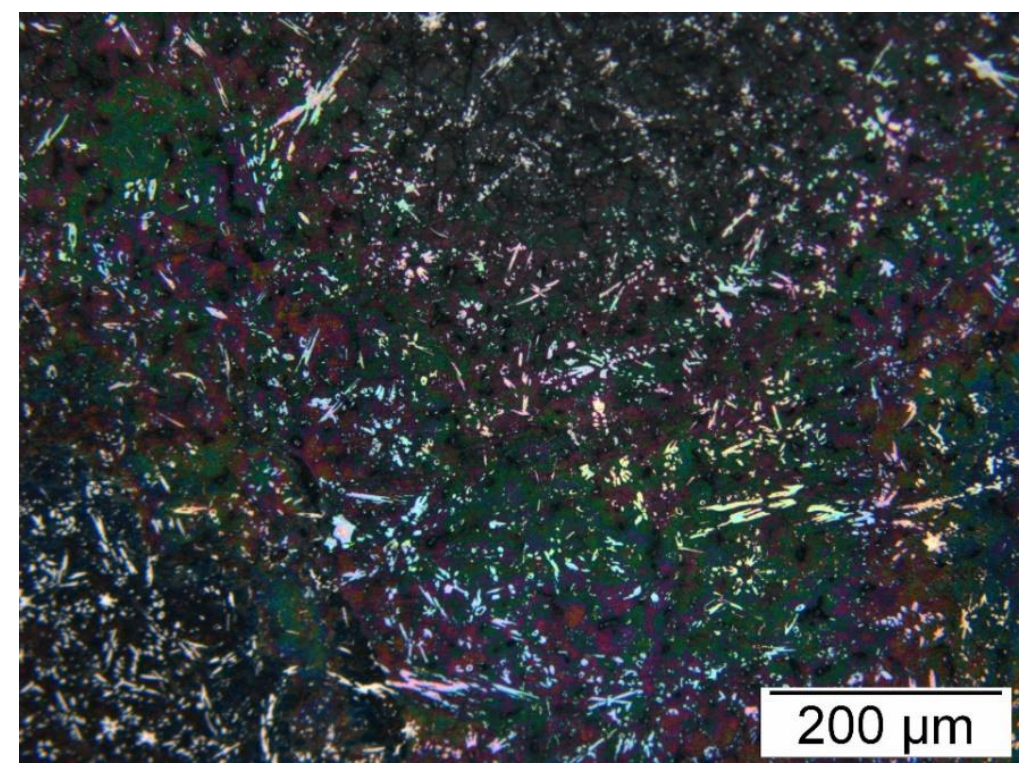

Figure A.25: Optical microscopy imaging of etched FFF 3D cast Sn89Sb7.5 sample (20X, Dark field ) 


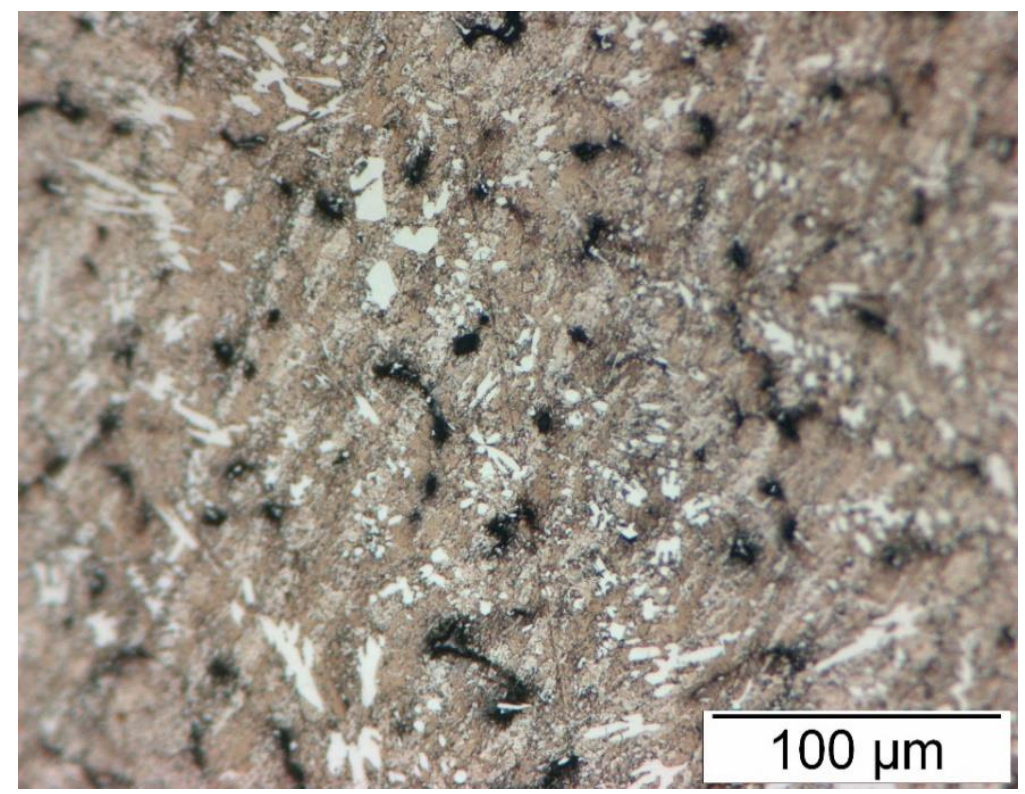

Figure A.26: Optical microscopy imaging of etched FFF 3D cast Sn89Sb7.5 sample (50X, Bright field )

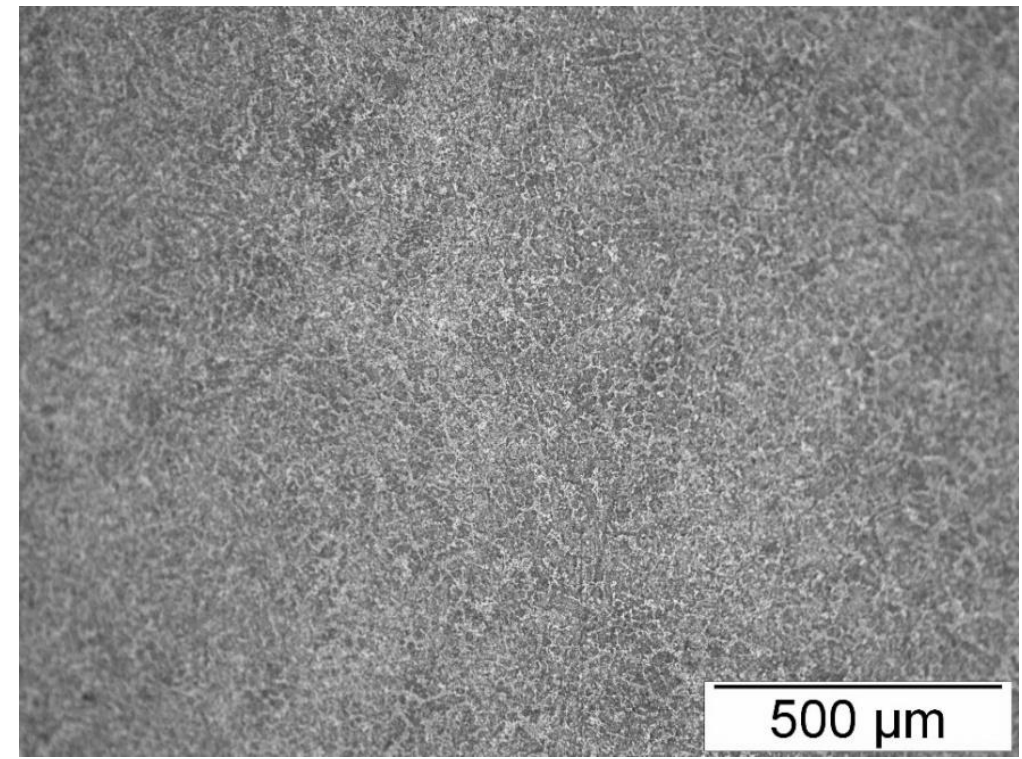

Figure A.27: Optical microscopy imaging of fast cooled FFF 3D cast Sn60Bi40 sample showing the fine colonies

(10X, Bright field ) 


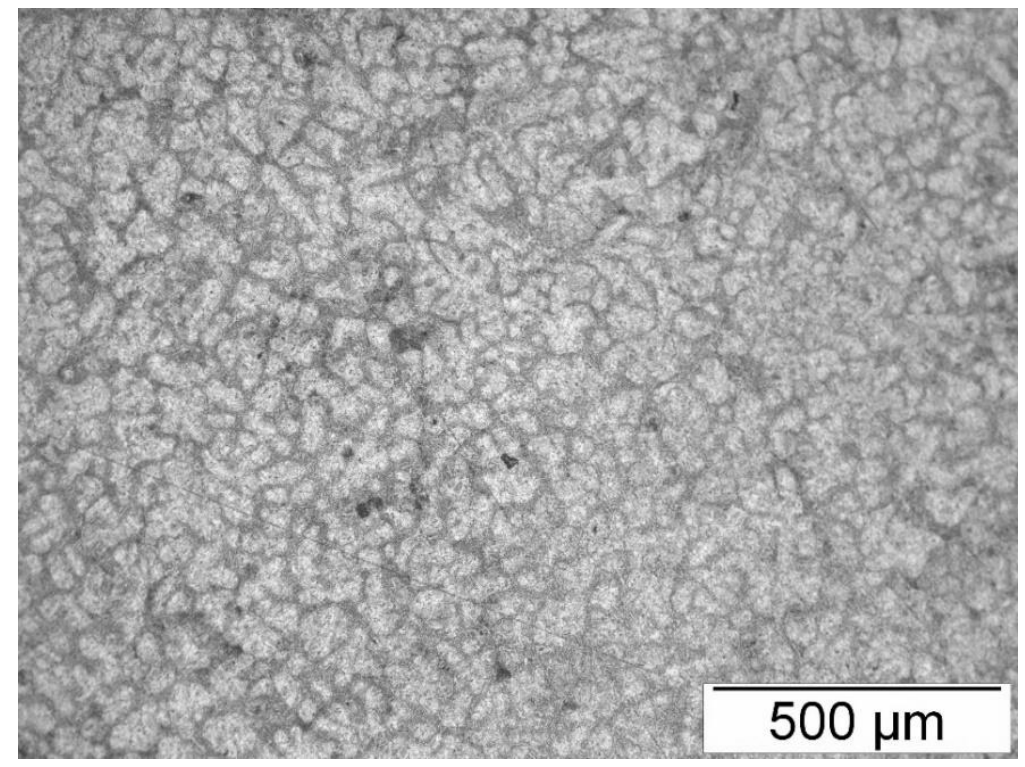

Figure A. 28: Optical microscopy imaging of slow cooled FFF 3D cast Sn60Bi40 sample showing the coarser colonies

(10X, Bright field )

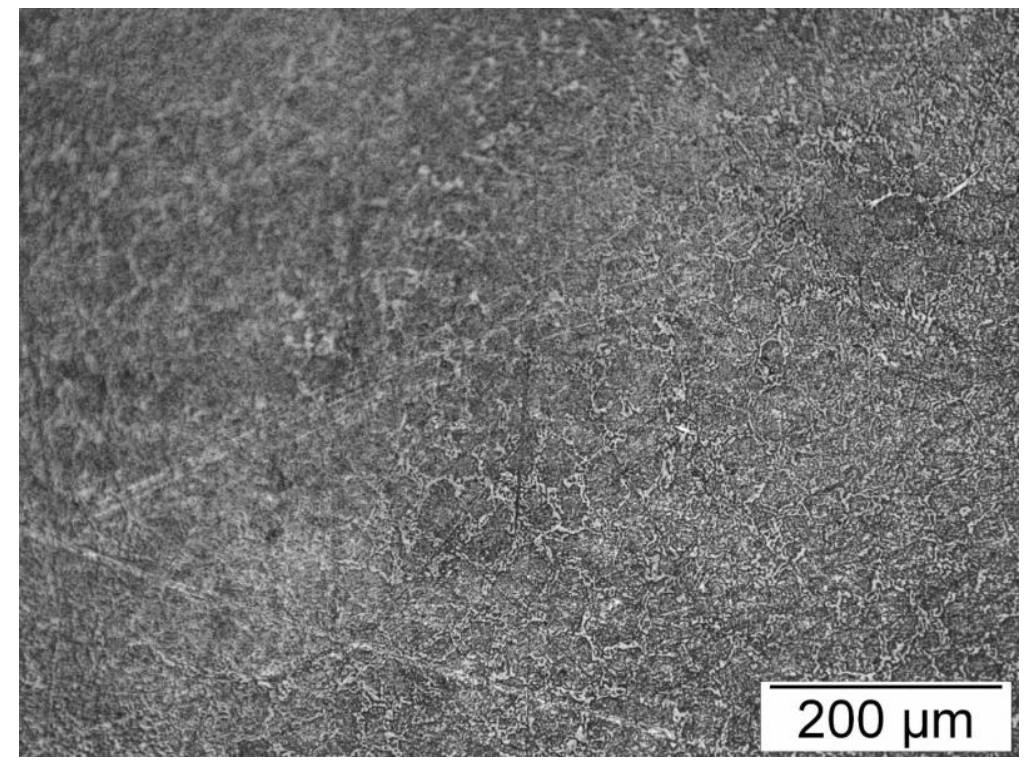

Figure A.29: Optical microscopy imaging of slow cooled FFF 3D printed Sn60Bi40 sample showing the coarser colonies

(20X, Bright field 


\section{APPENDIX N}

\section{HALL-PETCH EQUATION}

Grain boundary strengthening (or Hall-Petch strengthening) is a method of strengthening materials by changing their average crystallite (grain) size. It is based on the observation that grain boundaries impede dislocation movement and that the number of dislocations within a grain have an effect on how easily dislocations can traverse grain boundaries and travel from grain to grain.

Hall-Petch equation can be expressed by the equation,

$$
\sigma_{y}=\sigma_{0}+\frac{k_{y}}{\sqrt{d}}
$$

Where $\sigma_{y}$ is the yield strength, $\sigma_{0}$ is a materials constant for the resistance of the lattice to dislocation movement, $k_{y}$ is the strengthening coefficient and $d$ is the grain diameter .

The relationship between yield strength and grain size is inversely proportional. Hence, smaller the grain size, smaller the repulsion stress felt by a grain boundary dislocation and higher the applied stress needed to propagate dislocations through the material.

So, by changing the grain size, one can influence dislocation movement and yield strength. Grain size reduction is also a means to increase the toughness of a metal. For example, heat treatment after plastic deformation and changing the rate of solidification are ways to alter grain size. 


\section{CURRICULUM VITA}

NAME:

ADDRESS:

DOB :

EDUCATION \& TRAINING:

AWARDS
Nirupama Warrier

Room no.214

Shumaker Research Building

S.Brook St, Louisville-40208

April 13, 1992

B.Tech, Aerospace engineering

Amrita Vishwa Vidyapeetham, TN, India 2009- 13

MS, Mechanical engineering

University of Louisville

2016- 17

National Science Foundation Grant , 2017 
CONFERENCES AND

PRESENTATIONS:

PUBLICATIONS:
'FFF 3D Printing using low melting alloys', AMPM 2017, Las Vegas, NV, Jun'17

Warrier, Kate, 'Fused filament fabrication 3D printing with lowmelting alloys', AMPM2017 Conference Proceedings, 2017, pp 144150 